Linköping Studies in Science and Technology

Dissertation No. 2089

\title{
Color Tuning for Perovskite Light-Emitting Diodes
}

Hongling Yu

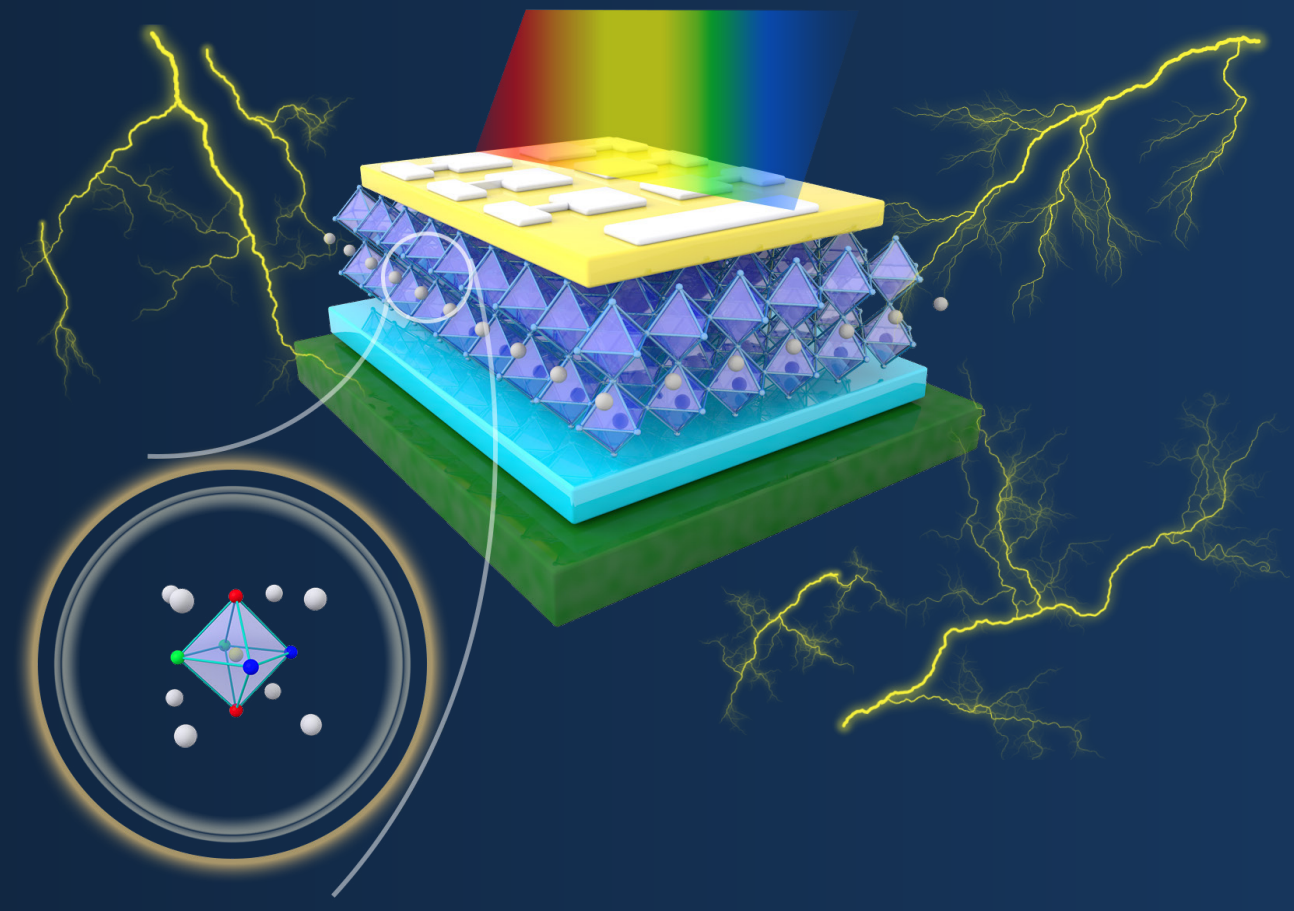


Linköping Studies in Science and Technology

No. 2089

\title{
Color Tuning \\ for Perovskite Light-Emitting Diodes
}

\author{
Hongling $\mathrm{Yu}$
}

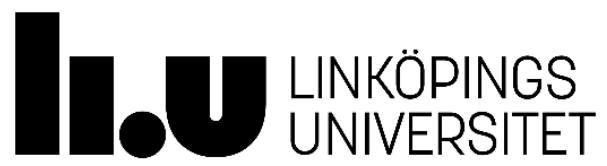

Electronic and Photonic Materials (EFM)

Department of Physics, Chemistry and Biology (IFM) Linköpings universitet, SE-581 83 Linköping, Sweden Linköping [2020] 
(C)Hongling $\mathrm{Yu}, 2020$

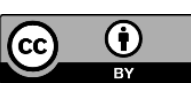

This work is licensed under the Creative Commons Attribution 4.0 International License. To view a copy of this license, visit http://creativecommons.org/licenses/by/4.0/.

Printed in Sweden by Liu-Tryck, Linköping, 2020

ISSN: 0345-7524

ISBN: 978-91-7929-809-8 


\section{Abstract}

Metal halide perovskites (MHPs) are recognized as promising semiconductor materials for a variety of optical and electrical device applications due to their cost-effective and outstanding optoelectronic properties. As one of the most significant applications, perovskite light-emitting diodes (PeLEDs) hold promise for future lighting and display technologies, attributed to their high photoluminescence quantum yield (PLQY), high color purity, and tunable emission color. The emission colors of PeLEDs can be tuned by mixing the halide anions, adjusting the size of perovskite nanocrystals, or changing the dimensionality of perovskites. However, in practice, all these different approaches have their own advantages and challenges. This thesis centres around the color tunability of perovskites, aiming to develop PeLEDs with different colors using different approaches.

We first demonstrate red and near-infrared PeLEDs using a straightforward approach - in situ solution-processed perovskite quantum dots (PQDs). PQDs prepared from colloidal approaches are widely reported and used in LEDs. In contrast, PQDs prepared from the in situ approaches are hardly reported, although they have advantages for device applications. By employing aromatic ammonium iodide (1-naphthylmethyl ammonium iodide, NMAI) as an agent into perovskite precursor solutions, together with annealing temperature modulation, we obtain in situ grown PQDs delivering high external quantum efficiencies (EQEs) of up to $11.0 \%$ with tunable electroluminescence (EL) spectra $(667-790 \mathrm{~nm})$. Our in situ generated PQDs based on pure-halogen perovskites can be easily obtained through a simple deposition process and free of phase segregation, making them a more promising approach for tuning the emission colors of perovskite LEDs.

We then move to blue PeLEDs using cesium-based mixed-Br/Cl perovskites. Although mixed halides are a straightforward strategy to tune the emission color, PeLEDs based on this approach suffer from poor color stability, which is attributed to surface defects at grain boundaries. Under the condition of optical excitations, light density over a certain value (a threshold), oxygen, and surface 
defects at perovskite grain boundaries are found to be key factors inducing photoluminescence (PL) spectral instability of $\mathrm{CsPb}\left(\mathrm{Br}_{1-x} \mathrm{Cl}_{x}\right)_{3}$ perovskites. Upon electrical bias, defects at grain boundaries provide undesirable halide migration channels, responsible for EL spectral instability issues. Through effective defect passivation, the PL spectral resistance to oxygen is enhanced; moreover, high-performance and color-stable blue PeLEDs are achieved, delivering a maximum luminance of $5351 \mathrm{~cd} \mathrm{~m}^{-2}$ and a peak EQE of $4.55 \%$ with a peak emission wavelength at $489 \mathrm{~nm}$. These findings provide new insights into the color instability issue of mixed halide blue perovskites, against which we also demonstrate an effective strategy.

We finally realize single-emissive-layer (EML) white PeLEDs by employing a mixed halide perovskite film as the EML. In spite of high-performance monochromatic blue, green, and red colors, the development of white PeLEDs, especially for single-EML ones, remains a very big challenge. By effective modulation of the halide salt precursors, we achieve single-EML white PeLEDs with Commission Internationale de L'Eclairage (CIE) coordinates of $(0.33$, $0.33)$, close to those $(0.3128,0.3290)$ of the CIE standard illuminant D65. This work not only provides a successful demonstration of a single-EML white PeLED, but also provides useful guidelines for the future development of highperformance single-EML white PeLEDs.

Keywords: Perovskite light-emitting diodes, color tuning, pure and mixed halide, spectral stability, white emission 


\section{Populärvetenskaplig Sammanfattning}

Metall halid-perovskiter (MHP) anses vara lovande halvledarmaterial för varierande optiska och elektroniska applikationer på grund av dess utomstående optoelektroniska egenskaper samt låga tillverkningskostnad. Som en av de mest betydande applikationerna uppvisar perovskitbaserade lysdioder (PeLED) stor potential inom framtida belysnings- och skärmteknologier, vilket beror på deras höga kvanteffektivitet, färgrenhet samt justerbara emissionsfärg. För att närma sig kommersialisering utav PeLED krävs att faktorer såsom enkel tillverkning, energiomvandlingseffektivitet och livstid, samt emission inom hela färgspektrumet hanteras och utvecklas för att göra PeLED till en kostnadseffektiv och högpresterande LED-teknik.

I den här avhandlingen fokuserar vi på färgjustering utav rena och blandhalid-perovskiter. För rena halidperovskiter demonstrerar vi ett processeffektivt tillvägagångssät - in situ lösningstillväxt - för att tillverka perovskitkvantprickar. Våra in situ-växta kvantprickar uppvisar hög extern kvanteffektivitet upp till 11,0\% med justerbart elektroluminiscensspektrum (667-790 nm) bundet till kvantmekaniska effekter. Dessa fynd visar att kemiska syntesprocesser inte är nödvändiga för att framställa kvantprickar. In situ-växta perovskitkvantprickar är ett lovande tillvägagångsätt för att anpassa emissionsfärgen hos PeLED.

Att blanda halogener är ett annat tillvägagångsätt för att anpassa färgen hos perovskiter vilket dock ger upphov till spektral instabilitet. I denna del undersöker vi den spektrala instabiliteten hos cesiumbaserade $\mathrm{Br} / \mathrm{Cl}$-perovskiter och visar att ytdefekter vid korngränser är ansvariga för den spektrala instabiliteten under antingen fotoexcitation eller vid elektrisk spänning. Genom effektiv passivering utav defekter blir fotoluminiscensspektra mer motståndskraftiga mot syrepåverkan. Vidare uppvisar lysdioderna färgstabilitet under drift. Dessa fynd ger nya insikter gällande färgstabilitetsproblematiken hos blåemitterande blandhalid-perovskiter, mot vilken vi också demonsterar en effektiv strategi. 
Därtill uppvisar vi för första gången vitt ljus från ett singellager baserat på blandhalid-perovskiter som emitterande film i en PeLED. Genom rationell modulering utav prekursorsalt möjliggör blandhalid-perovskiter simultan emission av blått och rött ljus, vilket ger upphov till dubbelfärgad vit elektroluminiscens. Vårt arbete ger användbara riktlinjer för framtida utveckling utav högpresterande singelskiktsemitterande vita PeLED. 


\section{Acknowledgement}

Study abroad has been one of my significant decisions in my life. This journey could never be so precious without the support and company of my supervisors, colleagues, friends, and families.

At first, I would like to express my great thankfulness to my main supervisor Prof. Feng Gao. Thank you for offering me this opportunity to pursue doctoral studies at Linköping University. Your immense knowledge and rigorous scholarship have deeply inspired me throughout my doctoral program. You always provide insightful suggestions on moving my research forward, and attach great importance to cultivate my independence. You are also caring and encouraging when I was down. My sincerest thanks to you.

My special thanks go to my co-supervisors: Dr. Xiao-Ke Liu, Prof. Olle Inganäs, and Prof. Fengling Zhang. Dr. Liu, thank you for all your endless patience and kind assistance during my doctoral journey. When I was a fresh student, I've received great support from you to be familiar with lab work. As I continued my research, you offered many constructive comments and encouragement; you also put kind effects on developing my scientific thinking and writing. Prof. Olle Inganäs and Prof. Fengling Zhang, you are respectable scholars while every dialogue with you was relaxing and enjoyable.

My sincere thanks go to Heyong Wang, who is ready for support and assistance all the time; to Feng Wang, Sai Bai, Chunyang Yin, Jian Qing, Zhongcheng Yuan, Guanghaojie Zheng, Rui Zhang, Jiajun Qin, Naresh Kumar Kumawat, Chaoyang Kuang, Fuxiang Ji, Weidong Cai, Huotian Zhang, Jianwei Yu, Nannan Yao, Ingemar Persson, Jun Lu, Xianjie Liu, Zhangjun Hu, Chunxia Du, Prof. Galia Pozina, and Prof. Wei-Xin Ni, who have provided me lots of help over the years; to Max Karlsson, Julia Morat, and Shan Anjum for the help with abstract translation; to Shanpeng Wang for the help with cover design. I would also like to acknowledge my collaborators: Prof. Mats Fahlman, Prof. Jianpu Wang, Prof. Tönu Pullerits, Prof. Richard H. Friend, Chang Yi, Lin Zhu, Weihua Lin, and Jiangbin Zhang. 
My sincere thanks also go to colleagues and friends from Gao Group and IFM; to our administrators (Anna-Maria Uhlin, Ann-Charlotte Svensson Holm, and Lena Martinsson); to Caroline Brommesson and Agora members; to friends who have left from LiU: Antonella Giuri, Katherine Calamba, Petro Deminskyi, Laurent Souqui, Thomas Osterberg, Luis Aguirre, Jonas Bergqvist, Wanzhu Cai, and Guangzheng Zuo. I would like to give my special thanks to Per-Olof Holtz, Katharina Bahle, Bei Yang, Lianlian Liu, Jiwen Hu, Jie Zhou, Wenjing Zhou, Ge Liu, Tingyun Wang, Zibing Jia, Ping Yang, Kuilin Wang, and Min Guo. Thank you for your caring and encouragement in my daily life.

At last, I want to thank my families for supporting me all the years. Thank my boyfriend Lichuan Wu for your understanding, love, and tolerance. Thank the China Scholarship Council (CSC) for financially supporting my doctoral project.

Hongling $\mathrm{Yu}$

Linköping, Oct 2020 


\section{Papers Included in the Thesis}

1. Efficient and tunable electroluminescence from in situ synthesized perovskite quantum dots

H. Yu, H. Wang, J. Zhang, J. Lu, Z. Yuan, W. Xu, L. Hultman, A. A. Bakulin, R. H. Friend, J. Wang, X.-K. Liu, F. Gao, Small 2019, 15, 1804947.

2. High-performance and color-stable blue light-emitting diodes enabled by effective passivation of mixed halide perovskites

H. Yu, H. Wang, C. Yi, G. Zheng, C. Yin, M. Karlsson, J. Qin, J. Wang, X.K. Liu, F. Gao. Submitted.

3. Atmospheric impact on photo-induced spectral stability of cesium-based mixed bromide-chloride perovskites

H. Yu, C. Yin, R. Zhang, W. Lin, H. Wang, J. Qin, G. Pozina, T. Pullerits, K. Zheng, X.-K. Liu, F. Gao. To be submitted.

4. Single-emissive-layer white light-emitting diodes employing segregated mixed halide perovskite crystals

H. Yu, H. Wang, G. Pozina, C. Yin, X.-K. Liu, F. Gao. Chem. Sci., 2020. DOI: 10.1039/D0SC04508J.

\section{Author contribution}

For the papers above, I prepared the LED devices, carried out most of the film and device characterizations, wrote the manuscript drafts, and revised the manuscripts together with the co-authors. 


\section{Papers Not Included in the Thesis}

1. Efficient perovskite light-emitting diodes based on a solution-processed tin dioxide electron transport layer

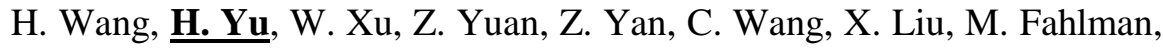
J. Liu, X. Liu, F. Gao, J. Mater. Chem. C, 2018, 6, 6996-7002

2. Efficient light-emitting diodes based on in situ self-assembled perovskite nanocrystals

H. Wang, $\underline{\mathbf{H} . \text { Yu}, ~ X . ~ L i u, ~ F . ~ G a o, ~ J o u r n a l ~ o f ~ P h o t o n i c s ~ f o r ~ E n e r g y, ~ 2018, ~}$ 8(4): 046002

3. Perovskite-molecule composite thin films for efficient and stable light-emitting diodes

H. Wang, F. U. Kosasih, H. Yu, G. Zheng, J. Zhang, G. Pozina, Y. Liu, C. Bao, Z. Hu, X. Liu, L. Kobera, S. Abbrent, J. Brus, Y. Jin, M. Fahlman, R.

H. Friend, C. Ducati, X.-K. Liu, F. Gao, Nat. Commun. 2020, 11, 891.

4. Pulsed terahertz emission from solution-processed lead iodide perovskite films

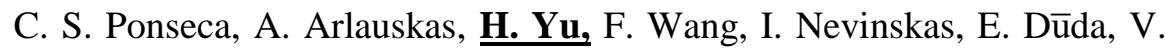
Vaičaitis, J. Eriksson, J. Bergqvist, X.-K. Liu, M. Kemerink, A. Krotkus, O. Inganas, F. Gao, ACS Photonics 2019, 6, 1175.

\section{Author contribution}

For these papers not included in the thesis, I contributed to partial experiment preparation, characterization, and data analysis. 


\section{Abbreviations}

\begin{tabular}{ll}
\hline Abbreviation & Meaning \\
\hline 3D & Three-dimensional \\
2D & Two-dimensional \\
BHCl & Benzamidine hydrochloride \\
CBM & Conduction band minimum \\
CIE & Commission Internationale de l'Eclairage \\
DMF & N,N-dimethylformamide \\
DMSO & Dimethyl sulfoxide \\
EL & Electroluminescence \\
EML & Emissive layer \\
ETL & Electron transport layer \\
FTIR & Fourier-transform infrared \\
FWHM & Full width at half maximum \\
GIWAXS & Grazing incidence wide angle X-ray scattering \\
HOMO & Highest occupied molecular orbital \\
HTL & Hole transport layer \\
IPA & Isopropanol \\
IQE & Internal quantum efficiency \\
IR & Infrared \\
ITO & Indium tin oxide \\
LUMO & Lowest unoccupied molecular orbital \\
MHP & Metal halide perovskite \\
MQW & Multiple quantum well \\
MSSC & Meso-superstructured solar cell \\
NMAI & 1-naphthylmethyl ammonium iodide \\
OA & Oleic acid \\
ODE & 1-octadecene \\
PCE & Power conversion efficiency \\
PeLED &
\end{tabular}


PLQY

$\mathrm{NC}$

QD

SEM

TA

TEM

UV

VBM

$\mathrm{XRD}$
Photoluminescence quantum yield

Nanocrystal

Quantum dot

Scanning electron microscope

Transient absorption

Transmission electron microscopy

Ultraviolet

Valence band maximum

$\mathrm{X}$-ray diffraction 


\section{Table of Contents}

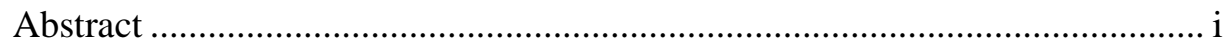

Populärvetenskaplig Sammanfattning .........................................................ii

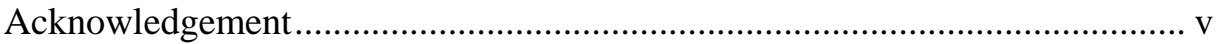

Papers Included in the Thesis ..................................................................... vii

Papers Not Included in the Thesis ............................................................ viii

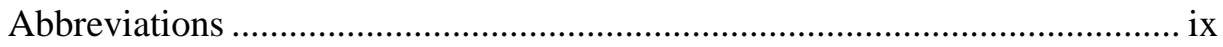

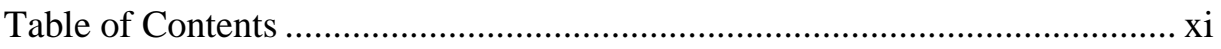

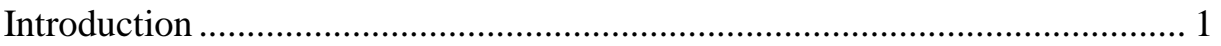

1.1 Discovery and History of Perovskites ..................................................... 1

1.2 Optoelectronic Applications ............................................................ 2

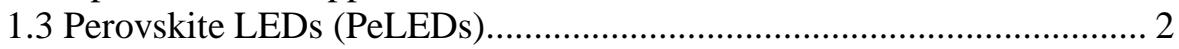

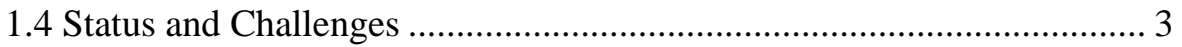

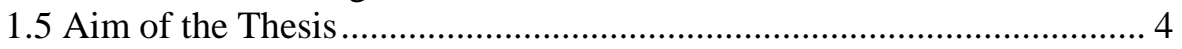

Fundamental Structure, Property, and Growth of Perovskites .......................... 5

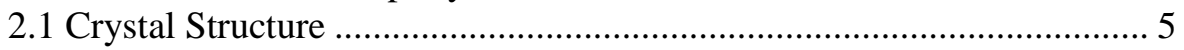

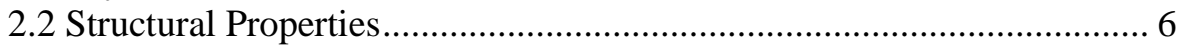

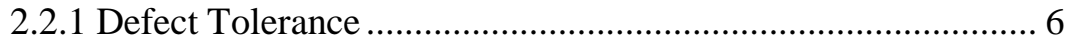

2.2.2 Bandgap Tunability ............................................................. 7

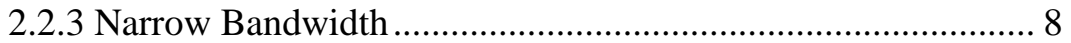

2.2.4 Charge-Carrier Dynamics ………………….......................... 8

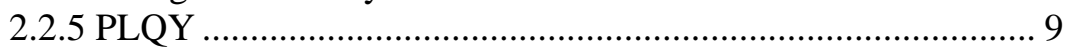

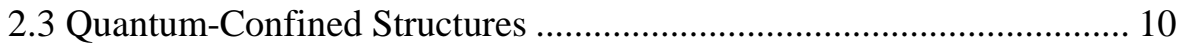

2.3.1 Ruddlesden-Popper Perovskites ............................................ 10

2.3.2 Perovskite QDs....................................................................... 12

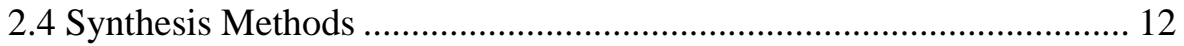

2.4.1 Thin-Film Perovskites.............................................................. 13

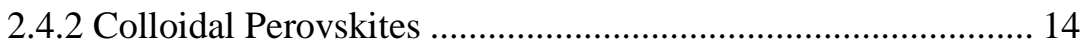

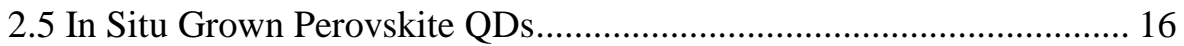

Principle, Characterization, and Optimization of PeLEDs.............................. 19

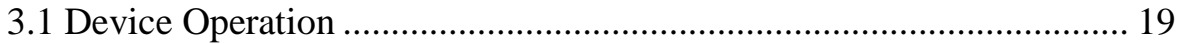

3.1.1 Working Principle ............................................................... 19

3.1.2 Architecture and Interlayers .................................................. 20

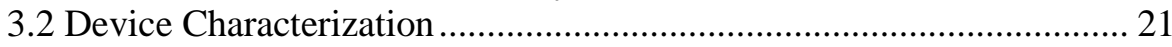

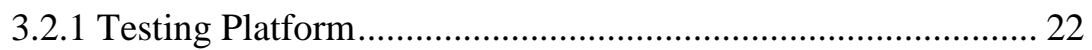

3.2.2 Key Parameters .................................................................... 22

3.2.3 Parameter Relationships...................................................... 23

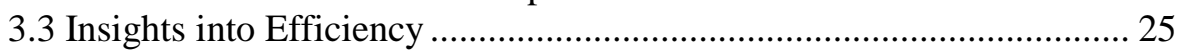

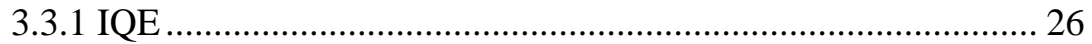

3.3.2 Light Extraction ............................................................ 26

3.3.3 Film Characterization Techniques .......................................... 28 
3.4 High-Performance PeLEDs ..............................................................28

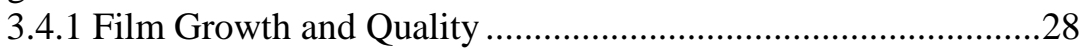

3.4.2 Surface Defect Passivation....................................................29

3.4.3 Charge Carrier Injection ..........................................................29

Progresses, Challenges, and Opportunities of Blue PeLEDs .............................31

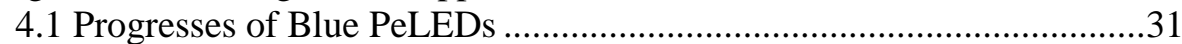

4.1.1 Significance of Blue Light .......................................................31

4.1.2 Developments and Status .........................................................31

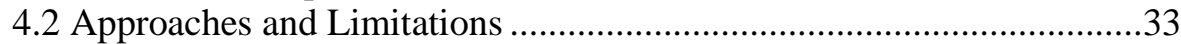

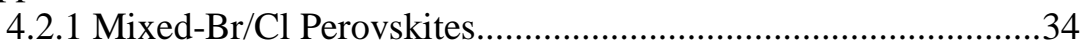

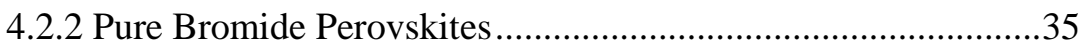

4.3 Color Stability of Mixed Halide Perovskites ...........................................36

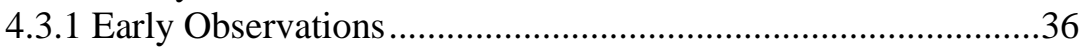

4.3.2 Current Understandings ...........................................................38

4.3.3 Methods Against Spectral Shift ..............................................39

4.4 Color Stability of $\mathrm{CsPb}\left(\mathrm{Br}_{1-x} \mathrm{Cl}_{x}\right)_{3}$ Perovskites ......................................

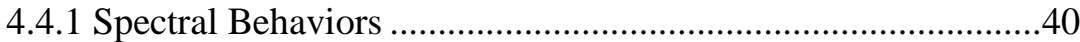

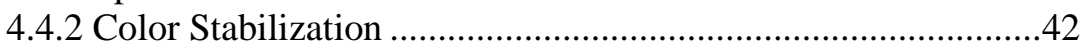

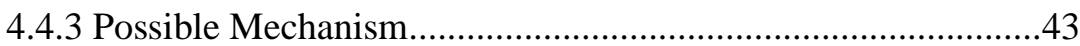

Development of Perovskite White LEDs ........................................................45

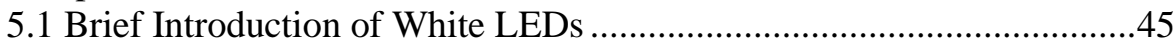

5.1.1 Emergence and Light Revolution ...........................................45

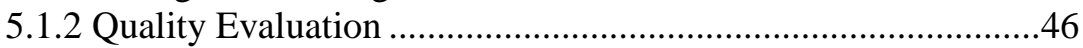

5.1.3 Methods and Challenges .........................................................47

5.2 Intrinsic White Light from Perovskites................................................48

5.3 White LEDs Based on Perovskites ...................................................49

5.3.1 Down-Converted White LEDs................................................49

5.3.2 Perovskite-Based Hybrid White LEDs ........................................49

5.3.3 Multi-EML All-Perovskite White LEDs...................................50

5.4 Single-EML All-Perovskite White LEDs ............................................51

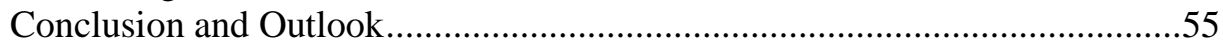

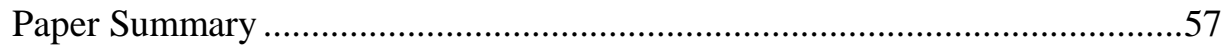

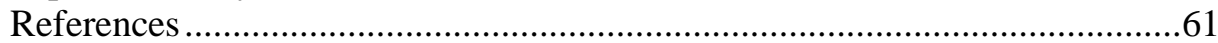




\section{Chapter 1}

\section{Introduction}

\subsection{Discovery and History of Perovskites}

Metal halide perovskites (MHPs) have attracted considerable attention in the field of semiconductors due to their outstanding optoelectronic properties. The term perovskite originally refers to the mineral of calcium titanate $\left(\mathrm{CaTiO}_{3}\right)$, which was discussed by Gustav Rose in 1839 and named in honour of a Russian mineralogist Lev Perovski. ${ }^{[1]}$ MHPs described in this thesis have the same characteristic crystal structure as $\mathrm{CaTiO}_{3}$, described by a formula of $\mathrm{ABX}_{3}$, where $\mathrm{A}$ is generally cesium (Cs), methylammonium (MA) and/or formamidinium (FA), $\mathrm{B}$ is lead $(\mathrm{Pb})$ and/or tin $(\mathrm{Sn})$, and $\mathrm{X}$ is iodide $(\mathrm{I})$, bromide $(\mathrm{Br})$ and/or chloride $(\mathrm{Cl}) .{ }^{[2]}$

The first MHP was reported in 1893 by reacting $\mathrm{PbX}_{2}$ and $\mathrm{CsX}$ salts to form $\mathrm{CsPbX}_{3}$ perovskites under aqueous solutions. ${ }^{[3]}$ But it was not well-known by the semiconductor research communities until 2009, when perovskites of $\mathrm{CH}_{3} \mathrm{NH}_{3} \mathrm{PbI}_{3}$ and $\mathrm{CH}_{3} \mathrm{NH}_{3} \mathrm{PbBr}_{3}$ were applied as sensitizing materials in dyesensitized solar cells for the first time. ${ }^{[4,5]}$ They exhibited power conversion efficiency (PCE) of $3.81 \%$ and $3.13 \%$, respectively, which pointed out the potential of realizing high-performance solar cells based on these materials. ${ }^{[4]}$ Since then, perovskites-based optoelectronic studies have attracted increasing attention.

Early researches mainly focused on perovskite-based perovskite solar cells. An evolutional breakthrough took place in 2012. By using $\mathrm{Al}_{2} \mathrm{O}_{3}$ as a mesoscale "scaffold" to adopt perovskites $\left(\mathrm{CH}_{3} \mathrm{NH}_{3} \mathrm{PbI}{ }_{2} \mathrm{Cl}\right)$, termed as "meso-superstructured solar cell" (MSSC), n-type and p-type assembled solar cells were created with a significantly improved PCE of $10.9 \% .{ }^{[6]}$ This achievement motivated more efforts in the study of perovskites-based solar cells. Shortly thereafter, MSSCs were replaced by simpler planar heterojunction configuration, in which perovskites acted as a single photoactive layer. ${ }^{[7]}$ Although the PCE was only 
around 5\%, it represented a significant breakthrough towards the development of low-cost thin-film perovskite solar cells. Upon intensive efforts, the certified PCE reached $25.2 \%$ in $2019 .{ }^{[8]}$

\subsection{Optoelectronic Applications}

The impressive progress made on solar cells has also triggered intensive investigations to understand fundamental optoelectronic properties, which made perovskites suitable for ideal light absorbers. The outstanding performance stems from their favourable properties, including high optical absorption coefficient, high charge mobility, high defect tolerance, and tunable bandgaps. ${ }^{[9]}$ These characters provide various opportunities for perovskites in optoelectronic applications beyond solar cells. At present, perovskites-based light-emitting diodes (LEDs), ${ }^{[10]}$ lasers,${ }^{[1]}$ transistors, ${ }^{[12]}$ photodetectors, ${ }^{[13]} \mathrm{X}$-ray detectors, ${ }^{[14]}$ and chemical sensors ${ }^{[15]}$ have also been widely demonstrated. ${ }^{[16]}$

\subsection{Perovskite LEDs (PeLEDs)}

LEDs are one kind of electronic devices that convert electricity into light via the progress called electroluminescence (EL). As an artificial smart light source, LEDs are becoming a key component of today's technology, widely used in lighting, display, communications, medical services, and signage. ${ }^{[17]}$ Since the first report of visible-spectrum LED based on GaAsP red light emitter in $1962,{ }^{[18]}$ varieties of LEDs have emerged, including inorganic LEDs, organic LEDs (OLEDs), and quantum-dot LEDs (QD-LEDs). ${ }^{[19]}$ Perovskites were also recognized as promising candidates for emissive semiconductor materials.

The first report of PeLEDs was actually prior to solar cells, in which layered structured halide perovskites were applied to generate light in early 1990s. However, due to the dramatically PL quenching at room temperature, PeLEDs were only achieved at low temperatures $(<110 \mathrm{~K})$ at that time. ${ }^{[20,21]}$ Until 2014 , room temperature PeLEDs were first reported, which delivered an external quantum efficiency (EQE) of $0.76 \%$ upon device architecture optimization. ${ }^{[10]}$ After that, the research on PeLEDs grew intensively. In 2015, the EQE has pushed to $8.53 \%$, which represented a big step for achieving high-efficiency PeLEDs. In 
2016, the EQE of PeLEDs has been updated to $11.7 \%$ by applying self-organized multiple quantum wells (MQWs). ${ }^{[22]}$ Afterwards, intensive efforts have been made to further improve the device performance of PeLEDs.

PeLEDs are competitive to the other LED counterparts. They not only encompass the advantages of inorganic (e.g., high carrier mobility) and organic (e.g., cost-effective and solution-processable) but also exhibit easily tunable bandgap with wider color gamut ( $\approx 140 \%$ ), high color purity, and high PL quantum yield (PLQY). ${ }^{[23,24]}$ These excellent optoelectronic and material-specific properties make perovskites a rising star of future light emitters.

\subsection{Status and Challenges}

In the past six years, numerous studies of PeLEDs concentrated on the improvement of device efficiency and operation lifetime, full-color PeLEDs, and understanding of their underlying mechanisms. These effects have resulted in many discoveries and advances.

At present, near-infrared, red, and green PeLEDs with EQEs of $21.6 \%,{ }^{[25]}$ $21.3 \%,{ }^{[26]}$ and $20.3 \%{ }^{[27]}$ have been reported. These values have approached the limit of $\approx 25 \%$ of single layer-based PeLEDs. ${ }^{[28,29]}$ Beyond the efficiency, the operation lifetime, which was just a few minutes in early reports, has increased up to a few hundreds of hours. These achievements are attributed to the optimization of perovskites materials and device configurations, which are wellknown factors determining the performance of PeLEDs. ${ }^{[30]}$ Although the development of higher bandgap emitters has been challenging, ${ }^{[31]}$ recent advances of blue PeLEDs are promising with the best EQE up to $12.3 \% .^{[32]}$

Despite the successes, significant challenges remain for future commercialization. For the monochromatic PeLEDs, the EQEs of blue color still lag significantly behind those of red and green counterparts. In addition to the efficiency, color stability issues are common in mixed-halide perovskites, which are mostly attributed to halide segregation; however, the origin is still an open question. ${ }^{[33]}$ Moreover, perovskite white EL remains a big challenge in spite of the facile 
monochromatic emissions. Beyond these limits, the operation lifetime of PeLEDs is far from the requirement for commercial use. ${ }^{[34]}$

\subsection{Aim of the Thesis}

The aim of this thesis is to investigate the color tuning and stability of PeLEDs in pure halide and mixed halide systems, in particular the spectral instability and stabilization of cesium-based mixed bromide/chloride, which are essential for exploring high-performance full-color PeLEDs. We also devise single-emissive-layer white PeLEDs upon mixed halide compositions with suppressed anion exchange. These results will provide valuable insights into the design of allperovskite single-emissive layer white LEDs. The remainder part of this thesis is structured as follows.

Chapter 2 presents the fundamental knowledge of perovskites, including the structure, properties, and growth. In particular, we demonstrate a simple method to grow perovskite QDs with tunable color via additive engineering (Paper I).

Chapter 3 gives a brief introduction of the basics of PeLEDs, including the work principle, configuration, characterization, and optimization.

Chapter 4 discusses the study of blue PeLEDs, especially by means of mixed halide approaches, which suffer from poor color purity during device operation. Based on our studies in Paper II and Paper III, we present the EL and PL spectral stability issues of $\mathrm{CsPb}\left(\mathrm{Br}_{1-x} \mathrm{Cl}_{x}\right)_{3}$ films. Their underlying reasons and solutions are also discussed.

Chapter 5 discusses the realization of white PeLEDs in both perovskitebased hybrid white LEDs and all-perovskite white LEDs. In Paper IV, we for the first time propose a practical strategy to design single-emissive-layer white PeLEDs. The single-layer perovskite film encompasses $\mathrm{CsPb}\left(\mathrm{Br}_{1-x} \mathrm{Cl}_{x}\right)_{3}$ and $\mathrm{CsPb}\left(\mathrm{Br}_{1-y} \mathrm{I}_{y}\right)_{3}$ grains with suppressed ion-exchange, leading to dual-color white light emission. 


\section{Chapter 2}

\section{Fundamental Structure, Property, and Growth of Perovskites}

\subsection{Crystal Structure}

Traditional perovskites $\left(\mathrm{ABX}_{3}\right)$ are assembled by $\mathrm{BX}_{6}$ octahedra and $\mathrm{A}$ cations. $\mathrm{B}$ cations and $\mathrm{X}$ anions form $\mathrm{BX}_{6}$ octahedra, locating at the center and corner, respectively (Figure 2.1a); A cations sit between the octahedral (Figure 2.1b). The corner-sharing octahedra with A cations in the voids extend towards three dimensions, forming a three-dimensional (3D) structure (Figure 2.1b). ${ }^{[23]}$

a

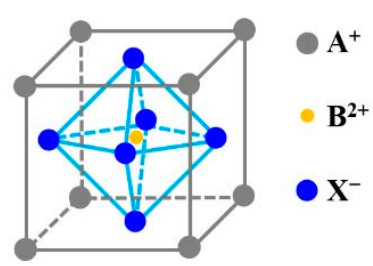

b

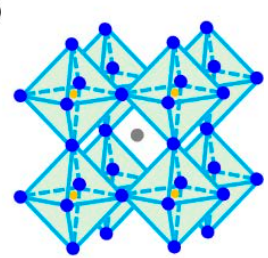

Figure 2.1 $\mathrm{ABX}_{3}$ perovskite (a) unit cell and (b) extended network structure.

The crystallographic stability needs to be considered when selecting atoms to fabricate 3D perovskites. In general, the Goldschmidt tolerance factor $t$ (equation 2.1) and octahedral factor $\mu$ (equation 2.2) are used as empirical rules to predict the crystallographic stability of target perovskites,

$$
\begin{aligned}
t & =\frac{\left(r_{A}+r_{X}\right)}{\sqrt{2}\left(r_{B}+r_{X}\right)} \\
\mu & =\frac{r_{B}}{r_{X}}
\end{aligned}
$$

where $r_{\mathrm{A}}, r_{\mathrm{B}}$ and $r_{\mathrm{X}}$ are the ionic radii of the corresponding ions. The $t$ and $\mu$ values of $0.81<t<1.11$ and $0.44<\mu<0.90$, respectively, are usually favorable for achieving 3D perovskites. ${ }^{[35]}$ Based on these rules, at present, $\mathrm{Cs}^{+}, \mathrm{MA}^{+}$, and/or $\mathrm{FA}^{+}$are recognized as the A-site cations to synthesize 3D perovskites; 
$\mathrm{Pb}^{2+}$ and/or $\mathrm{Sn}^{2+}$ are for the $\mathrm{B}$ site; and $\mathrm{I}^{-}, \mathrm{Br}^{-}$, and/or $\mathrm{Cl}^{-}$are for the $\mathrm{X}$ site (listed in Table 2.1). ${ }^{[36]}$

Table 2.1 Widely used ions and ionic radii for $3 \mathrm{D}$ perovskites.

\begin{tabular}{cccccc}
\hline \multicolumn{2}{c}{ A site } & \multicolumn{2}{c}{ B site } & \multicolumn{2}{c}{$\mathrm{X}$ site } \\
\hline Ion & Radius $(\AA)$ & Ion & Radius $(\AA)$ & Ion & Radius $(\AA)$ \\
\hline $\mathrm{Cs}^{+}$ & 1.67 & $\mathrm{Sn}^{2+}$ & 1.18 & $\mathrm{Cl}^{-}$ & 1.81 \\
$\mathrm{MA}^{+}$ & 1.80 & $\mathrm{~Pb}^{2+}$ & 1.19 & $\mathrm{Br}^{-}$ & 1.96 \\
$\mathrm{FA}^{+}$ & 2.53 & & & $\mathrm{I}^{-}$ & 2.20 \\
\hline
\end{tabular}

\subsection{Structural Properties}

\subsubsection{Defect Tolerance}

Ideal perovskite crystals (Figure 2.1b) with every atom locating at the prescribed site are very rare. During the synthesis processes, various defects are introduced inevitably in the crystals with fairly high density $\left(\sim 10^{14}-10^{17} \mathrm{~cm}^{-3}\right) \cdot{ }^{[37]}$ Whereas, a large number of the defects are point defects, distributed within the crystals and at grain boundaries. ${ }^{[38]}$ As shown in Figure 2.2a, these point defects include vacancies, interstitials, and antisites, among which vacancies are located exclusively due to their lower formation energies. ${ }^{[35,39]}$ Moreover, most vacancies form states locating within the valence band (VB) and conduction band (CB), or are shallow defects near band edges (Figure 2.2b). ${ }^{[40]}$ These defects are ready to be efficiently reduced by a variety of approaches, like crystallinity enhancement, ${ }^{[41]}$ passivation agent incorporation, ${ }^{[25]}$ and surface passivation ${ }^{[42]}$. 

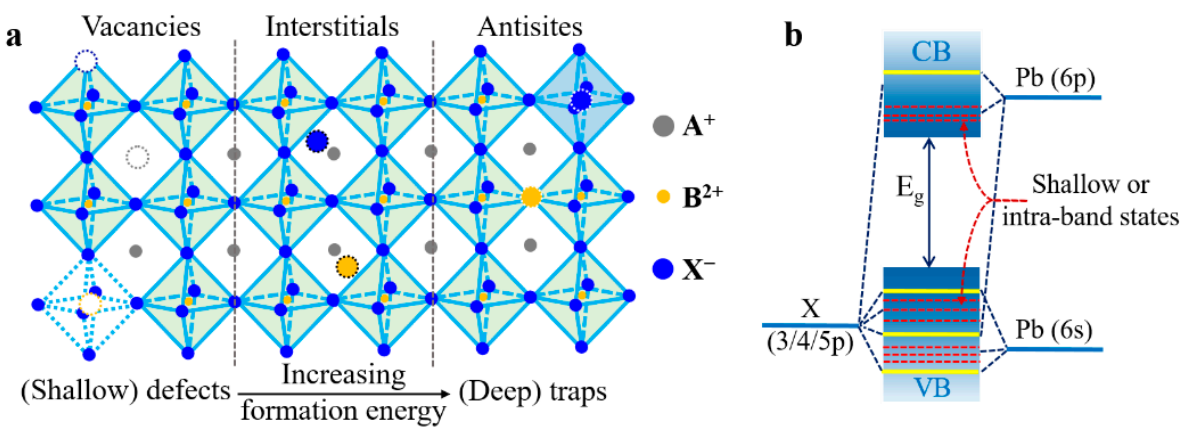

Figure 2.2 (a) Typical point defects in perovskites. (b) Bonding diagram of defect-tolerant perovskites. Adapted from references. ${ }^{[39,40]}$

\subsubsection{Bandgap Tunability}

The tunable bandgap is an exceptional property of perovskites. $\mathrm{ABX}_{3}$ perovskites are direct bandgap semiconductors (Figure 2.2b), in which the conduction band minimum (CBM) is formed by the hybridization of $6 p$-orbitals of B cations; the valence band maximum (VBM) is the antibonding hybrid states between a large portion of $p$-orbitals of $\mathrm{X}$ anions and a small portion of $s$-orbitals of B cations. ${ }^{[43]}$ Although A cations have no direct contributions to the formation of CBM and VBM, they can alter the covalent or ionic character of the B-X bond and, in turn, change the bandgap. ${ }^{[44]}$ Therefore, as shown in Figure 2.3, the bandgap of perovskite can be tuned over a wide range by changing their composition. In addition, the high optical absorption coefficient $\left(10^{4}-10^{5} \mathrm{~cm}^{-1}\right)$ is also emerged from the direct-gap $p_{(\mathrm{B})}-p_{(\mathrm{X})}$ transition of perovskites. ${ }^{[35,45]}$

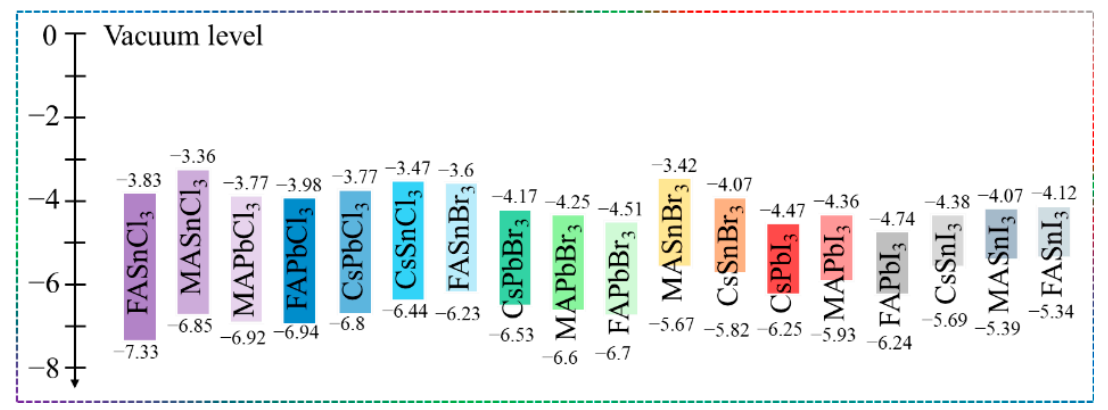

Figure 2.3 Bandgaps of $\mathrm{ABX}_{3}$ perovskites with respect to their composition. ${ }^{[46]}$ 


\subsubsection{Narrow Bandwidth}

Perovskites exhibit narrow bandwidth with the full width at half maximum (FWHM) less than $40 \mathrm{~nm} \cdot{ }^{[47]}$ This feature arises from the inherent crystal structure, ${ }^{[23]}$ in which Fröhlich interaction is existent between charge carriers and longitudinal optical (LO) phonons in the perovskite crystal. The interaction provides a dominant contribution to homogeneous linewidth broadening of perovskite 3D structures. In addition, the defects in perovskites are mostly nonradiative recombination centers, exhibiting negligible defect-contributed linewidth broadening. ${ }^{[23,48]}$ A narrow bandwidth promises a high color purity, which is an advantage of perovskite emitters for their use in LEDs.

\subsubsection{Charge-Carrier Dynamics}

The charge-carrier recombination in $3 \mathrm{D}$ perovskites follows the standard $\mathrm{ABC}$ model, which involves monomolecular recombination, bimolecular recombination, and Auger recombination (Figure 2.4). ${ }^{[49]}$ The decay of the charge carriers associating with different pathways can be expressed via the rate equation

$$
\frac{d n}{d t}=\mathrm{G}-n k_{1}-n^{2} k_{2}-n^{3} k_{3}
$$

where $\mathrm{G}$ is the charge-carrier generation rate, $n$ is the charge carrier density, $k_{l}$, $k_{2}$, and $k_{3}$ are the monomolecular $\left(\sim 10^{6} \mathrm{~s}^{-1}\right)$, bimolecular $\left(\sim 10^{-10} \mathrm{~cm}^{3} \mathrm{~s}^{-1}\right)$, and Auger recombination $\left(\sim 10^{-28} \mathrm{~cm}^{6} \mathrm{~s}^{-1}\right)$ coefficients, respectively.

The monomolecular recombination dynamics depend on the dimension of perovskites. Since the exciton binding energy of 3D perovskites is as low as tens of $\mathrm{meV}$, the generated charge carriers are thus free carriers instead of bound excitons at room temperature. Hence, the monomolecular recombination in $3 \mathrm{D}$ perovskites is trap-mediated recombination (Figure 2.4a); for quantum-confined perovskites (will be discussed in Section 2.3) which have high binding energy of hundreds of $\mathrm{meV}$, the monomolecular recombination is radiative recombination of excitons. The bimolecular recombination of free carriers is radiative, 
contributing to the light emission of perovskites (Figure 2.4b). Auger recombination is inherently nonradiative, in which the energy is consumed by intra- or interband transitions (Figure 2.4c)..$^{[49,50]}$

a

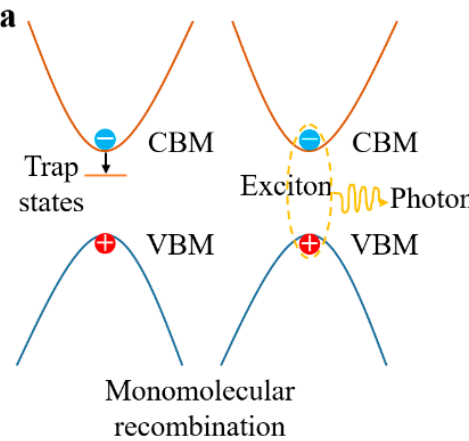

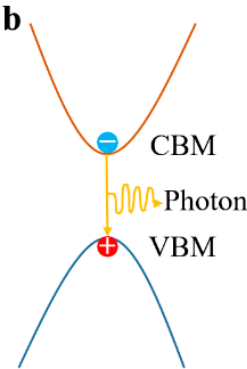

Bimolecular recombination
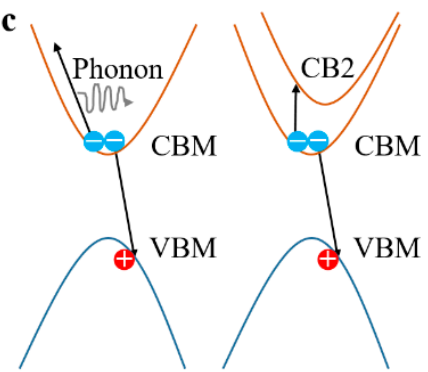

Auger recombination

Figure 2.4 Schematic diagram of recombination pathways of charge carriers. (a) Monomolecular recombination, (b) bimolecular recombination, and (c) Auger recombination. Adapted from reference. ${ }^{[51]}$

\subsubsection{PLQY}

The PLQY is defined as the ratio between the number of photons emitted and the number of photons absorbed. It is one of the most important parameters to assess the radiative efficiency of luminescent materials, which can be determined by the ratio of radiative $\left(k_{r a d}\right)$ to total recombination $\left(k_{\text {rad }}+k_{\text {non }}\right)$ rates: ${ }^{[52]}$

$$
\text { PLQY }=\frac{k_{\text {rad }}}{k_{\text {rad }}+k_{\text {non }}} \times 100 \%
$$

Given that only the bimolecular recombination is radiative in $3 \mathrm{D}$ perovskites, it is therefore reasonable to rewrite equation 2.4 as follows (combined with equation 2.3):

$$
\operatorname{PLQY}_{(n)}=\frac{n k_{2}}{k_{1}+n k_{2}+n^{2} k_{3}} \times 100 \%
$$




\section{Chapter 2}

Obviously, the PLQY value strongly depends on the excitation intensity. At low charge carrier density, the PLQY is limited by the monomolecular recombination of traps. At high charge carrier density, the traps are predominantly filled and the bimolecular recombination of free carries becomes dominant, leading to the increase of PLQY until entering the regime of Auger recombination. ${ }^{[19]}$ However, the injected carrier densities of an operating PeLED $\left(<10^{15}\right.$ $\left.\mathrm{cm}^{-3}\right)$ can be even lower than the trap density $\left(\sim 10^{14}-10^{17} \mathrm{~cm}^{-3}\right)$. As such the efficiency of the PeLED could be low under device operation, in the situation where there is a significant amount of traps. ${ }^{[37]}$ Therefore, minimizing the nonradiative recombination rate and maximizing the radiative recombination rate are equally important to achieve high-efficiency PeLEDs.

\subsection{Quantum-Confined Structures}

Quantum-confined structures are important members in the perovskite family besides the above-mentioned 3D counterparts. They have two distinct merits, tunable bandgaps and high PLQYs, making them particularly suitable for PeLED applications.

\subsubsection{Ruddlesden-Popper Perovskites}

Low-dimensional Ruddlesden-Popper perovskites have a general formula of $\mathrm{R}_{2} \mathrm{~A}_{n-1} \mathrm{~B}_{n} \mathrm{X}_{3 n+1},{ }^{[53,54]}$ where $\mathrm{R}$ represents an additional long organic cation, acting as spacers between the $\mathrm{BX}_{6}$ octahedra; $n$ defines the number of stack $\mathrm{BX}_{6}$ layers (Figure 2.5). A-free $(n=1)$ terms 2D perovskites; however, the EL in 2D perovskites is only observed at low temperatures, limiting their applications. ${ }^{[55]}$ In contrast, quasi-2D perovskites $(n \geq 2)$, fabricated from mixing $2 \mathrm{D}$ and $3 \mathrm{D}$ perovskites with controlled stoichiometry, are widely employed in high-performance full-color PeLEDs. ${ }^{[50,56]}$ 

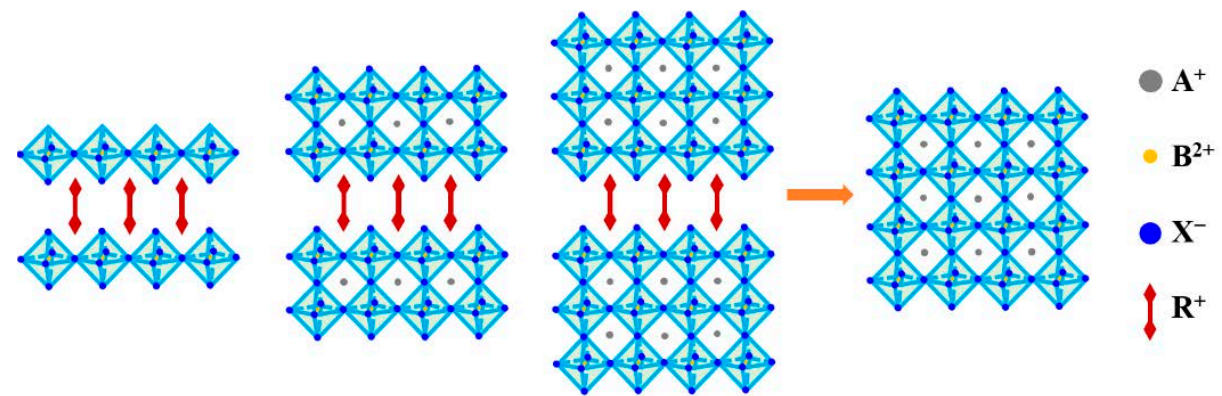

$n=1$
$2 \mathrm{D}: \mathrm{R}_{2} \mathrm{BX}_{4}$

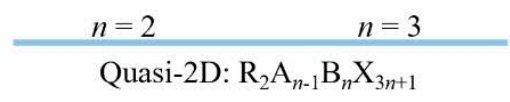

$\frac{n=\infty}{3 \mathrm{D}: \mathrm{ABX}_{3}}$

Figure 2.5 Schematic illustration of low-dimensional Ruddlesden-Popper perovskites. ${ }^{[53]}$

Quasi-2D perovskites have self-assembled quantum wells, offering tunable bandgaps and high PLQYs. The layered sheets of $\mathrm{BX}_{6}$ octahedra act as potential wells, in which charge carriers are firmly combined as excitons; varying the $n$ value changes the width of the wells, leading to a change in bandgap (Figure 2.6a). ${ }^{[22,50]}$ In addition, there is a spontaneously created energy transfer channel from small- $n$ to large- $n$ wells within these films, in which the absorption mainly occurs in the small- $n$ wells and the emission occurs the large- $n$ wells (Figure 2.6b). ${ }^{[22]}$ The cascade energy transfer process is found to be ultrafast, in the time scale of picoseconds; this feature can suppress nonradiative recombination in trap states and result in high local carrier density in the large- $n$ value phases, leading to high PLQY even at a low excitation density.

a

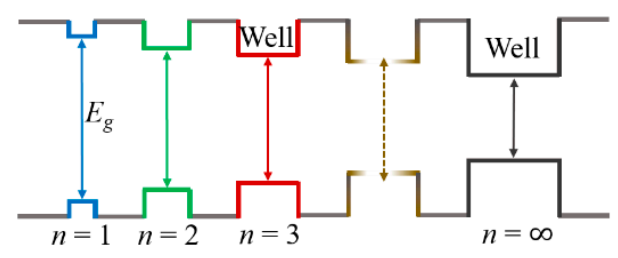

b

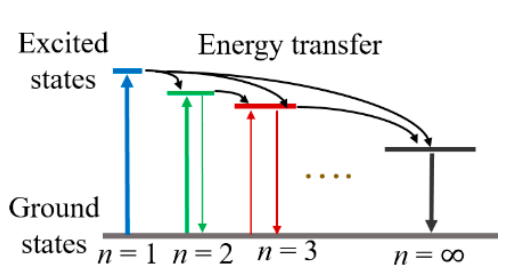

Figure 2.6 Schematic illustration of (a) self-assembled quantum wells ${ }^{[57]}$ and (b) cascade energy transfer of quasi-2D perovskite films. ${ }^{[22]}$ 


\subsubsection{Perovskite QDs}

Similar to traditional QDs, the quantum confinement effect in perovskite QDs is the most attractive properties for their applications (Figure 2.7). When the grain size of 3D perovskites decreases to nanoscale, typically $\sim 2-20 \mathrm{~nm}$, the energy levels are less overlapped. The discrete energy levels cause the increase of bandgap; further reducing the size of grains leads to more discrete energy levels and larger bandgaps, the so-called size-dependent bandgap. ${ }^{[58]}$ Moreover, the existence of quantum confinement effect largely increases the binding energy $\left(E_{b}\right)$ of excitons, upon which the excitons are bound firmly in perovskites, ${ }^{[59,60]}$ leading to high radiative recombination rate and high PLQYs (> $90 \%) .{ }^{[61]}$

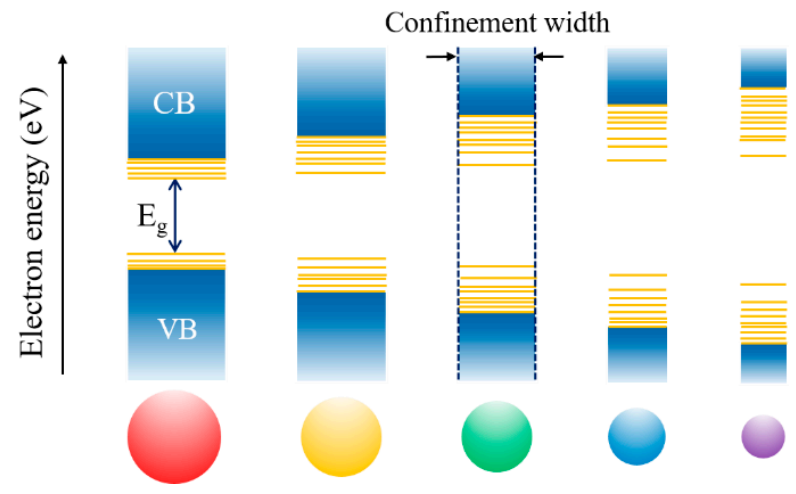

Figure 2.7 Schematic illustration of the quantum confinement effect. Adapted from reference. ${ }^{[58]}$

1D perovskite nanowires also possess quantum-confined structure. They are promising for photodetector and laser applications because of their high crystallinity and high charge carrier mobility, however, the other optoelectronic applications are limited by the poor morphology and surface coverage. ${ }^{[62]}$

\subsection{Synthesis Methods}

Considering the fabrication process, perovskites can be divided into two categories, thin-film perovskites and colloidal perovskites. The former one can be 
perovskites with all different dimensions, while the latter is mainly for nanocrystals or QDs.

\subsubsection{Thin-Film Perovskites}

There are three general deposition techniques to synthesize thin-film perovskites, namely, solution deposition, vapor deposition, and vapor-assisted solution deposition (Figure 2.8). ${ }^{[63,64]}$ Among these methods, solution deposition is the most straightforward method. The precursor solution is easily prepared by mixing B-site (e.g., $\mathrm{PbX}_{2}$ ) and A-site cation halides (e.g., MAX) in a polar solvent, such as dimethyl sulfoxide (DMSO) and N,N-dimethylformamide (DMF). Then the clear precursor solution is applied for spin-coating and followed by thermal annealing to promote the formation of perovskite phases. Despite the easy process, this method could result in poor film quality without process or precursor solution optimization, such as nonuniform surface-coverage, low crystallinity, and high trap density. ${ }^{[10]}$

$\mathbf{a}$

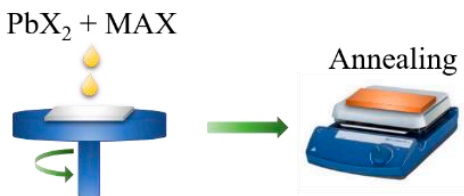

Solution deposition

c

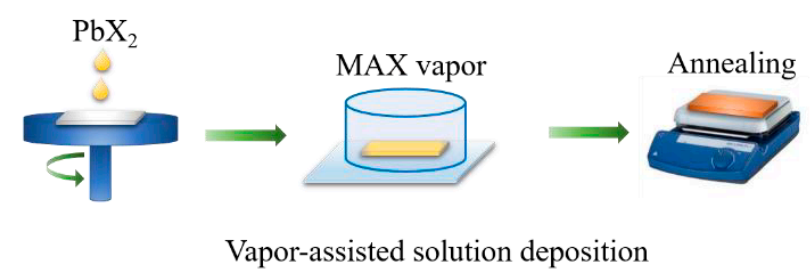

Figure 2.8 General deposition techniques for perovskite films (taking $\mathrm{MAPbX}_{3}$ perovskite as an example): (a) solution deposition, (b) vapor deposition, and (c) vapor-assisted solution deposition.

Various techniques have been applied to optimize the deposition process. One of them is the anti-solvent deposition, as shown in Figure 2.9a ${ }^{[65,66]}$ This 


\section{Chapter 2}

method involves another nonpolar solvent such as toluene, chlorobenzene (CB), and chloroform (CF), or green solvents such as isopropanol (IPA) and ethyl acetate (EA). ${ }^{[67,68]}$ When the nonpolar solvent is spin-coated on the wet film, the precursor solution becomes super saturation and precipitates rapidly, leading to fast crystallization and improved film morphology. However, the efficacy of this approach strongly depends on the nature of the anti-solvent, the volume being used, and exact dripping time, etc, which complicate the film preparation process. ${ }^{[69]}$ Another one is the two-step deposition (Figure 2.9b), in which $\mathrm{PbX}_{2}$ and MAX are dissolved in different targeted solvents (MAX is commonly dissolved in isopropanol (IPA)). ${ }^{[70]}$ The method enables balanced solubility and crystallization of $\mathrm{PbX}_{2}$ and MAX, giving access to high surface-coverage and crystalline perovskite films, however, fine-tuning temperature and concentration are crucial. ${ }^{[71]}$

a

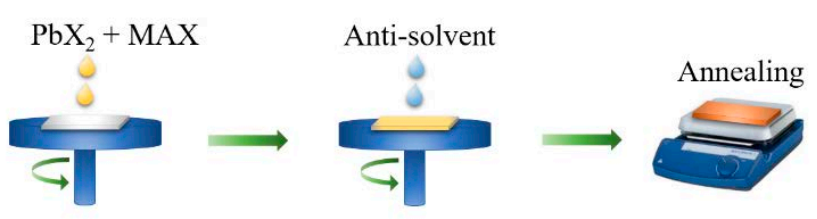

b

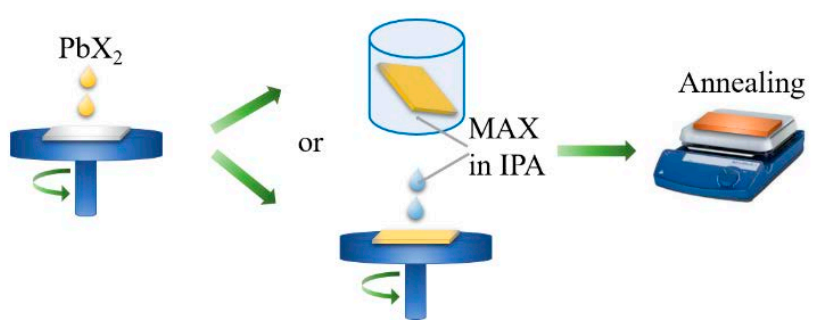

Figure 2.9 Schematic illustration of the (a) anti-solvent deposition and (b) two-step deposition.

\subsubsection{Colloidal Perovskites}

Colloidal perovskites have evolved into a significant class of semiconductor nanocrystals (NCs). Owing to the highly ionic bonding, the synthesis of colloidal perovskites also exhibits high practical implications. ${ }^{[39]}$ 
The hot-injection method is widely adapted to synthesize different types of colloidal perovskites (Figure 2.10a). It is produced via rapidly injecting A cation-oleate into a hot solution of $\mathrm{PbX}_{2}$ in 1-octadecene (ODE) $\left(140-200{ }^{\circ} \mathrm{C}\right)$, whereas A cation-oleate is prepared by the reaction between A-cation salt (dissolved in ODE) and oleic acid (OA); long-chain organic molecules, like OA and oleylamine (OLA), are used as capping ligands to prevent aggregation. The rapid injection and high temperature can lead to supersaturation and nucleation in a very short time; after a few seconds of injection $(\sim 5 \mathrm{~s})$, an ice-water bath is used to obtain precipitates of QDs, followed by isolation and purification processes with the help of nonpolar solvents to collect the QDs. ${ }^{[59]}$

Compared with hot-injection, the ligand-assisted re-precipitation method is more simplified. As shown in Figure 2.10b, a perovskite precursor solution of A-cation halide salt and $\mathrm{PbX}_{2}$ in DMF with ligands is injected dropwise into a non-polar solvent like toluene, resulting in the precipitation of perovskite QDs due to the polarity difference. Similar to the hot-injection method, isolation and purification processes are needed to collect the QDs. ${ }^{[72]}$

a

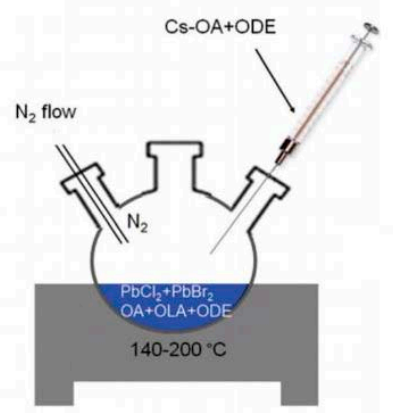

b

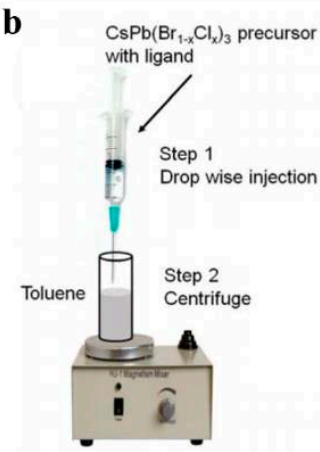

Figure 2.10 Schematic illustration of (a) hot-injection method and (b) ligand-assisted reprecipitation method. Adapted from reference. ${ }^{[29]}$

Colloidal perovskites are promising emitters to achieve high PLQY (80 $95 \%)^{[39]}$ and high color purity $(\mathrm{FWHM}<40 \mathrm{~nm}) \cdot{ }^{[73]}$ The quality of the resulting QDs, including the nucleation, shape, size, etc., shows strong organic liganddependence, which requires careful selection and control. ${ }^{[74,75]}$ In addition, structural stability is another big challenge; the crystal structure and surface ligands 
of the perovskite QDs are easy to break during the purification and dispersion processes. ${ }^{[39]}$

\subsection{In Situ Grown Perovskite QDs}

The ligand-assisted method is a pleasant alternative to grow QDs in an in situ way. ${ }^{[76]}$ A previous study has shown that perovskite QDs with size as small as $10 \mathrm{~nm}$ can self-assemble by loading a large-sized cation n-butylammonium (BA) into perovskite precursor solution $\left(\mathrm{MAPbX}_{3}\right){ }^{[77]}$ The $\mathrm{BA}$ cation acted as a surfactant impeding the growth of $3 \mathrm{D}$ perovskite grains, leading to considerable improvement in PLQY (from $0.2 \%$ to $40.1 \%$ ) and EQE (from $1 \%$ to $10.4 \%$ ). Thus, in situ grown perovskite QDs is very promising, which requires simple preparation processes.

We also demonstrated in situ grown QDs by introducing large organic ligands into perovskite precursor solution $\left(\mathrm{FAPbI}_{3}\right)$, which show tunable particle size by controlling the annealing temperatures. ${ }^{[78]}$ Figure $2.11 \mathrm{a}$ illustrates the preparation process of the in situ grown $\mathrm{FAPbI}_{3}$ QDs. A large organic cation 1naphthylmethyl ammonium (NMA) ${ }^{[22]}$, employed as the ligand, FAI and $\mathrm{PbI}_{2}$ were dissolved in DMF with a ratio of $1: 1: 1$ to form the precursor solution. After obtaining a clear solution (stirring at $50{ }^{\circ} \mathrm{C}$ for $2 \mathrm{~h}$ ), one step spin-coating method was applied to deposit the film, followed by thermal annealing for 10 min with different temperatures. Afterwards, in situ grown $\mathrm{FAPbI}_{3}$ QDs selfassembled, as shown in the transmission electron microscopy (TEM) image in Figure 2.11b.

a

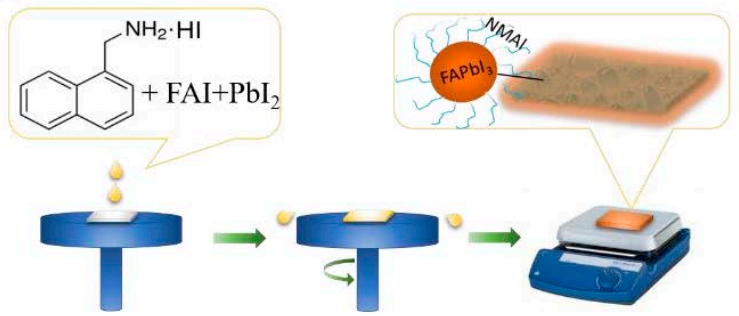

b

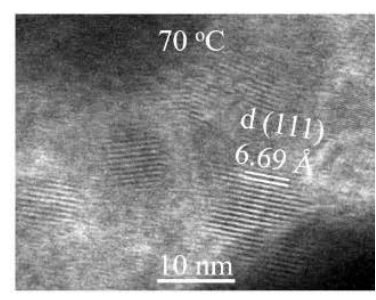

Figure 2.11 (a) Schematic illustration of in situ grown perovskite QDs. (b) TEM image of the film annealed at $70{ }^{\circ} \mathrm{C}$ for $10 \mathrm{~min}$. Adapted from reference. ${ }^{[78]}$ 
The grain size of these in situ grown $\mathrm{FAPbI}_{3}$ QDs exhibited strong annealing temperature dependence, as summarized in Table 2.2. By controlling the annealing temperature, the grain size varied in the range of $8.3-17.9 \mathrm{~nm}$, resulting in tunable PL emission with peak wavelengths of $667-778 \mathrm{~nm}$. These resultant QDs-based LED devices also delivered high EQEs of up to $11 \%$ with tunable EL spectra (667 - $790 \mathrm{~nm}$ ). The tunable color based on the obtained purehalogen $\mathrm{FAPbI}_{3}$ QDs were achieved by the quantum confinement effect, holding the promise of efficient perovskite LEDs with cost-effective and easily tunable colors.

$\frac{\text { Table 2.2 XRD and PL parameters of the in situ grown QDs. Adapted from reference. }{ }^{[78]}}{\text { XRD }}$

\begin{tabular}{ccccccc}
$\mathrm{T}\left({ }^{\circ} \mathrm{C}\right)$ & $\begin{array}{c}\text { FWHM (in } \\
\text { radian) }\end{array}$ & $\begin{array}{c}\text { Crystal size } \\
(\mathrm{nm})\end{array}$ & $\begin{array}{c}\text { PL peak } \\
(\mathrm{nm})\end{array}$ & $\begin{array}{c}\text { FWHM } \\
(\mathrm{eV} / \mathrm{nm})\end{array}$ & $E_{\mathrm{g}}(\mathrm{eV})$ & $\begin{array}{c}\text { PLQY } \\
(\%)\end{array}$ \\
\hline 100 & 0.0081 & 17.9 & 778 & $0.10 / 51.5$ & 1.59 & 50.8 \\
90 & 0.0098 & 14.8 & 770 & $0.11 / 53.2$ & 1.61 & 21.6 \\
80 & 0.0111 & 13.1 & 728 & $0.17 / 72.4$ & 1.70 & 12.5 \\
70 & 0.0154 & 9.5 & 690 & $0.22 / 83.8$ & 1.80 & 8.3 \\
60 & 0.0162 & 9.0 & 672 & $0.17 / 61.6$ & 1.85 & 7.3 \\
50 & 0.0175 & 8.3 & 667 & $0.21 / 77.2$ & 1.86 & 5.2 \\
\hline
\end{tabular}





\section{Chapter 3}

\section{Principle, Characterization, and Optimization of PeLEDs}

\subsection{Device Operation}

PeLEDs are solid-state devices with nanometer-thick perovskite films as the emissive layers (EMLs). They work in a similar way as other LEDs with the principles of standard p-n junction LEDs. Instead of employing two types of semiconductors, the EL process of PeLEDs is completed within the perovskite layer.

\subsubsection{Working Principle}

Generally, a PeLED contains five fundamental layers: an anode, a hole transport layer (HTL), a perovskite EML, an electron transport layer (ETL), and a cathode (Figure 3.1a). Under forward bias, holes (electrons) are injected from the anode (cathode) and transported through the HTL (ETL) before reaching the perovskite EML. When holes and electrons meet in the EML, some can be captured by traps within the bandgap or at the surface. As a result, only a portion of holes and electrons recombine to generate light, contributing to the efficiency of PeLEDs. When the device is reverse-biased, the charge flow is minimal due to the large injection barriers. ${ }^{[79]}$

Based on the electronic property of the bottom electrode (generally indium tin oxide (ITO) coated glass), the device structure is divided into two types, namely, p-i-n and n-i-p (Figure 3.1b). In the p-i-n structure, the bottom electrode is adjacent to HTL, acting as an anode to inject holes; in the n-i-p structure, the bottom electrode is adjacent to ETL, acting as a cathode to inject electrons. The selection of device structure and interlayers are critical for promoting the efficiency of PeLEDs, which requires careful consideration before device preparation. 
a

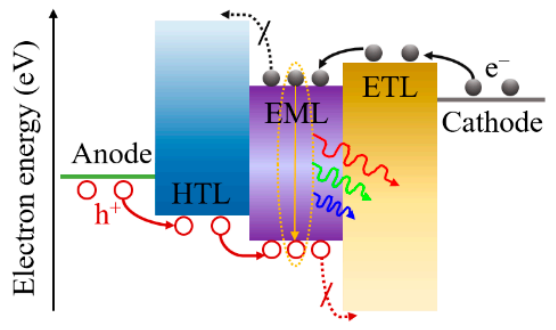

b

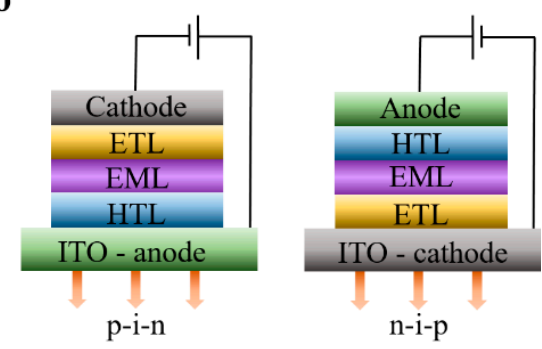

Figure 3.1 Schematic illustration of (a) the operation ${ }^{[23]}$ and (b) planar structures of PeLEDs.

\subsubsection{Architecture and Interlayers}

Ideal ETLs and HTLs usually possess the following attributions: well-aligned energy levels with EML and electrodes, balanced charge injection and blocking ability, facile deposition, good stability, and cost-effective. ${ }^{[80]}$ A large number of materials, including inorganic, and organic semiconductors, have been reported as suitable ETLs and HTLs. ${ }^{[81]}$

The energy level alignment at each interface of the device aims to create excellent charge injection and effective blocking barrier for the opposite charge carrier. Figure 3.2 shows the energy levels of commonly used electrodes, HTLs, and ETLs; ${ }^{[29]}$ perovskite EMLs with different composition and their energy levels have been presented in Figure 2.3. The CBM and VBM of perovskite EML need to be aligned with the lowest unoccupied molecular orbital (LUMO) of ETL and highest occupied molecular orbital (HOMO) of HTL to facilitate electron and hole injection. In addition, a much lower HOMO of ELT and higher LUMO of HTL are required to block the hole and electron within the perovskite layer. Similarly, the alignment between interlayers and electrodes should also be taken into account. 


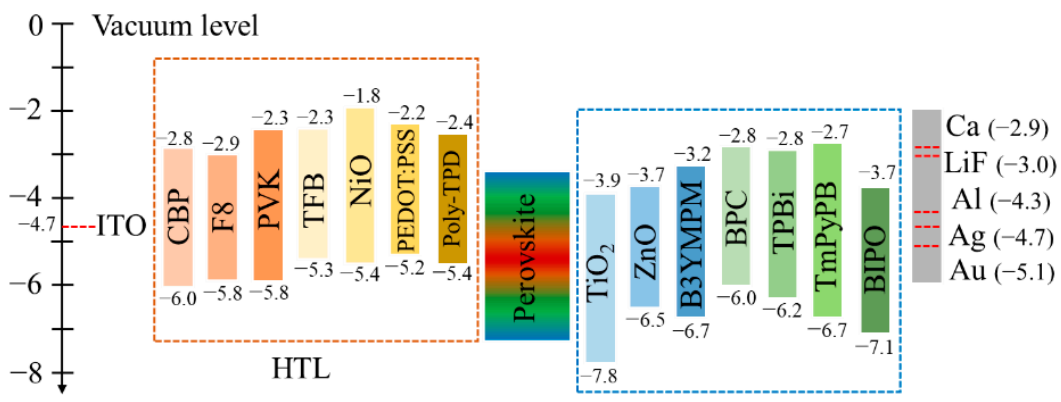

ETL

Figure 3.2 Energy level diagram of different HTLs and ETLs (CBP: 4,4'-bis(N-carbazolyl)-1,1'-biphenyl; F8: poly(9,9'-dioctylfluorene); PVK: poly(9-vinylcarbazole); TFB: poly((9,9-dioctylf- luorenyl-2,7-diyl)-co-(4,4'-(N-(4-secbutylphenyl)diphenylamine); PEDOT:PSS: Poly(3,4-ethylenedioxythiophene)-poly(styrenesulfonate); PolyTPD: $\quad$ poly(N,N'-bis(4-butylphenyl)-N,N'-bis(phenyl)benzidine); B3YMPM: 4,6bis(3,5-di(pyridin-3-yl)phenyl)-2-methylpyrimidine; BPC: 2,9-dimethyl-4,7-diphenyl1,10-phenanthroline; TPBi: 2,2',2"-(1,3,5-benzinetriyl)-tris(1-phenyl-1-H-benzimidazole); TmPyPB: 1,3,5-tri(m-pyrid-3-yl-phenyl)benzene; BIPO: bis(1-phenyl-1Hbenzo[d]imidazole)phenylphosphine oxide). ${ }^{[29]}$

In addition to well-aligned energy levels, balanced charge injection is of equal importance. ${ }^{[82]}$ The carrier mobilities of interlayers are different; for instance, the charge mobility gap between PVK $\left(2.5 \times 10^{-6} \mathrm{~cm}^{2} \mathrm{~V}^{-1} \mathrm{~s}^{-1}\right)$ and $\mathrm{ZnO}$ $\left(\sim 1.8 \times 10^{-3} \mathrm{~cm}^{2} \mathrm{~V}^{-1} \mathrm{~s}^{-1}\right)$ is up to three orders of magnitude. These differences can cause imbalanced charge injection and high injection current, which are found to degrade the device performance. ${ }^{[2,83]}$ Thus, a buffer layer, like poly(methyl methacrylate) (PMMA) or polyvinyl pyrrolidine (PVP), is usually employed to optimize the charge injection.

\subsection{Device Characterization}

To assess the performance of a LED device, a set of characterizations are required to determine important parameters, such as luminance/radiance, device efficiency, and operational stability. In fact, all these parameters can be calculated by measuring the spectral radiant flux $\left(\Phi_{e, \lambda}\right.$, unit: $\left.\mathrm{W} \mathrm{nm}^{-1}\right)$ and electrical power consumption through a LED testing platform. 


\subsubsection{Testing Platform}

The LED testing platform used in our lab compromises an integrating sphere, a spectrometer, a power supply, and a computer, as illustrated in Figure 3.3. Keithley 2400 is used as the power supply to drive the LED and acquire the input electrical signals (current and voltage). The integrating sphere and an optical fiber cable $(1000 \mu \mathrm{m})$ are used to collect the optical signals. The signals are then transformed into the spectrometer (ocean optics QE Pro) to read spectral radiant flux $\Phi_{e, \lambda}$. The computer is used to collect $\Phi_{e, \lambda}$ and current-voltage data and convert them into key parameters of LEDs (see in Section 3.2.3).

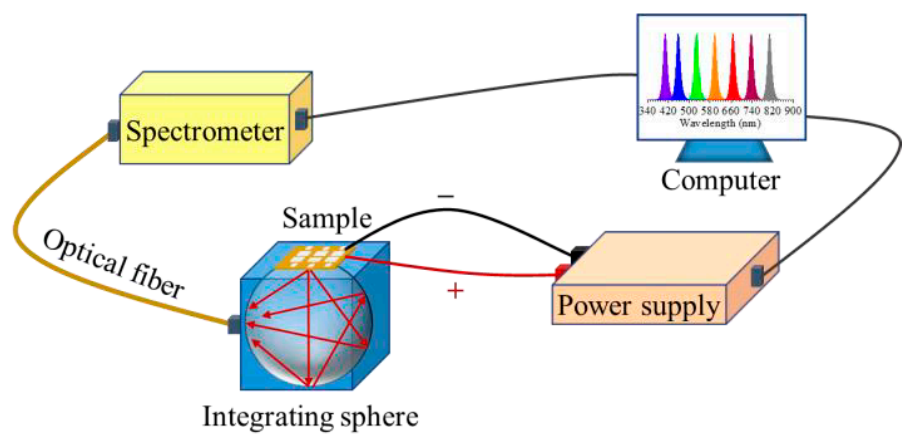

Figure 3.3 Schematic illustration of the LED testing platform. ${ }^{[84]}$

\subsubsection{Key Parameters}

An LED is a semiconductor device to convert electricity into light emission. Thus, parameters related to energy conversion efficiency and light quality are considered to evaluate the performance of PeLEDs. Table 3.1 lists the commonly used parameters for LEDs. ${ }^{[61]}$ 
Table 3.1 Commonly used parameters for LEDs.

\begin{tabular}{ccc}
\hline Parameter & Symbol & Unit \\
\hline CIE coordinates & - & - \\
Current density & $J$ & $\mathrm{~mA} \mathrm{~cm}^{-2}$ \\
Radiance & $L_{e}$ & $\mathrm{~W} \mathrm{sr}^{-1} \mathrm{~m}^{-2}$ \\
Luminance & $L_{v}$ & $\mathrm{~cd} \mathrm{~m}^{-2}$ \\
Turn-on voltage & $V_{o n}$ & $\mathrm{~V}$ \\
Power efficiency & $\eta_{p o w e r}$ & $\mathrm{~lm} \mathrm{~W}^{-1}$ \\
Current efficiency & $\eta_{c u}$ & $\mathrm{~cd} \mathrm{~A}^{-1}$ \\
Wall-plug efficiency & $\eta_{w p e}$ & $\%$ \\
EQE & $\eta_{\text {ext }}$ & $\%$ \\
Operation lifetime & $T_{50}$ & $\mathrm{~h}$ \\
\hline
\end{tabular}

Briefly, CIE coordinates, where CIE stands for Commission Internationale de l'Eclairage, are an assessment of the color purity; current density is a basic parameter to access the charge injection behavior. Radiance and luminance are indicators of how bright the emission color, also known as brightness. Turn-on voltage is the driving voltage above which the device is turned on, usually defined as the voltage at the luminance of $1 \mathrm{~cd} \mathrm{~m}^{-2}$ for visible LEDs. ${ }^{[85]}$ Power efficiency, current efficiency, wall-plug efficiency, and EQE are all indicators of the efficacy from different perspectives. The operation lifetime of the device is usually the lasting time for the luminance/radiance drops to $50 \%$ of its initial value. ${ }^{[25,86]}$

\subsubsection{Parameter Relationships}

The key parameters of PeLEDs listed in Table 3.1 involve radiometry and photometry, which are two different ways to determine optical radiation. Radiometry deals with optical radiation across the entire light region. In practical, it is more used in ultraviolet (UV) and infrared (IR) regions. The radiation of visible light region $(380-780 \mathrm{~nm}$ ) is characterized by the photometry which is closely relevant to the sensitivity of human eyes. Prior to discussing the correlations between the key parameters, related radiometric and photometric quantities are summarized in Table 3.2 for better understanding. 
Table 3.2 Commonly used radiometric and photometric quantities. ${ }^{[87]}$

\begin{tabular}{|c|c|c|c|c|c|c|}
\hline \multirow{2}{*}{ Definition } & \multicolumn{3}{|c|}{ Radiometric } & \multicolumn{3}{|c|}{ Photometric } \\
\hline & Quantity & Symbol & Unit & Quantity & Symbol & Unit \\
\hline $\begin{array}{l}\text { Energy per unit } \\
\text { time }\end{array}$ & $\begin{array}{l}\text { Radiant } \\
\text { flux }\end{array}$ & $\Phi_{e}$ & W & $\begin{array}{l}\text { Luminous } \\
\text { flux }\end{array}$ & $\Phi_{v}$ & $\operatorname{lm}$ \\
\hline $\begin{array}{c}\text { Power per unit } \\
\text { area }\end{array}$ & Irradiance & $E_{e}$ & $\mathrm{~W} \mathrm{~m}^{-2}$ & Illuminance & $E_{v}$ & $\operatorname{lm~} \mathrm{m}^{-2}$ \\
\hline $\begin{array}{l}\text { Power per unit } \\
\text { solid angle }\end{array}$ & $\begin{array}{l}\text { Radiant } \\
\text { intensity }\end{array}$ & $I_{e}$ & $\mathrm{~W} \mathrm{sr}{ }^{-1}$ & $\begin{array}{l}\text { Luminous in- } \\
\text { tensity }\end{array}$ & $I_{v}$ & $\begin{array}{c}\mathrm{cd}(\mathrm{lm} \\
\left.\mathrm{sr}^{-1}\right)\end{array}$ \\
\hline $\begin{array}{l}\text { Power per area } \\
\text { solid angle }\end{array}$ & Radiance & $L_{e}$ & $\begin{array}{l}\mathrm{W} \mathrm{sr}^{-1} \\
\mathrm{~m}^{-2}\end{array}$ & Luminance & $L_{v}$ & $\mathrm{~cd} \mathrm{~m}^{-2}$ \\
\hline
\end{tabular}

Combining Table 3.1 and 3.2, it is clear that radiant flux $\Phi_{e}$ and luminous flux $\Phi_{v}$ are two basic quantities. The former is integrated from spectral radiant flux $\Phi_{e, \lambda}$ (collected by the spectrometer), as shown in equation 3.1.

$$
\Phi_{e}=\int \Phi_{e, \lambda} \mathrm{d} \lambda
$$

Luminous flux $\Phi_{v}$ is actually converted from spectral radiant flux $\Phi_{e, \lambda}$ by considering human eye sensitivity function $V(\lambda)$, as given by equation 3.2 and 3.3,

$$
\begin{gathered}
\Phi_{v}=K_{m} \int \Phi_{e, \lambda} \cdot V(\lambda) \mathrm{d} \lambda \\
V(\lambda)=1.019 e^{-285.4(\lambda-0.559)^{2}}
\end{gathered}
$$

where $K_{m}$ is a scaling factor, which equals to $683 \mathrm{~lm}$ per watt. By definition, radiance $L_{e}$ is irradiance intensity per unit solid angle $(\Omega)$ or radiant intensity per unit emitting area $(A)$, as described in equation 3.4 ,

$$
L_{e}=\frac{\partial^{2} \Phi_{e}}{\partial \Omega \cdot(\cos \theta \cdot \partial A)}
$$

where $\theta$ is the angle between the given direction and normal to the emitting surface. Given that PeLEDs are Lambertian-type LEDs, ${ }^{[22]}$ equation 3.4 can be written as

$$
L_{e}=\frac{1}{\pi \cdot A} \int \Phi_{e, \lambda} \mathrm{d} \lambda
$$

where the unit emitting area $A$, in our case, is $0.0725 \mathrm{~cm}^{2}$. Correspondingly, luminance $L_{v}$ is given by 


$$
L_{v}=\frac{K_{m}}{\pi \cdot A} \int \Phi_{e, \lambda} \cdot V(\lambda) \mathrm{d} \lambda
$$

Power efficiency $\left(\eta_{\text {power }}\right)$, current efficiency $\left(\eta_{c u}\right)$, and wall-plug efficiency $\left(\eta_{\text {wpe }}\right)$ are defined as the ratio of visible light output power (luminous flux) to electrical input power, luminous intensity to current density, and total light output power (radiant flux) to electrical input power, respectively, given by equations 3.7-3.9.

$$
\begin{aligned}
& \eta_{\text {power }}=\frac{K_{m} \int \Phi_{e, \lambda} \cdot V(\lambda) \mathrm{d} \lambda}{I \cdot V} \\
& \eta_{c u}=\frac{K_{m} \int \Phi_{e, \lambda} \cdot V(\lambda) \mathrm{d} \lambda}{\pi \cdot I} \\
& \eta_{\text {wpe }}=\frac{\int \Phi_{e, \lambda} \mathrm{d} \lambda}{I \cdot V} \times 100 \%
\end{aligned}
$$

EQE $\left(\eta_{\text {ext }}\right)$, is defined as the ratio of the number of photons $\left(N_{\mathrm{p}}\right)$ emitted from the LED to the number of charge carriers $\left(N_{\mathrm{e}}\right)$ crossing the LED, given by equations 3.10-3.12,

$$
\begin{gathered}
\eta_{\text {ext }}=\frac{N_{p}}{N_{e}} \times 100 \% \\
N_{p}=\frac{\Phi_{e}}{E}=\frac{\int \Phi_{e, \lambda} \cdot \lambda \mathrm{d} \lambda \cdot t}{\hbar c} \\
N_{e}=\frac{I \cdot t}{e}
\end{gathered}
$$

where $\hbar$ is the plank constant $\left(6.626 \times 10^{-34} \mathrm{~J} \mathrm{~s}^{-1}\right), c$ is the speed of light $\left(3.0 \times 10^{8}\right.$ $\left.\mathrm{m} \mathrm{s}^{-1}\right), t(\mathrm{~s})$ is the spectrometer integrating time, $I(\mathrm{~A})$ is the current, and $e$ is the elementary charge $\left(1.602 \times 10^{-19} \mathrm{C}\right)$, respectively.

\subsection{Insights into Efficiency}

The emitted photons mentioned in equation 3.11 are termed to those escaping outside the device, allowing for detection by the integrating sphere. This can be reflected by another description of EQE, described as follows, ${ }^{[28]}$

$$
\eta_{\text {ext }}=\eta_{\text {int }} \cdot \eta_{o}=\gamma \cdot \eta_{S / T} \cdot q_{\text {eff }} \cdot \eta_{o}
$$


where $\eta_{\text {int }}$ and $\eta_{o}$ are the internal quantum efficiency (IQE) and light outcoupling efficiency, respectively. $\gamma$ is charge carrier balance factor, $\eta_{S / T}$ is the fraction of excitons capable of radiative decay at room temperature, and $q_{\text {eff }}$ is the effective radiative quantum efficiency. The product of these three terms is defined as the IQE. Note that $\eta_{S / T}$ is only applicable when the perovskite EML is low-dimensional structures with relatively high binding energy, like 2D perovskites and perovskite QDs. Equation 3.13 indicates that maximizing IQE and light outoupling efficiency is of great importance for acquiring high EQE.

\subsubsection{IQE}

IQE is defined as the ratio of the total number of generated photons to the total number of injected charge carriers, which can be the indicator of the utilization and loss of the injected charge carriers in a device. ${ }^{[88]}$ Similar to PL process, trap-mediated recombination, bimolecular recombination, and Auger recombination are three main recombination pathways of the injected charge carriers in a device (Figure 2.4). ${ }^{[89]}$ The decay of the injected charge carriers can be also expressed via equation 2.3. High IQE therefore needs to operate in the current density regime for bimolecular recombination.

In a real device, it is hard to directly acquire the number of photons within the device. Instead, PLQY is usually a measure of the radiative recombination efficiency of the device. Thus, strategies applied to improve the PLQYs are capable for the improvement of IQE, such as film quality control, defect passivation, quantum-confined structure employment. As described in equation 3.13 , in addition to maximizing the radiative recombination efficiency, improving the charge carrier injection efficiency also contributes to the total IQE.

\subsubsection{Light Extraction}

Light outcoupling efficiency is an assessment of light extraction, defined as the ratio of the number of photons escaping from the device to the total number of photons generated in the device. ${ }^{[90]}$ It is an inevitable restriction of the achievable maximum EQE despite the nearly $100 \%$ of IQE, mainly caused by the difference of refractive indices $(n)$ among the individual layers in the device. ${ }^{[1]}$ 
Figure 3.4 illustrates the main pathways of light losses in an LED device. The substrate mode is due to the refractive indices difference between the glass substrate $(n \sim 1.5)$ and air $(n \sim 1.0)$. The waveguide mode is related to the limited thickness of EML (100 - $200 \mathrm{~nm}$, which is smaller than the wavelength of emitted photons) and refractive indices differences of adjacent layers, leading to totally internal reflection or even reabsorption in some conditions. The surface plasmon mode is about the waves, propagating along the surface of metal, which causes the quenching of excitons. ${ }^{[90]}$ The light losses in these three modes result in light outcoupling efficiency of around $20 \%$ in OLEDs. ${ }^{[92]}$ In PeLEDs, this value is predicted between $20 \sim 25 \%$ for iodide perovskites based planar devices. $^{[28]}$

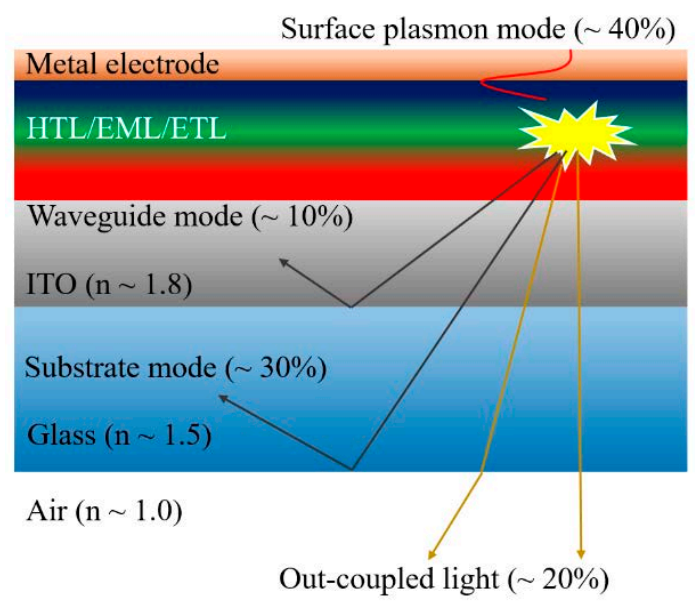

Figure 3.4 Schematic illustration of the light outcoupling of conventional LEDs. ${ }^{[90]}$

Although optical energy losses are unavoidable, numbers of approaches aimed at suppressing the above channels can effectively improve the light outcoupling efficiency, such as employing an additional scattering film, ${ }^{[93]}$ reducing the refractive indices of EML, ${ }^{[94]}$ and modifying the EML layer ${ }^{[95]}$. 


\subsubsection{Film Characterization Techniques}

Towards a better understanding of the performance of PeLEDs, film characterization is very necessary. In this thesis, a variety of techniques are employed to investigate the crystallinity, morphology, optical property, and chemical interaction of perovskite films. These techniques include X-ray diffraction (XRD), grazing incidence wide angle X-ray scattering (GIWAXS), scanning electron microscope (SEM), TEM, steady-state absorption, transient absorption (TA), steady-state PL, time-resolved PL, and Fourier-transform infrared (FTIR).

\subsection{High-Performance PeLEDs}

The EQE is determined by the charge injection efficacy and radiative recombination efficiency for PeLEDs without light outcoupling techniques. To reach high EQEs, numerous effects, from material design to device architecture optimization, have been made. ${ }^{[96]}$

\subsubsection{Film Growth and Quality}

Experimentally, a wide range of aspects can influence the film growth and the final quality of perovskites. Traditional 3D perovskites are fabricated from a mixture of $\mathrm{AX}$ and $\mathrm{BX}_{2}$ with a mole ratio of $1: 1$. However, the resultant films usually suffer from low luminescence efficiency, which is closely related to the poor morphology and high defect density. ${ }^{[65,97]}$

Composition engineering has shown a positive impact on these issues. ${ }^{[98]}$ For instance, the incorporation of $\mathrm{MABr}(13 \%)$ into $\mathrm{CsPbBr}_{3}$ was found helpful to suppress the formation of $\mathrm{Pb}$ metallic phase, which acts as a common non-radiative recombination centre; it also assisted the formation of pinhole-free morphology ${ }^{[83]}$ Besides the perovskite compositions, the addition of small molecules, like 2,2'-[oxybis(ethylenoxy)]diethylamine (ODEA), ${ }^{[25]} 5$-aminovaleric acid (5AVA) $)^{[99]}$ has demonstrated impressive device efficiencies due to the reduction of nonradiative recombination. Some organic polymers like poly(ethylene oxide) $(\mathrm{PEO})^{[100]}$ and polyimide precursor dielectric (PIP) ${ }^{[101]}$ have demonstrated pinhole-free films when blended with perovskite precursor solution. 
Dimensionality engineering is another widespread approach to grow perovskite films with improved EQEs. As mentioned in Section 2.3, owing to the quantum confinement effect, quasi-2D perovskites and QDs possess high PLQYs. This appealing advantage has resulted in a number of high-performance

PeLEDs in recent years. ${ }^{[102]}$ Moreover, the processing technique also plays a pivotal role in improving the film quality, such as two-step and anti-solvent deposition (discussed in Section 2.4.1).

\subsubsection{Surface Defect Passivation}

Surface defects such as halide vacancies are abundant in solution-processed perovskite films, which need to be healed in order to achieve high PLQY. ${ }^{[103]}$ The above-mentioned composition engineering is the most extensive approach to form surface passivation. In particular, passivation agents including alkali halides and organic molecules containing amine $\left(-\mathrm{NH}_{2}\right)$, hydroxyl $(-\mathrm{OH})$, carbonyl $(\mathrm{C}=\mathrm{O})$, and carboxyl $(-\mathrm{COOH}),{ }^{[104]}$ have demonstrated efficient surface passivation effect on the perovskite layer.

Apart from material composition, an additional layer can also facilitate the surface passivation. For instance, the employment of trioctylphosphine oxide (TOPO) on the top of perovskite layer has increased the EQE of up to $14.36 \%$ due to the chemical bonding between $\mathrm{P}=\mathrm{O}$ of TOPO and perovskites. ${ }^{[105]}$

\subsubsection{Charge Carrier Injection}

Charge carrier injection efficiency is highly correlated to the quality of perovskite films and the design of the device architecture. ${ }^{[83]}$ The quality of perovskite films is mainly characterized by defects and morphology. Low defect densities lead to high utilization of injected charge carriers by reducing nonradiative recombination rate.

To improve the charge carrier injection efficiency, a device architecture with well-aligned energy levels and balanced charge injection is required (discussed in Section 3.1.2). Apart from this, an interfacial layer is needed in some conditions. The interfacial layer usually plays two roles, reducing the energy level mismatch and minimizing the interfacial quenching of charges between the ETL 
or HTL and EML. One of the well-known cases is the modification of the interface between $\mathrm{ZnO}$ layer and perovskite layer. $\mathrm{ZnO}$ is widely used in the $\mathrm{n}$-i-p architecture due to the high charge mobility, high transparency, and wide energy band. ${ }^{[106]}$ However, perovskites are easy to degrade when deposited on $\mathrm{ZnO}$ directly due to the residual hydroxyl groups of $\mathrm{ZnO}^{[107]}$ and the interaction between $\mathrm{ZnO}$ and MA or FA cations. ${ }^{[98]}$ Studies have proved that an additional interlayer, like polyethyleneimine (PEI) ${ }^{[108]}$ can hinder the degradation process; in addition, it allows for better charge injection by decreasing the work function of the $\mathrm{ZnO}{ }^{[109]}$ 


\section{Chapter 4}

\section{Progresses, Challenges, and Opportunities of Blue PeLEDs}

\subsection{Progresses of Blue PeLEDs}

The easily tunable bandgap of perovskites favors the development of full-color LEDs. In contrast to near-infrared, red, and green counterparts, blue PeLEDs (410 - $490 \mathrm{~nm}$ ) have shown EQEs far lagging behind. Fortunately, the efficiency gap is significantly reduced in the recent two years. ${ }^{[32]}$ Further improving the device performance of blue light tends to be one of the hottest topics in the field of PeLEDs.

\subsubsection{Significance of Blue Light}

Blue LED is one of the greatest innovations in the 20th century, enabling bright and energy-saving white LEDs. The first visible LED was reported in 1962, however, the technique was hard to benefit mankind in the application of lighting due to lack of blue light. Until the early 1990s, the invention of high-power blue LEDs by Isamu Akasaki together with Hiroshi Amano and Shuji Nakamura brought a revolution for lighting, which was awarded the Noble Prize in Physics in 2014. These blue LEDs enable white light in a new way; by combining with red light, white light can cover a wide spectrum, leading to practical applications. ${ }^{[10,111]}$ Thus, the study of blue PeLEDs remains an important area in view of the role of blue light for solid state lighting applications.

\subsubsection{Developments and Status}

Blue PeLEDs were first report in 2015 by Kumawat et al., in which $\operatorname{MAPb}\left(\mathrm{Br}_{1-x} \mathrm{Cl}_{x}\right)_{3}$ was employed as the EML, with a low EQE $(<0.001 \%) .{ }^{[12]}$ Despite ongoing research efforts, the EQEs of blue PeLEDs are still less than $10 \%$ in 2018, as described in Figure 4.1. In contrast, the EQEs of their nearinfrared, red, and green counterparts have exceeded $20 \%,{ }^{[26,27,99]}$ which are quite close to the theoretical maximum EQE. ${ }^{[28]}$ The efficiency gap has been reduced 


\section{Chapter 4}

in the past two years; quite recently, a record EQE of $12.3 \%$ was demonstrated for blue PeLEDs based on high-quality $\mathrm{CsPbBr}_{3}$ perovskite QDs. ${ }^{[32]}$

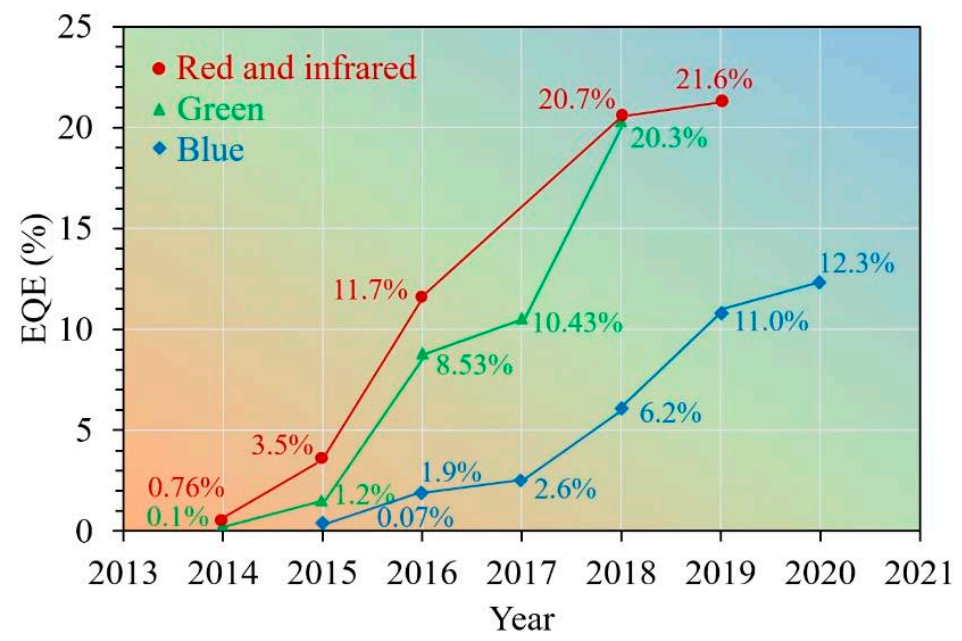

Figure 4.1 Progress and representative work of PeLEDs since 2014. Adapted from reference. ${ }^{[113]}$

The low PLQY of blue perovskites is an impediment to high-performance blue PeLEDs. ${ }^{[14]}$ Previous studies have revealed that the PLQY dramatically decreases as the light emission shifts to the blue region. ${ }^{[115]}$ Some works attributed this to the more easily formed defects along with lack of sufficient passivation method for wide-bandgap perovskites; ${ }^{[116]}$ however, the exact reason is still under debate. ${ }^{[117]}$ Nevertheless, strategies promising high PLQY have been attempted to develop high-performance blue PeLEDs.

Reducing non-radiative recombination centers is a practical way to improve the PLQY of blue perovskite films. For instance, the doping of $\mathrm{Mn}^{2+}$ into $\operatorname{CsPb}\left(\mathrm{Br}_{1-x} \mathrm{Cl}_{x}\right)_{3}$ nanocrystals leads to the increase of PLQY from $9 \%$ to $28 \%$ due to the reduced trap states; as result, the $\mathrm{EQE}$ of the device was improved from $0.50 \%$ to $2.12 \%{ }^{[114]}$ Another successful case is the $2 \% \mathrm{YCl}_{3}$ doped CsP$\mathrm{bBr}_{3}: \mathrm{PEACl}(1: 1)$ film (PEACl stands for phenylethylammonium chloride), which resulted in the increase of PLQY from 19.8 to $49.7 \%$ and a peak EQE of $11.0 \%{ }^{[117]}$ 
Mixed-dimensional perovskites and perovskite QDs are more popular for the development of blue PeLEDs owing to their high PLQYs. As plotted in Figure 4.2, the start-of-the-art blue PeLEDs are mainly based on low-dimensional perovskites. In sharp contrast, efficient blue PeLEDs based on 3D perovskite structures were rarely reported, and the EQE was no more than $2 \%$.

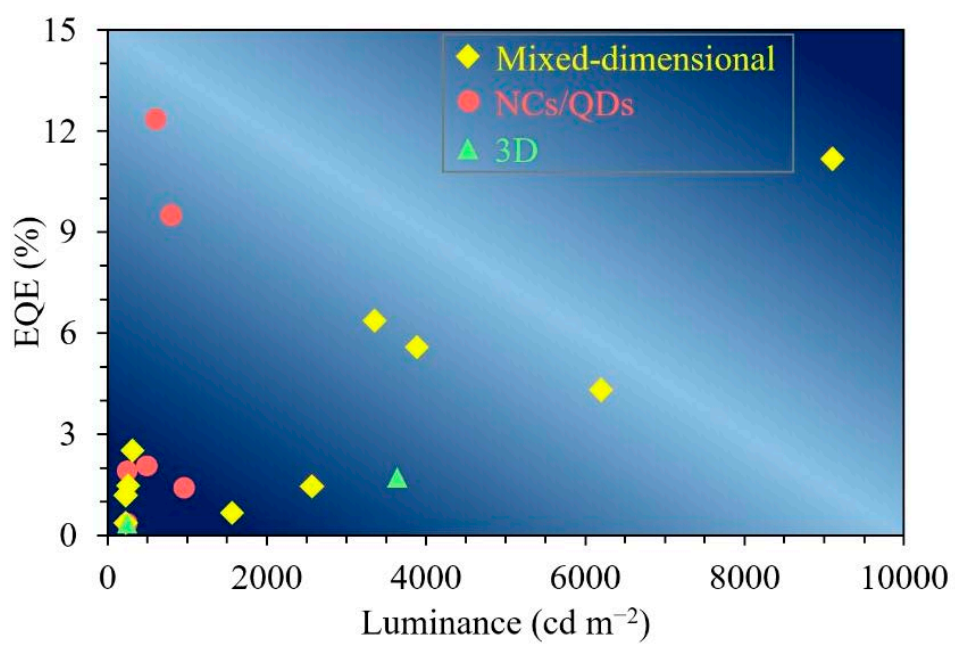

Figure 4.2 Summary of the state-of-the-art blue PeLEDs.

The development of 3D perovskites based blue LEDs has been challenging. Besides the poor efficiency, the spectral instability is another main concern which needs to be overcome. Moreover, regardless of the dimensionality, blue PeLEDs are suffering from poor operational lifetime. To date, the best reported $T_{50}$ was just $120 \mathrm{~min}$ with an initial luminance of around $100 \mathrm{~cd} \mathrm{~m}^{-2} \cdot{ }^{[117]}$ In short, the development of high-efficiency and color-stable blue PeLEDs with long operational lifetime requires extensive efforts.

\subsection{Approaches and Limitations}

The synthesis of blue perovskite emitters focuses on efficiency and operational stability. The diverse dimensionality of perovskites and their unique optoelectronic properties allow for various approaches with different advantages. At the same time, these different approaches bring different limitations, which will be discussed in the following sections, together with corresponding solutions. 


\section{Chapter 4}

\subsubsection{Mixed-Br/Cl Perovskites}

Mixed- $\mathrm{Br} / \mathrm{Cl}$ is the most straightforward approach to obtain blue perovskite emitters. As mentioned in Section 2.2.2, bandgap tunability is an appealing property of perovskites; any change of $\mathrm{A}, \mathrm{B}$, and $\mathrm{X}$ site ions can vary the bandgap (Figure 2.3). Regardless of $\mathrm{A}$ and $\mathrm{B}$ sites, mixing $\mathrm{Cl}$ with $\mathrm{Br}$ is needed for traditional 3D perovskites to ensure wide bandgaps. Taking $\mathrm{MAPb}\left(\mathrm{Br}_{1-x} \mathrm{Cl}_{x}\right)_{3}$ as an example, increasing the ratio of $\mathrm{Cl}$ results in blue-shift of the emission color from $537 \mathrm{~nm}$ to $409 \mathrm{~nm} .^{[12]}$

Mixed- $\mathrm{Br} / \mathrm{Cl}$ is also commonly used in mixed-dimensional perovskites to obtain target emission colors. ${ }^{[118]}$ For instance, the EL peak of $\mathrm{BA}_{2} \mathrm{Cs}_{n-1} \mathrm{~Pb}_{n} \mathrm{Br}_{3 n+1}$ perovskite (BA stands for butyl ammonium) locates at 506 $\mathrm{nm}$; the replacement of $\mathrm{CsBr}(16 \%)$ with $\mathrm{CsCl}$ shifts the EL peak to $486 \mathrm{~nm}$, making it more suitable for blue PeLEDs. ${ }^{[19]} \mathrm{CsPbCl}_{0.9} \mathrm{Br}_{2.1}$ perovskite with the emission of $484 \mathrm{~nm}$ was also selected as the initial composition before adding phenylethylammonium bromide (PEABr) to synthesize mixed-dimensional blue perovskites. $^{[120]}$

Despite the apparent simplicity, color instability is the biggest issue for the mixed-Br/Cl approach. Most of the reported mixed $\mathrm{Br} / \mathrm{Cl}$-based blue PeLEDs suffer from spectral shift upon device operation. ${ }^{[119-121]}$ As shown in Figure 4.3, a redshift was observed in $\mathrm{CsPCl}_{0.9} \mathrm{Br}_{2.1}: 100 \% \mathrm{PEABr}$ perovskite-based device under either different applied voltages (Figure 4.3a) or a constant applied voltage of $4.4 \mathrm{~V}$ (Figure 4.3b). ${ }^{[120]}$ 

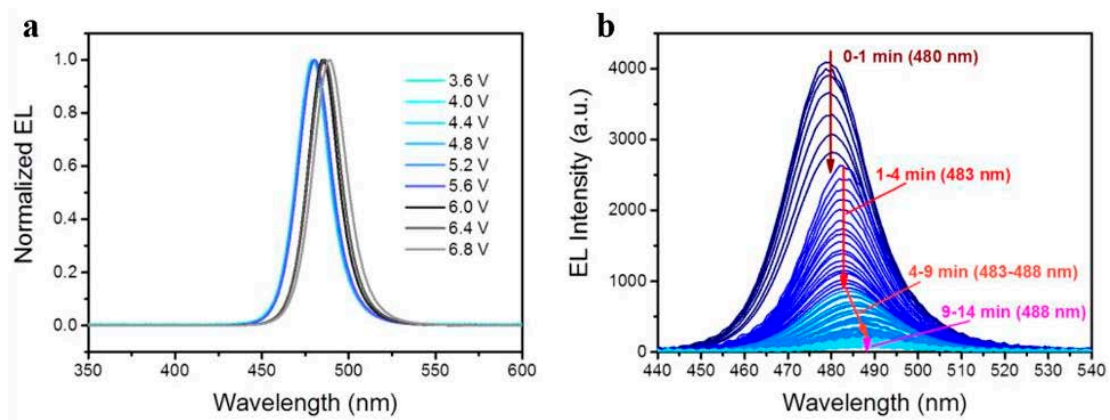

Figure 4.3 EL spectral shift of $\mathrm{CsPbCl}_{0.9} \mathrm{Br}_{2.1}: 100 \% \mathrm{PEABr}$ perovskite based device under (a) different applied voltages and (b) a constant applied voltage of $4.4 \mathrm{~V}$ as a function of time. Adapted from reference. ${ }^{[120]}$

\subsubsection{Pure Bromide Perovskites}

Quantum confinement effect of low-dimensional perovskites offers bandgap tunability beyond halide substitution (discussed in Section 2.3). Thus, in view of the spectral instability of mixed- $\mathrm{Br} / \mathrm{Cl}$ systems, pure-bromide perovskite QDs and mixed-dimensional structures have emerged as alternatives to fabricate color-stable blue LEDs.

In order to form a size-tunable bandgap, the diameter of pure bromide perovskite QDs should be close to or smaller than the exciton Bohr diameter. The exciton Bohr diameter of $\mathrm{CsPbr}_{3}$ QDs is estimated as $7 \mathrm{~nm}$; reducing the diameter from $11.8 \mathrm{~nm}$ to $3.9 \mathrm{~nm}$ results in blue shifted spectra from 518 to 467 $\mathrm{nm} .{ }^{[59]}$ Very recently, a record EQE of $12.3 \%$ at $479 \mathrm{~nm}$ was demonstrated based on $\mathrm{CsPbr}_{3}$ QDs with an average diameter of $4 \mathrm{~nm}$, in which no spectral shift was observed. ${ }^{[122]}$

The bandgap of $\mathrm{R}_{2} \mathrm{~A}_{n-1} \mathrm{~Pb}_{n} \mathrm{Br}_{3 n+1}$ perovskites is decided by the number of inorganic layers (n) due to the self-assembled quantum wells; reducing the $n$ value facilitates wider-bandgap phases. Taking $\mathrm{PEA}_{2} \mathrm{~A}_{n-1} \mathrm{~Pb}_{n} \mathrm{Br}_{3 n+1}$ as an example, the bandgap of $n=4,3,2$, and 1 is 2.6, 2.7, 2.9, and $3.1 \mathrm{eV}$, respectively. ${ }^{[56]} \mathrm{By}$ replacing PEA with iso-propylammonium (IPA) to control the film growth, a sky-blue color $(490 \mathrm{~nm})$ with an EQE of $1.5 \%$ was demonstrated. 


\section{Chapter 4}

Despite the stable spectra, pure bromide perovskites QDs and mixed-dimension structures both suffer from low luminance and limited color gamut. Both these two structures are formed by incorporating long-chain organic ligands to suppress crystal growth. The insulating nature of the ligands usually results in poor charge injection and hence low luminance. ${ }^{[123,124]}$ For $\mathrm{CsPbBr}_{3}$ QDs, achieving deeper blue colors $(<467 \mathrm{~nm})$ is technically difficult, which requires a much smaller size $(<3.9 \mathrm{~nm})$ with high uniformity. ${ }^{[59]}$ As for $\mathrm{R}_{2} \mathrm{~A}_{n-1} \mathrm{~Pb}_{n} \mathrm{Br}_{3 n+1}$ perovskites, it is also hard to obtain deep blue colors due to the existence of multiple phases, which sometimes even lead to broad emission. ${ }^{[125]}$ Overall, the state-of-the-art blue PeLEDs are mainly based on mixed- $\mathrm{Br} / \mathrm{Cl}$ perovskites regardless of their dimensionalities, yet with unsatisfactory spectral stability.

\subsection{Color Stability of Mixed Halide Perovskites}

The color stability issue has been one of the main concerns for the application of mixed-halide PeLEDs, which appears in both mixed-Br/I and $\mathrm{Br} / \mathrm{Cl}$ systems. In spite of intensive investigations, the origin of poor color stability in mixed halide perovskites remains under debate. In addition, the understanding of color stability issue of mixed- $\mathrm{Br} / \mathrm{Cl}$ system is borrowed from mixed-Br/I system, the mechanism of which might be fundamentally different. In the following part, I summarise early observations and current understandings of this issue, and also discuss methods against color instability.

\subsubsection{Early Observations}

The color instability of mixed halide perovskites was first reported by Hoke et al. in $\operatorname{MAPb}\left(\mathrm{I}_{1-x} \mathrm{Br}_{x}\right)_{3}(0.2<x<1.0)$ perovskites, which exhibit PL shift upon illumination. ${ }^{[126]}$ As illustrated in Figure 4.4a, over $45 \mathrm{~s}$ illumination, the initial PL spectrum of $\mathrm{MAPb}\left(\mathrm{I}_{0.6} \mathrm{Br}_{0.4}\right)_{3}$ film continuously redshifts from $\sim 670 \mathrm{~nm}$ to $\sim 740 \mathrm{~nm}$. It is explained by the formation of I-rich and Br-rich domains after light illumination, upon which I-rich domains stabilize holes and lead to dominant I-rich emission, that is, so-called light-induced halide segregation. This process is reversible after dark treatment (Figure 4.4b), through which the shifted PL peak can move back to the initial location due to entropically driven 
remixing. Although the underlying origins are ambiguous, these findings represent a starting point for the study of spectral stability of mixed halide perovskites.
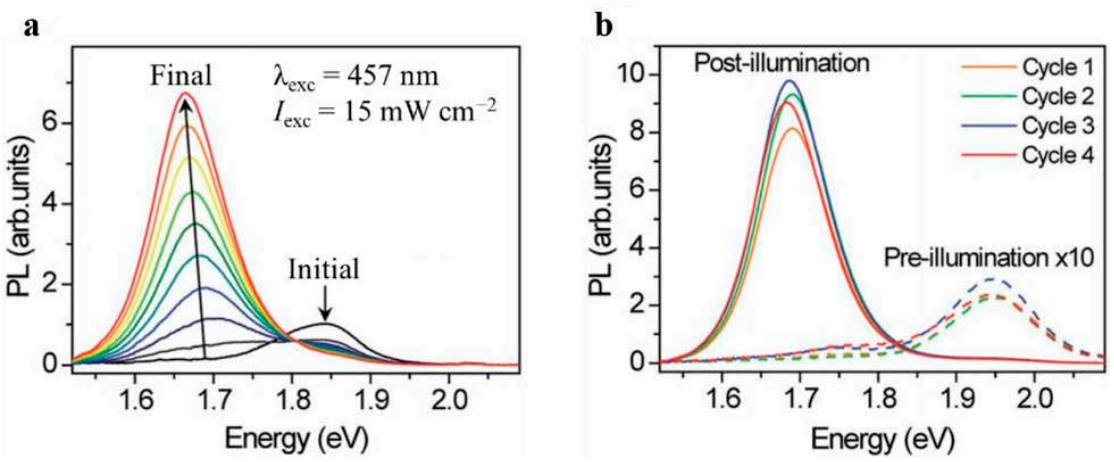

Figure 4.4 (a) PL spectra of $\mathrm{MAPb}\left(\mathrm{I}_{0.6} \mathrm{Br}_{0.4}\right)_{3}$ perovskite over $45 \mathrm{~s}$ in $5 \mathrm{~s}$ segments. (b) $\mathrm{PL}$ spectra of $\mathrm{MAPb}\left(\mathrm{I}_{0.4} \mathrm{Br}_{0.6}\right)_{3}$ perovskite after sequential cycles of illumination for 2 min (post-illumination), followed by dark-treatment for 5 min (pre-illumination). Adapted from reference. ${ }^{[126]}$

A considerable amount of studies have reproduced the effects since the first report, yet with mixed success. ${ }^{[127]}$ Studies by MaMeekin et al. show that the spectral stability of mixed halide perovskites is closely relevant to the composition. ${ }^{[128]}$ As illustrated in Figure 4.5, under identical illumination conditions, $\mathrm{FA}_{0.83} \mathrm{Cs}_{0.17} \mathrm{~Pb}\left(\mathrm{I}_{0.6} \mathrm{Br}_{0.4}\right)_{3}$ perovskite exhibits better color stability in contrast to $\operatorname{MAPb}\left(\mathrm{I}_{0.6} \mathrm{Br}_{0.4}\right)_{3}$. Though not discussed in details, the color instability might not be an intrinsic issue for mixed halide perovskites. Besides composition, other aspects like crystallinity, ${ }^{[129]}$ crystal structure, ${ }^{[130]}$ film thickness, ${ }^{[131]}$ and atmospheric conditions ${ }^{[132]}$ have been used to explain the spectral shift. 


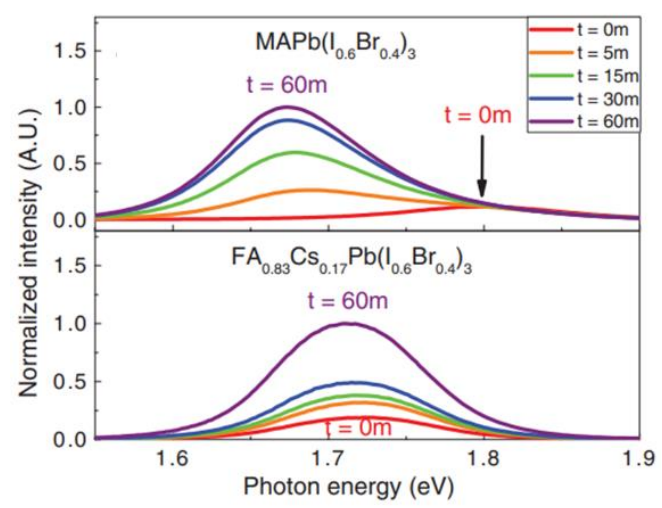

Figure 4.5 PL spectra of (a) $\mathrm{MAPb}\left(\mathrm{I}_{0.6} \mathrm{Br}_{0.4}\right)_{3}$ and (b) $\mathrm{FA}_{0.83} \mathrm{Cs}_{0.17} \mathrm{~Pb}\left(\mathrm{I}_{0.6} \mathrm{Br}_{0.4}\right)_{3}$ perovskites over $60 \mathrm{~min}\left(\lambda_{\mathrm{exc}}=550 \mathrm{~nm}, I_{\mathrm{exc}}=3 \mathrm{~mW} \mathrm{~cm}^{-2}\right)$. Adapted from reference. ${ }^{[128]}$

\subsubsection{Current Understandings}

Tremendous efforts have been made to understand the spectral instability in mixed halide perovskites. At present, the consensus is that light or electric field induces halide segregation. ${ }^{[133]}$ However, the underlying origin is still under debate; different factors under consideration include thermodynamic stability, lattice strain, surface defects and so forth. ${ }^{[33,127]}$

The thermodynamic origin points to the light-induced destabilization of mixed halide alloys. ${ }^{[134]}$ A computational investigation by Brivio et al. reveals that there is a large miscibility gap in heavily mixed $\operatorname{MAPb}\left(\mathrm{I}_{1-x} \mathrm{Br}_{x}\right)_{3}(0.3<x<$ $0.6)$ perovskites, which tend to decompose under illumination. ${ }^{[135]}$ The structure stability might be linked to the halide segregation. For instance, $\mathrm{Cs}_{y} \mathrm{FA}_{1-y} \mathrm{~Pb}\left(\mathrm{I}_{1-x} \mathrm{Br}_{x}\right)_{3}(0.1<y<0.3)$ perovskites locate well within the Goldschmidt tolerance factor, exhibiting high photo-stability against halide segregation. ${ }^{[136]}$

Local lattice strain has also been proposed to explain the light-induced halide segregation, which invokes localized polarons and their companying lattice distortions. The localized polarons are formed by hole localization in the I-rich region of initial mixed halide perovskite film, which induce local lattice strain. The formation of strain further promotes the $\mathrm{I}^{-}$migration towards the distorted 
lattice, yielding the nucleation of I-rich clusters $(\sim 8 \mathrm{~nm}) .^{[137,138]}$ Therefore, photo-induced phase segregation is regarded as the result of local lattice straininduced halide demixing.

Defect-mediated halide segregation upon photoexcitation or current injection has also been widely used. ${ }^{[139-142]}$ This model suggests that the halide segregation is a result of electric field-induced ionic movement. When the excited charge carriers, created by the photo-absorption or current injection, are caught by the trap states, an electric field pointing toward the surface of the film can be formed. This electric field provides the driving force for the halide ion migration and accumulation at the surface, which induces halide segregation subsequently. ${ }^{[139]}$

Despite the well-proposed mechanisms above, none of them rationalize all the PL and EL spectral behaviors observed in mixed halide perovskites, which likely stems from differences in the resultant films, such as composition, crystallinity, morphology, defect density, and device architecture. ${ }^{[134]}$ Thus, the exact origin of the spectral stability is still under investigation.

\subsubsection{Methods Against Spectral Shift}

The color stability issue of mixed halide perovskites can be tackled through a wide range of methods. ${ }^{[127]}$ Regardless of the underlying mechanisms, composition control, crystallinity enhancement, and defect passivation have demonstrated successful in mitigating the spectral shift.

A-cation modification of $\mathrm{APbX}_{3}$ perovskites presents a practical method to improve the photostability. $\mathrm{Cs}_{y} \mathrm{FA}_{1-y} \mathrm{~Pb}\left(\mathrm{I}_{1-x} \mathrm{Br}_{x}\right)_{3}$ based perovskites with carefully tuned composition ratios have shown enhanced photostability than their MA or FA counterparts. ${ }^{[136,143]} \mathrm{K}^{+}$incorporated (CsFAMA) $\mathrm{Pb}\left(\mathrm{I}_{1-y} \mathrm{Br}_{y}\right)_{3}$ perovskites also demonstrate high photostability across a wide range of bandgaps, confirming that composition engineering is an implemented method to stabilize the emission color. ${ }^{[144]}$ 


\section{Chapter 4}

A growing body of literature has proved that films with reduced trap density are more stable against halide segregation. For instance, improving the crystallinity with passivated grain boundaries demonstrates stabilized PL spectra under continuous illumination. ${ }^{[129,145]}$ Defects passivation, like passivation agent incorporation, ${ }^{[146]}$ surface treatment, ${ }^{[140,147]}$ is also promising for spectra stabilization. Despite these successes, the links between trap and spectral shift remain unclear. The high trap density and ionic mobility at the grain boundaries are highlighted as possible driving forces for halide segregation. ${ }^{[148,149]}$

The above-mentioned methods mainly focus on mixed-Br/I perovskites and their photostability in solar cells. Among these strategies, defect passivation has proved promising for color stabilization of mixed-Br/Cl PeLEDs, which will be discussed in the following part.

\subsection{Color Stability of $\mathrm{CsPb}\left(\mathrm{Br}_{1-x} \mathrm{Cl}_{x}\right)_{3}$ Perovskites}

$\mathrm{CsPb}\left(\mathrm{Br}_{1-x} \mathrm{Cl}_{x}\right)_{3}$ perovskites are widely employed in blue PeLEDs compared with their MA and FA counterparts. Similar to the mixed-Br/I system, they suffer from color stability issues when employed as the EML in a LED device, with rare reported $x$ threshold. ${ }^{[121]}$ However, the PL stability is found strongly dependent on the atmospheric conditions and excitation densities. Fortunately, both EL and PL spectral stability issues can be addressed through effective defect passivation, which implies a defect-correlated color stability of $\mathrm{CsPb}(\mathrm{Br}-$ $\left.{ }_{1-x} \mathrm{Cl}_{x}\right)_{3}$ perovskites.

\subsubsection{Spectral Behaviors}

Similar to $\mathrm{MAPb}\left(\mathrm{I}_{1-x} \mathrm{Br}_{x}\right)_{3}(0.2<x<1.0)$ perovskites, ${ }^{[126]}$ the color stability issue of $\mathrm{CsPb}\left(\mathrm{Br}_{1-x} \mathrm{Cl}_{x}\right)_{3}$ based device is $\mathrm{Cl}$ loading-dependent. As shown in Figure 4.6a, the emission color of $\mathrm{CsPb}\left(\mathrm{Br}_{1-x} \mathrm{Cl}_{x}\right)_{3}$ perovskites can be tuned from 523 $\mathrm{nm}$ to $464 \mathrm{~nm}$ by increasing the faction of $\mathrm{Cl}$. The spectra are stable in the devices with $\mathrm{Cl}$ fraction less than $31 \%$ (Figure $4.6 \mathrm{~b}-\mathrm{c}$ ); however, the color stability issue appears in the form of parasitic emission peak with lower energy when $\mathrm{Cl}$ fraction $\geq 38 \%$ (Figure $4.6 \mathrm{~d}-\mathrm{f}$ ). 

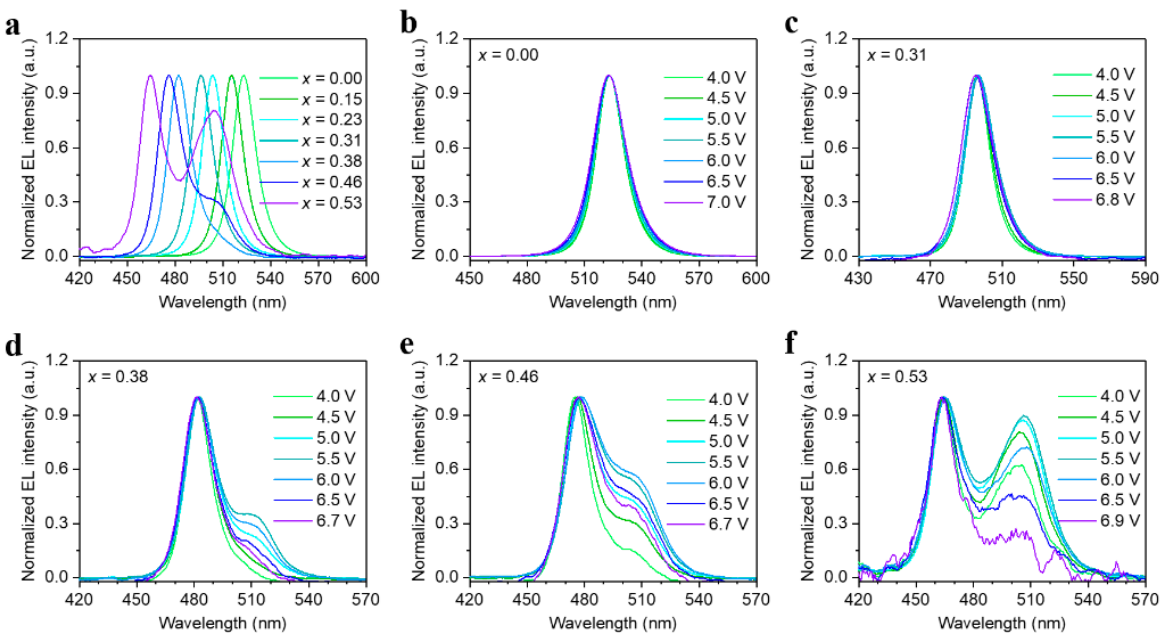

Figure 4.6 (a) Normalized EL spectra of $\mathrm{CsPb}\left(\mathrm{Br}_{1-x} \mathrm{Cl}_{x}\right)_{3}$ based devices acquired at 4.5 V. Normalized EL spectra of devices based on (b) $x=0.00$, (c) $x=0.31$, (d) $x=0.38$, (e) $x=0.46$, and (f) $x=0.53$ films as a function of driving voltage. Adapted from paper II.

The additional low-energy peaks might result from ion migration under EL process instead of multiple phases. The transient absorption (TA) results prove that there is only a single phase in the resulting films (Figure 4.7), indicating that no phase segregation occurs. This is confirmed by the PL process.
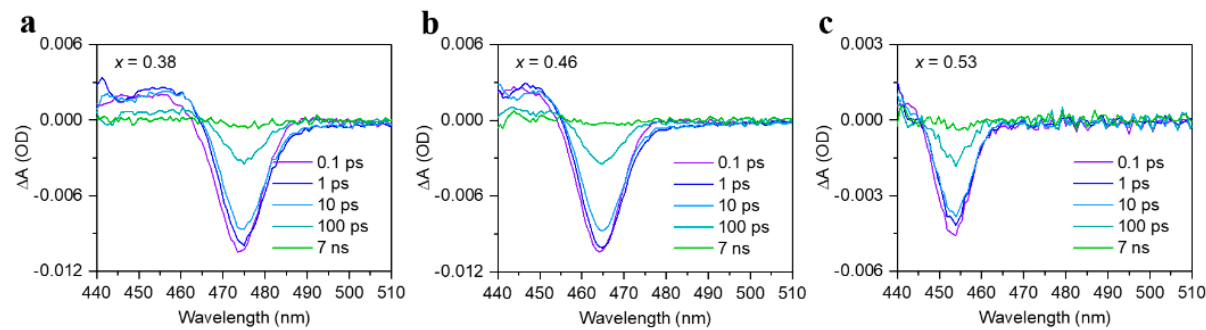

Figure 4.7 TA spectra for $\mathrm{CsPb}\left(\mathrm{Br}_{1-x} \mathrm{Cl}_{x}\right)_{3}$ perovskites with (a) $x=0.38$, (b) $x=0.46$, and (c) $x=0.53$. Adapted from paper II.

The $\mathrm{PL}$ spectral stability of $\mathrm{CsPb}\left(\mathrm{Br}_{0.54} \mathrm{Cl}_{0.46}\right)_{3}$ perovskite shows atmospheric condition dependence. The PL spectra acquired in the vacuum condition are against shifting (Figure 4.8a); in contrast, spectral shift appears when measured in the air at high excitation density (Figure 4.8b). The atmospheric impact on 


\section{Chapter 4}

the PL spectral stability is further confirmed by changing the condition from air to vacuum (Figure $4.8 \mathrm{c}$ ) or the pure $\mathrm{O}_{2}$ condition (Figure 4.8d). These observations suggest that light intensity and atmospheric conditions are two combined factors behind the spectral stability issues. ${ }^{[141]}$
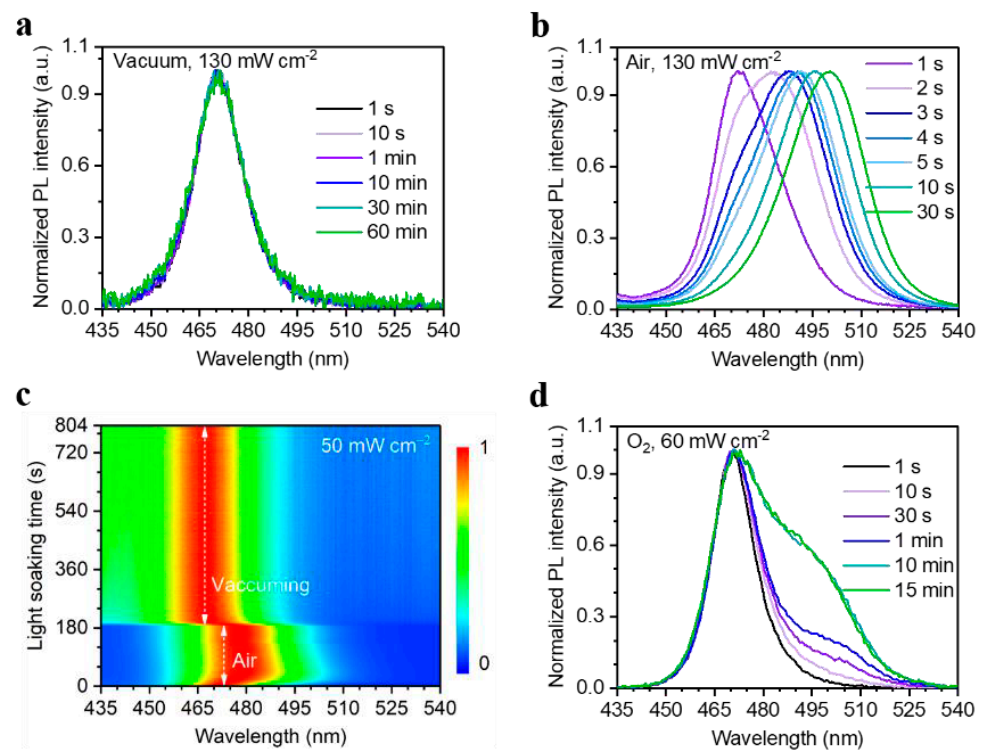

Figure 4.8 $\mathrm{PL}$ spectra for $\mathrm{CsPb}\left(\mathrm{Br}_{0.54} \mathrm{Cl}_{0.46}\right)_{3}$ perovskites measured in the (a) vacuum, (b) air, (c) changed atmospheric, and (d) $\mathrm{O}_{2}$ conditions. Adapted from paper III.

\subsubsection{Color Stabilization}

As discussed in Section 4.3.2, traps in mixed halide perovskites might be the driving force behind the color stability issue. Hence, it is possible to obtain color-stable $\mathrm{CsPb}\left(\mathrm{Br}_{1-x} \mathrm{Cl}_{x}\right)_{3}$ perovskites via crystallinity enhancement and grain boundary passivation to reduce the trap density.

Metal ion doping presents significant success in the color stabilization of $\mathrm{CsPb}\left(\mathrm{Br}_{1-x} \mathrm{Cl}_{x}\right)_{3}$ based devices, together with the improvement of EQE. For instance, Hou et al. demonstrated a color-stable blue PeLED (466 nm) with EQE of $2.12 \%$ based on $\mathrm{Mn}$-doped $\mathrm{CsPb}\left(\mathrm{Br}_{1-x} \mathrm{Cl}_{x}\right)_{3}$ perovskite, which was attributed to the reduced trap density due to $0.19 \% \mathrm{Mn}^{+}$doping. ${ }^{[114]}$ Following this success, 
other passivation agents like $\mathrm{Y}^{+}$and $\mathrm{K}^{+}$have demonstrated similar functions. $^{[117,150]}$

Organic additives have also proven to be effective for defect passivation via forming chemical bonding. ${ }^{[151]}$ In our work, benzamidine hydrochloride $(\mathrm{BHCl}$, the chemical structure inserted in Figure 4.9a) is incorporated into $\mathrm{CsPb}(\mathrm{Br}$ $\left.{ }_{1-x} \mathrm{Cl}_{x}\right)_{3}$ precursor solution (referred to as $x=0.46(\mathrm{BHCl})$ ), enabling the formation of high-quality crystals with suppressed defect states due to the interaction between $\mathrm{C}=\mathrm{N}$ group in $\mathrm{BHCl}$ and $\mathrm{PbX}_{2}$. As a result, EL spectra are stabilized under different driving voltages (Figure 4.9a); the PL spectra also exhibit enhanced tolerance to the $\mathrm{O}_{2}$ condition (Figure 4.9b).
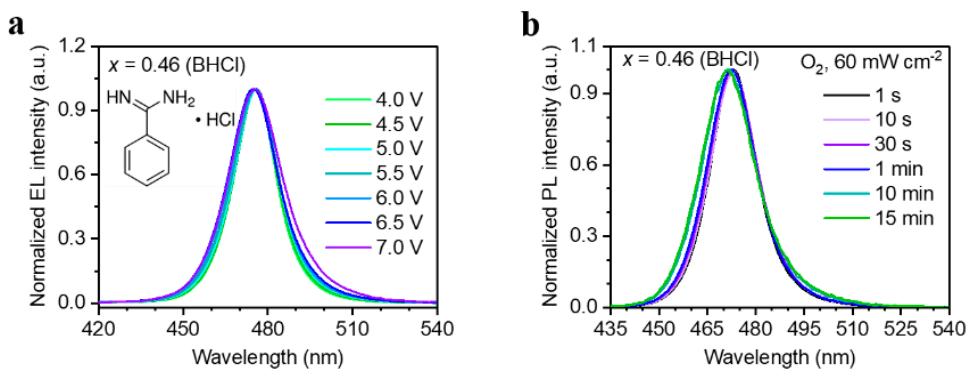

Figure 4.9 (a) EL and (b) PL spectra for $\mathrm{CsPb}\left(\mathrm{Br}_{0.54} \mathrm{Cl}_{0.46}\right)_{3}$ perovskite as a function of driving voltage and light soaking time, respectively. Adapted from paper II and III.

\subsubsection{Possible Mechanism}

We demonstrate that either EL or PL spectral stability issues are consistent with traps in $\mathrm{CsPb}\left(\mathrm{Br}_{1-x} \mathrm{Cl}_{x}\right)_{3}$ perovskites, especially the defects at the grain boundaries. As illustrated in Figure 4.10a, a large number of surface defects exist at grain boundaries for spin-coated $\mathrm{CsPb}\left(\mathrm{Br}_{1-x} \mathrm{Cl}_{x}\right)_{3}$ perovskite films. Upon current injection, halide ion migration and aggregation occur assisted by surface defects, resulting in low-energy emissions. Upon photoexcitation, low-energy emissive species form with the participation of both light and $\mathrm{O}_{2}$, which may be correlated to the formation of oxygen-related species, like superoxide $\left(\mathrm{O}_{2}{ }^{-}\right){ }^{[152]}$ After $\mathrm{BHCl}$ incorporation (Figure $4.10 \mathrm{~b}$ ), the perovskite crystals are preferentially oriented with reduced defect density, in which the ion migration channels or low- 


\section{Chapter 4}

energy emissive species are effectively suppressed, leading to color-stable $\mathrm{CsPb}\left(\mathrm{Br}_{1-x} \mathrm{Cl}_{x}\right)_{3}$ perovskites.
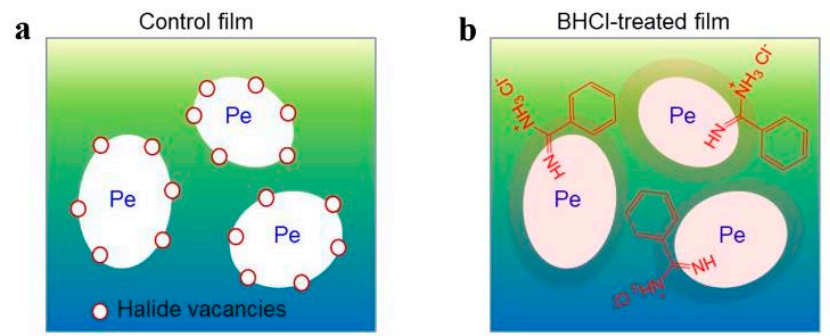

Figure 4.10 Schematic illustration of $\mathrm{BHCl}$ incorporation induced surface passivation (Pe: perovskite). Adapted from paper II. 


\section{Chapter 5}

\section{Development of Perovskite White LEDs}

\subsection{Brief Introduction of White LEDs}

In addition to monochromatic red, green, and blue LEDs, white LEDs are also significantly important devices especially for the application of solid-state lighting. ${ }^{[153]}$ Compared with conventional incandescent and fluorescent bulbs, white LEDs offer low manufacturing cost, high energy conversion efficiency, and long operational lifetime. ${ }^{[154,155]}$ Compared with the impressive achievements of PeLEDs in monochromatic red, ${ }^{[26]}$ green, ${ }^{[27]}$ and blue colors, ${ }^{[32]}$ the white color is less investigated. Tackling the development gap between monochromatic color and white color is among the most important topics in the research field of PeLEDs. ${ }^{[156]}$

\subsubsection{Emergence and Light Revolution}

Following the attainment of high-efficiency blue LEDs, the first white LED was enabled in 1995 and launched for sale one year later. ${ }^{[155,157]}$ Early white LEDs were produced by coating yellow-light cerium doped phosphors onto blue LED chips, resulting in a yellow and blue combined white light. These devices were yet unsatisfactory for commercialization due to the poor power efficiency of around $5 \mathrm{~lm} \mathrm{~W}^{-1}{ }^{[158]}$ which was even lower than those of the incandescent lamp $\left(12-17 \mathrm{~lm} \mathrm{~W}^{-1}\right)^{[159]}$ and fluorescent lamp $\left(60-70 \mathrm{~lm} \mathrm{~W}^{-1}\right)^{[160]}$.

The breakthrough in power efficiency and operation lifetime drove the commercialization white LEDs. Improving the EQE of blue LEDs, acting as both the excitation light source and complementary color, is found to be very helpful for enhancing the power efficiency of white LEDs. The IQE optimization of blue LEDs has driven power efficiency up to $150 \mathrm{~lm} \mathrm{~W}^{-1}$, which promised highperformance white LEDs. ${ }^{[161]}$ A further step took place in the increment of light outcoupling, which reduced optical energy losses by modifying nitride films and electrodes. ${ }^{[158]}$ In addition to the power efficiency, practical use requires a long 


\section{Chapter 5}

lifetime $\geq 10,000 \mathrm{~h}$ under a luminance $\geq 1000 \mathrm{~cd} \mathrm{~m}^{-2}$, which has been achieved in OLEDs. ${ }^{[162]}$

The commercialization of white LEDs brought a big revolution for the lighting market, as shown in Figure 5.1. According to a survey from the Department of Energy of the United States, around a quarter of the electricity consumed in buildings was accounted for lighting, among which $40 \%$ was accounted for incandescent lamps. At present, white LEDs are taking over conventional light sources in many appliances, including homes, industries, and public. By 2025, the national energy consumption is expected to decrease by $29 \%$ due to the application of white LEDs. ${ }^{[159,163]}$

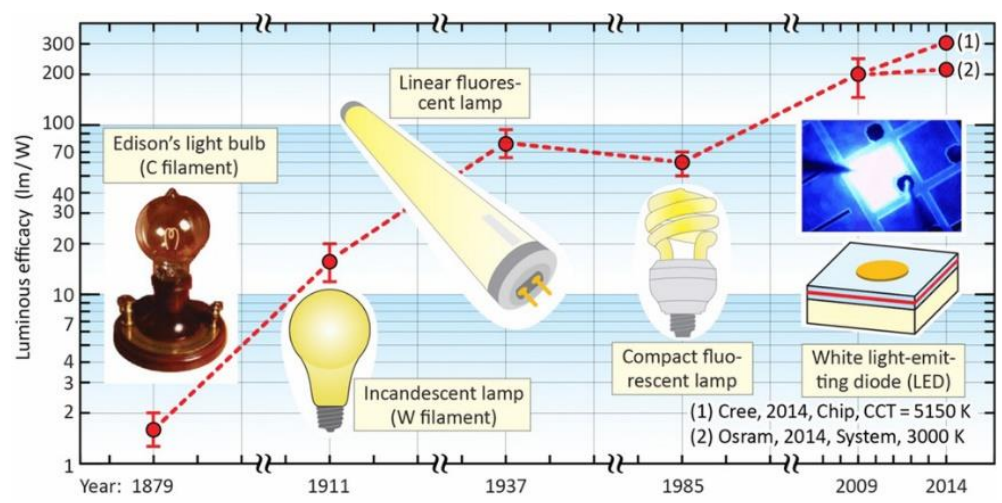

Figure 5.1 Temporal evolution of solid light sources (Cree and Osram are the names of companies). Adapted from reference. ${ }^{[153]}$

\subsubsection{Quality Evaluation}

Apart from the key parameters discussed in Section 3.2.2, three more parameters need to be considered for the development of white LEDs, namely, the CIE coordinates, color rendering index (CRI), and correlated color temperature (CCT). According to the CIE 1931 chromaticity diagram, the CIE coordinates of standard white light are $(0.33,0.33)$, contributed from equal red, green, and blue colors. ${ }^{[162]}$ The CRI, an assessment of how well a light source to render the color naturally, is required to be over 80 for human eye-friendly considerations. ${ }^{[164]}$ The CCT is a measure of color appearance, which is between $2500 \mathrm{~K}$ and 6500 $\mathrm{K}^{\left[{ }^{[159]}\right.}$ These requirements jointly define the quality of white LEDs. 


\subsubsection{Methods and Challenges}

In nature, there are rare semiconductor materials that emit a continuous wide spectrum (400 - $800 \mathrm{~nm}$ ) intrinsically. Instead, white light is produced by combining the colors from different emissive semiconductors, either three primary colors (red, green, and blue) or two complementary colors (like red and cyan). In general, there are five methods to generate white LEDs, as described in Figure 5.2 .
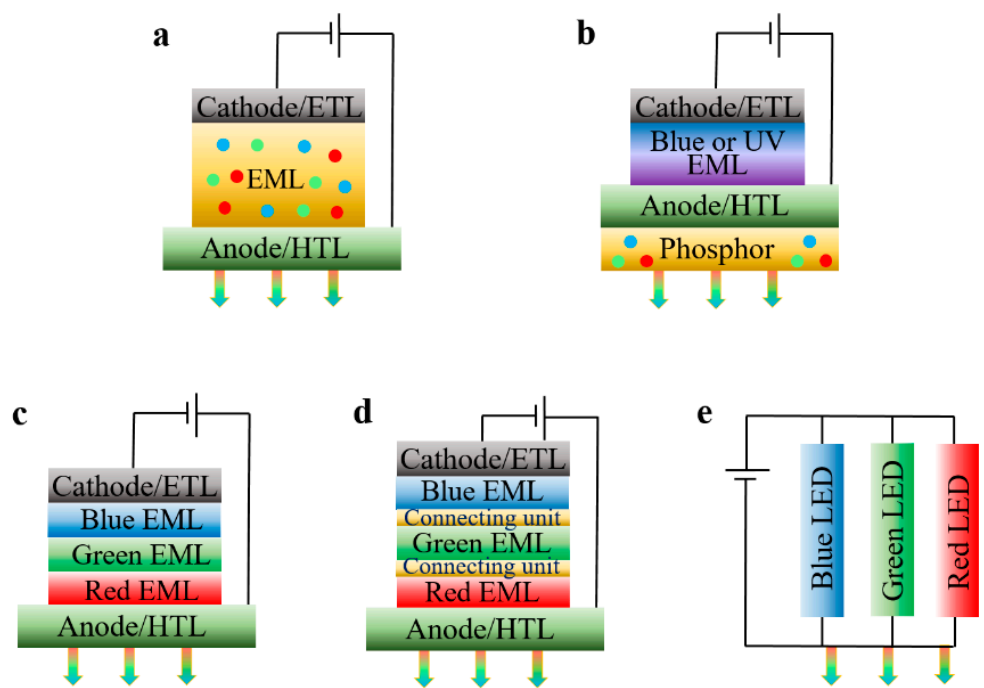

Figure 5.2 General methods to produce white LEDs. (a) Single-emissive-layer (EML) white LEDs; (b) down-converted white LEDs; (c) multi-EML white LEDs; (d) tandem multi-EML white LEDs; (e) spatial multiplexing white LEDs. ${ }^{[165]}$

Single-EML white LEDs (Figure 5.2a) are regarded as the most processingand cost-effective methods. The single-EML is formed by blending different emissive species that emit primary or complementary colors, which can be simply sandwiched between the electrodes to generate white light. However, this method has been risky in color shifting due to the blend phase separation over time, which requires careful chemical design to avoid this obstacle. ${ }^{[165]}$

Currently, the white LED lamp market is heavily reliant on the product of blue GaInN LED coated with yellow-emitting $\mathrm{Y}_{3} \mathrm{Al}_{5} \mathrm{O}_{12}$ : Ce, which is one type 


\section{Chapter 5}

of down-converted white LEDs (Figure 5.2b). However, the lack of red color usually brings two acknowledged drawbacks, that is, a low CRI $(<80)$ and high CCT (>4000 K). Thus, the development of high-quality red emitters is desired to optimize the performance of the device. ${ }^{[166]}$

Owing to separated EMLs with full-color emission, multi-EML white LEDs offer more possibilities in terms of better phase stability and CRI. Adapting distinct EMLs into a single LED device (Figure 5.2c) is one of the strategies, yet holding the risk of color shift, which is attributed to the shift of recombination zone upon increasing driving voltage. ${ }^{[167]}$ Tandem white LEDs exhibit less current-dependent color shift due to the employment of connecting units (Figure 5.2d). ${ }^{[168]}$ However, both methods bring challenges for the solution deposition technique.

Spatial multiplexing white LEDs, placing red, green, and blue LEDs in close proximity (Figure 5.2e), show great compatibility with display techniques. However, few reports based on OLEDs in spite of the success of inorganic LEDs; moreover, this approach is much more complex and costly. ${ }^{[169]}$

\subsection{Intrinsic White Light from Perovskites}

In principle, a single material with a broadband emission of $400-800 \mathrm{~nm}$ is an ideal candidate for achieving single-EML white LEDs. Exploring this type of materials is of special interest. In terms of perovskite family, some 2D perovskites and lead-free double perovskites have demonstrated intrinsic white-light emission upon photoexcitation.

The white-light emission is more commonly in certain $2 \mathrm{D} \mathrm{Pb}-\mathrm{Br}$ and $\mathrm{Pb}-\mathrm{Cl}$ based perovskites. ${ }^{[170]}$ The origin of the white light is attributed to the "excitedstate defects", which locate below the CBM of the 2D perovskites, acting as additional emitting centres via self-trapped excitons. It is worth noting that not all the 2D perovskites possess intrinsic white light; up to now, there are only less than 20 reported cases. Furthermore, none of them has demonstrated white EL. 
Similar self-trapped exciton induced white-light emission are found in leadfree double perovskites. ${ }^{[156]}$ Lead-free double perovskites are a new generation of perovskites with a general formula of $\mathrm{A}_{2} \mathrm{~B}^{\prime} \mathrm{B}^{\prime \prime} \mathrm{X}_{6}$, where the divalent cation $\mathrm{Pb}^{2+}$ is replaced by a monovalent cation $\mathrm{B}^{\prime}$ and a trivalent cation $\mathrm{B}^{\prime \prime} .{ }^{[171]}$ The self-trapped excitons are induced by the distortion of $\mathrm{B}^{\prime} \mathrm{X}_{6}$ octahedron, which can be manipulated to generate white PL, yet with unsatisfactory white EL. ${ }^{[156]}$

\subsection{White LEDs Based on Perovskites}

To date, there have been several approaches to generate white light upon perovskites, including perovskite down-converted white LEDs, perovskite-based hybrid white LEDs, and multi-EML all-perovskite white LEDs.

\subsubsection{Down-Converted White LEDs}

Similar to commercial white LEDs, down-conversion is the most popular approach to generate white light upon perovskites, which carries advantages of easily optimized CRI and CCT due to the incorporation of suitable phosphors. ${ }^{[172]}$ In this approach, perovskites, especially $\mathrm{CsPbX}_{3}$ QDs, are employed as phosphors to coat with blue LED chips for white light emission.

Overall, $\mathrm{CsPbX}_{3}$ QDs act as either multi-color phosphors ${ }^{[173]}$ or the green phosphor with the incorporation of inorganic red phosphors (e.g., $\mathrm{K}_{2} \mathrm{SiF}_{6}$ : $\mathrm{Mn}^{4+}(\mathrm{KSF})$ and CdSe) ${ }^{[174,175]}$ For instance, a decent white light with power efficiency of $61.2 \mathrm{~lm} \mathrm{~W}^{-1}$ and CIE chromaticity coordinates of $(0.33,0.33)$ has been demonstrated by employing the architecture of blue chip (458 nm)/CsP$\mathrm{bBr}_{3} / \mathrm{SiO}_{2}+\mathrm{CsPb}(\mathrm{Br} / \mathrm{I})_{3} / \mathrm{SiO}_{2}$ QDs/PMMA. ${ }^{[176]}$ However, the stability of perovskite QDs needs to be enhanced before the widespread application of such white LEDs.

\subsubsection{Perovskite-Based Hybrid White LEDs}

Blends of perovskite and additional emitters (such as organic emitters) are employed as the EML to generate white LEDs, termed as perovskite-based hybrid white LEDs. For a reliable device, a well-aligned energy level is required between perovskites and additional emitters to set up energy transfer channels 


\section{Chapter 5}

from wide-bandgap to narrow-bandgap emitters. In the study of single-EML white OLEDs, Dexter and Förster transfer are two commonly employed channels, which can be predicted from the energy level offset and emission and absorption spectral overlap between these two emitters, respectively. ${ }^{[177]}$ Moreover, the additional emissive species should have a good solubility in perovskite precursor solution. ${ }^{[178]}$

There have been some successful examples. For instance, by blending blue $\mathrm{CsPbBr}_{x} \mathrm{Cl}_{3-x}$ QDs with orange polymer of poly[2-methoxy-5-(2-ethylhexyloxy)1,4-phenylenevinylene] (MEH:PPV) with the ratio of $9: 1$, a single-EML white LED with CIE chromaticity coordinates of $(0.33,0.34)$ was demonstrated (Figure 5.3). ${ }^{[179]}$ Other additional emitters, like rare-earth ion $\mathrm{Sm}^{3+},{ }^{[180]}$ alkali metal $\mathrm{Mg}^{2+},{ }^{[181]}$ also show good compatibilities with perovskites.

a

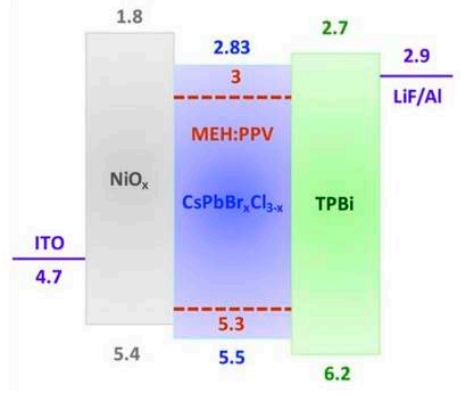

b

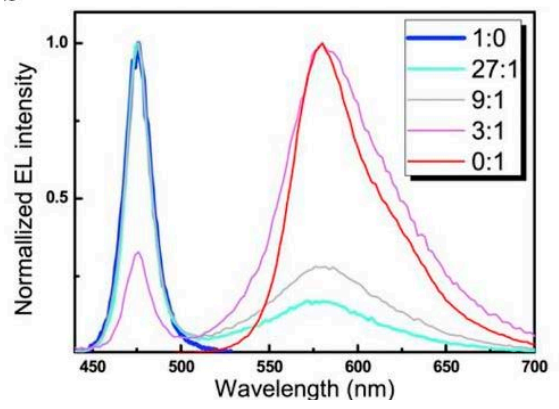

Figure 5.3 (a) Band structure illustration and (b) EL spectra of $\mathrm{CsPbBr}_{x} \mathrm{Cl}_{3-x}$ QD and MEH:PPV blend white LED. Adapted from reference. ${ }^{[179]}$

\subsubsection{Multi-EML All-Perovskite White LEDs}

Different from down-converted and perovskite-based hybrid white LEDs, three primary (or two complementary) colors can be from emissive perovskites in allperovskite white LEDs. A successful example is based on the multi-EML architecture. For multi-EML all-perovskite white LEDs, the individual perovskite EMLs require orthogonal solvents to avoid the damage of the underneath layer. However, perovskite precursors are only soluble in a limited number of polar solvents, ${ }^{[182]}$ significantly limiting the application of this technique. 
In view that solution-processed thin-film perovskites and colloidal perovskite nanocrystals are dissolved in polar and non-polar solvents, respectively, employing these two types of materials as individual EMLs is an alternative strategy to avoid damage by solvents. There was a report about such a multiEML all-perovskite white $\mathrm{LED}^{[183]}$ where an architecture of ITO/PEDOT:PSS/thin-film 2D perovskite (DMSO solvent)/interlayer/ $\mathrm{CsPb}(\mathrm{Br}, \mathrm{Cl})_{3} \mathrm{QD}$ (n-octane solvent)/TPBi/LiF/Al was used, as shown in Figure 5.4. The interlayer is either the mixture of BIPO and Poly-TPD or the mixture of Poly-TPD and $\mathrm{PC}_{61} \mathrm{BM}$, of which the former one with BIPO: PolyTPD of $1: 1$ gives better charge injection for balancing the light intensity of red and sky-blue colors. In addition, the interlayer can prevent the anion exchange between the EMLs.

a

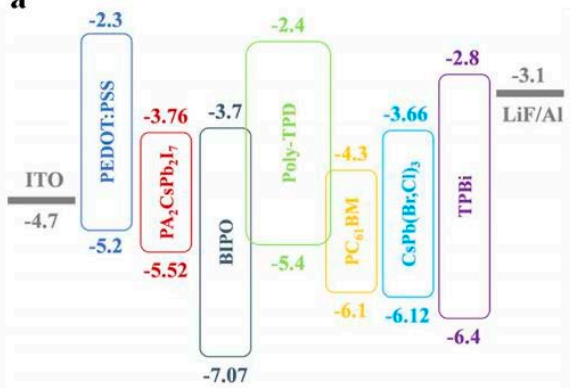

b

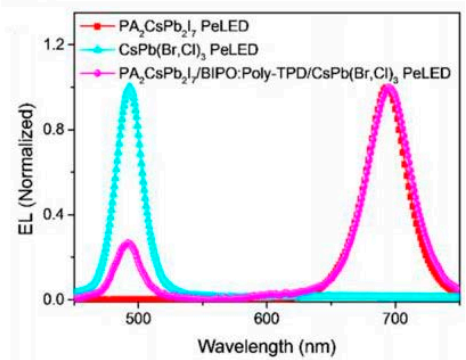

Figure 5.4 (a) Band structure illustration of the multi-EML all-perovskite white LED $\left(\mathrm{PA}_{2} \mathrm{CsPb}_{2} \mathrm{I}_{7}\right.$ is short for $\left.\left(\mathrm{CH}_{3} \mathrm{CH}_{2} \mathrm{CH}_{2} \mathrm{NH}_{3}\right)_{2} \mathrm{CsPb}_{2} \mathrm{I}_{7}\right)$. (b) EL spectra of PeLEDs based on the individual EMLs and multi-EML. Adapted from reference. ${ }^{[183]}$

Despite the reliability of the multi-EML method, all-perovskite white LEDs produced from the single-EML are of more interest for the sake of simplicity and low cost. However, this technique has been quite challenging when multiple emissive perovskites are blended into a single EML.

\subsection{Single-EML All-Perovskite White LEDs}

To obtain perovskite white light via the single-EML method, two issues upon perovskite emitter blending need to be solved, namely fast anion exchange and charge transfer. 


\section{Chapter 5}

Fast anion exchange, a universal phenomenon in mixed halide perovskites, can lead to monochromatic emission. ${ }^{[15,184]}$ Blending Br/I-based red perovskites, Br-based green perovskites and $\mathrm{Br} / \mathrm{Cl}$-based blue perovskites tends to induce halogen exchange, which usually results in monochromatic color instead of white color. Thus, this anion exchange process should be effectively suppressed to maintain red, green, and blue perovskite emitters to achieve white light emission.

Charge transfer from high- to low-energy species is another factor for the resultant of monochromatic emission. ${ }^{[22,50]}$ Blending low-dimensional perovskites (high-energy species) and 3D perovskites (low-energy species) usually exhibits low-energy emission due to the efficient charge transfer from high- to low-energy species (Figure 2.6b). ${ }^{[105]}$ Hence, although dimensional engineering based on pure halide perovskite facilitates color tuning without anion exchange, the internal charge transfer fundamentally hinders its application in the singleEML method.

We demonstrate a first attempt to fabricate a single-EML all-perovskite white LED (Figure 5.5), in which both the anion exchange and charge transfer are suppressed. As shown in Figure 5.5a, this single-EML all-perovskite white LED employs a typical p-i-n architecture of ITO/PEDOT:PSS (40 nm)/perovskite $(30 \mathrm{~nm}) / \mathrm{TPBi}(35 \mathrm{~nm}) / \mathrm{LiF}(1 \mathrm{~nm}) / \mathrm{Al}(100 \mathrm{~nm})$. The perovskite film (denoted as BCPX) is deposited using one step spin-coating method, where the perovskite precursor solution is prepared by mixing $\mathrm{CsI}, \mathrm{PbBr}_{2}$, and $\mathrm{BHCl}$ (the chemical structure has inserted in Figure 4.9a) with a molar ratio of 1.25 : 1.0 : 1.0 (Figure 5.5b). The EL spectra and a photograph of the working device demonstrate the achievement of white light (Figure 5.5c), exhibiting a peck EQE of $0.008 \%$ and CIE coordinates of $(0.33,0.33)$. The dual-color emission implies both anion exchange and energy transfer progress are supressed in our singleEML all-perovskite white LED. 
a

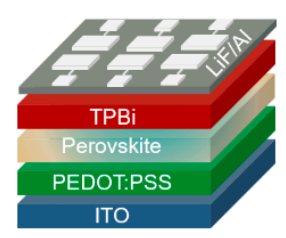

b

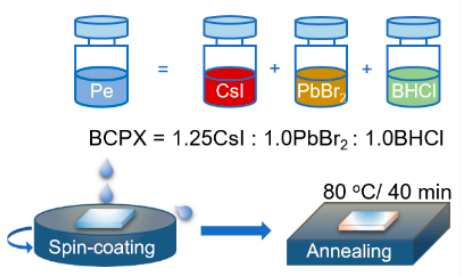

c

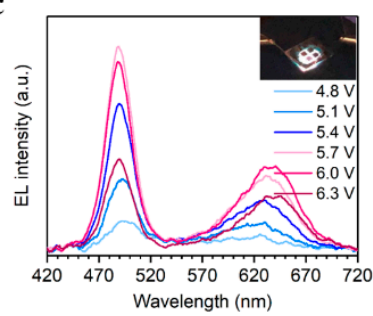

Figure 5.5 (a) Device architecture, (b) schematic diagram of the preparation of precursor solution and perovskite films, and (c) EL spectra as a function of driving voltages (inset: photograph of a working device) for the single-EML white PeLED. Adapted from paper reference. ${ }^{[185]}$

The effective modulation of the perovskite precursor solution is the key to the suppression of anion exchange and energy transfer. The secondary electron (SE) image in Figure 5.6a shows that there are two different types of grains in the perovskite film, rod-like (like Point 1) and plate-like grains (like Point 2). These two types of grains possess different emission behaviours, probed by the cathodoluminescence (CL) measurements (Figure 5.6b). The rod-like grain (Point 1) only shows sky-blue emission (498 nm), indicating that $\mathrm{CsPb}\left(\mathrm{Br}_{1-x} \mathrm{Cl}_{x}\right)_{3}$ domains are dominated in this type of grains; in contrast, both sky-blue emission $(498 \mathrm{~nm})$ and red emission $(684 \mathrm{~nm})$ are detected in platelike grain (Point 2), suggesting the coexistence of $\mathrm{CsPb}\left(\mathrm{Br}_{1-x} \mathrm{Cl}_{x}\right)_{3}$ and $\mathrm{CsPb}\left(\mathrm{Br}_{1-y} \mathrm{I}_{y}\right)_{3}$ domains. More importantly, it is found that the special film morphology and emission behaviour are associated with the presence of both $\mathrm{BHCl}$ and $\mathrm{PbBr}_{2}$ in the precursor solution, which induces the formation of intermediates with both $\mathrm{Br}$ and $\mathrm{Cl}$ (Figure 5.6c). 

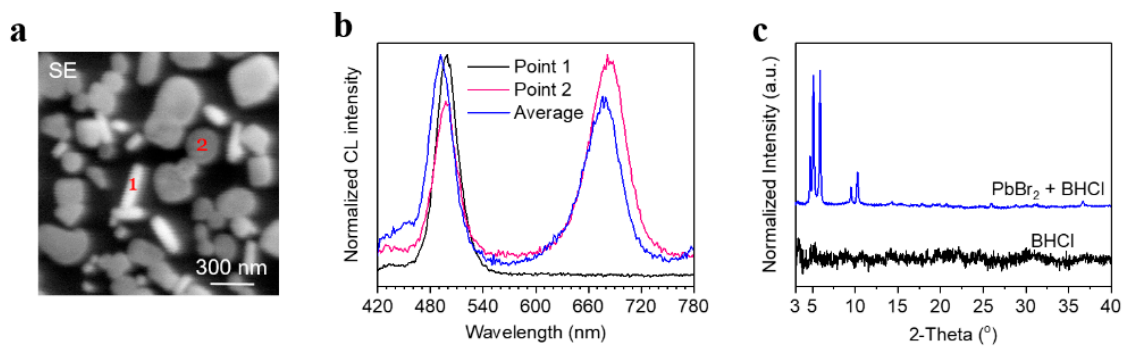

Figure 5.6 (a) SE image and (b) CL spectra of the single-EML all-perovskite film acquired at $5.0 \mathrm{keV}$. (c) $\mathrm{XRD}$ patterns of pure $\mathrm{BHCl}$ and $\mathrm{PbBr}_{2}+\mathrm{BHCl}$ mixed films. Adapted from paper reference. ${ }^{[185]}$

Our findings reveal that single-EML all-perovskite white LEDs are possible via effective modulation of perovskite precursor solution, which will spur new development of high-performance white PeLEDs. 


\section{Chapter 6}

\section{Conclusion and Outlook}

MHPs have received enormous success in the field of LEDs owing to the unique optoelectronic properties, facile fabrication process, and low cost. Their tunable bandgaps are of particular interest for their use in full-color LED applications. In view of the approaches, quantum confinement effect and halide substitution are both widely employed, yet with unsatisfactory results including complicated process and color instability, respectively. In this thesis, we present useful strategies to render these two approaches, which are expected to make them more facile and promising.

The contributions of this thesis on the color tuning are in four aspects. Firstly, we have demonstrated in situ grown PQDs with tunable EL spectra in the range of $667-790 \mathrm{~nm}$. Compared with colloidal PQDs, our additive-assisted in situ synthesized PQDs are more process-effective. Secondly, we have investigated the color stability issue of $\mathrm{CsPb}\left(\mathrm{Br}_{1-x} \mathrm{Cl}_{x}\right)_{3}$ perovskite based devices, which appears in compositions of $x \geq 0.38$ in the form of low-energy emission peaks. We have proved that these parasitic peaks can be eliminated via additive agent incorporation, which results in high-quality perovskite crystals with suppressed trap density. Thirdly, we have studied the PL spectral stability of $\mathrm{CsPb}(\mathrm{Br}-$ $\left.{ }_{1-x} \mathrm{Cl}_{x}\right)_{3}$ perovskite. Taking $\mathrm{Cs} \mathrm{Pb}\left(\mathrm{Br}_{0.54} \mathrm{Cl}_{0.46}\right)_{3}$ perovskite as an example, we find that the PL stability issue is correlated to the defects at grain boundaries with the participation of both light and $\mathrm{O}_{2}$. Finally, we have demonstrated a singleEML all-perovskite white LED through effective modulation of perovskite precursor solution, in which the halide ion exchange and charge transfer are suppressed, enabling a dual-color white LED.

There have been tremendous efforts on achieving high-performance monochromatic PeLEDs, upon which the EQEs of near-infrared, red, and green colors are approaching the theoretical limit. In recent two years, blue PeLEDs are making rapid progress with the best $\mathrm{EQE}$ of $12.3 \%$. Yet reducing the efficiency gap between blue color and its counterparts is of significant interest. In addition, 


\section{Chapter 6}

long-term operation of PeLEDs is highly demanded to meet the requirement for commercial use.

Beyond the efficiency and operation lifetime, the color tunability upon mixed halides has been challenging due to stability issues, which impedes the development of high-performance full-color PeLEDs. Moreover, the origin has not been rationalized yet. Based on our observations in Paper II and III, we tend to believe that the spectral shift in our mixed halide perovskite is not due to halide segregation. Instead, it is from low-energy emissive species induced by the defects at grain boundaries under current injection. However, upon photoexcitation (high excitation density), the low-energy emissive spices may be correlated to surface defects induced oxygen-related species, like $\mathrm{O}_{2}^{-}$. Alternatively, pure halide perovskites offer color tunability via quantum confinement effect, which are free of spectral shift (Paper I). However, color tuning through this approach has limited tunability in the bandgaps compared with halide mixing.

Halide substitution enables color tuning, however, it is one of the biggest obstacles for the development of perovskite white LEDs. Our findings in Paper IV provide a novel strategy to overcome the halide exchange. Despite the novelty, the interaction mechanism between the additive and lead halide needs further investigation. 


\section{Chapter 7}

\section{Paper Summary}

Paper I Efficient and tunable electroluminescence from in situ synthesized perovskite quantum dots

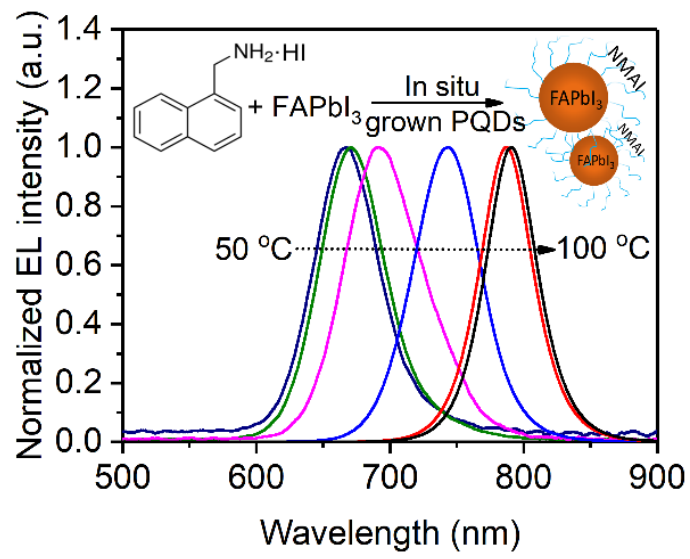

We demonstrated a straightforward route to produce in situ solution-grown $\mathrm{FAPbI}_{3} \mathrm{PQDs}$, which deliver optical and electrical properties comparable to the ex-situ colloidal-grown ones. These in situ grown PQDs also achieve high EQEs up to $11.0 \%$ with tunable emissions ranging from $667 \mathrm{~nm}-790 \mathrm{~nm}$ in LEDs based on pure-halogen perovskite thin films. 


\section{Chapter 7}

Paper II High-performance and color-stable blue light-emitting diodes enabled by effective passivation of mixed halide perovskites

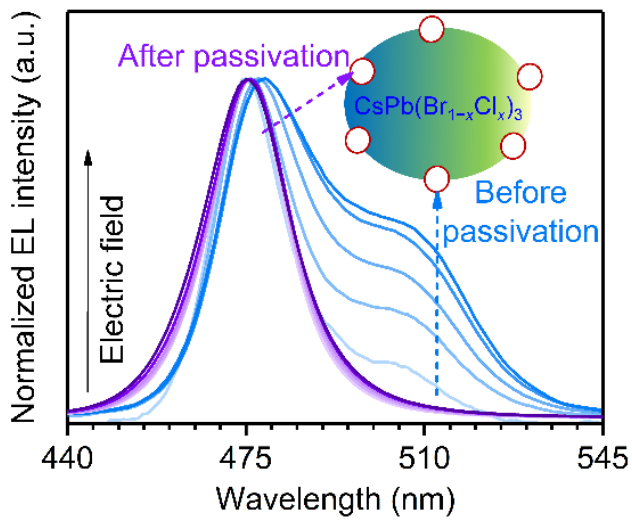

We demonstrated color-stable blue electroluminescence from $\operatorname{CsPb}\left(\mathrm{Br}_{1-x} \mathrm{Cl}_{x}\right)_{3}$, with maximum external quantum efficiencies of up to $4.55 \%$ and high luminance of up to $5351 \mathrm{~cd} \mathrm{~m}^{-2}$. The color instability of $\mathrm{CsPb}\left(\mathrm{Br}_{1-x} \mathrm{Cl}_{x}\right)_{3}$ based perovskite light-emitting diodes results from the surface defects at grain boundaries, which can be effectively eliminated via defect passivation. 
Paper III Atmospheric impact on photo-induced spectral stability of cesiumbased mixed bromide-chloride perovskites

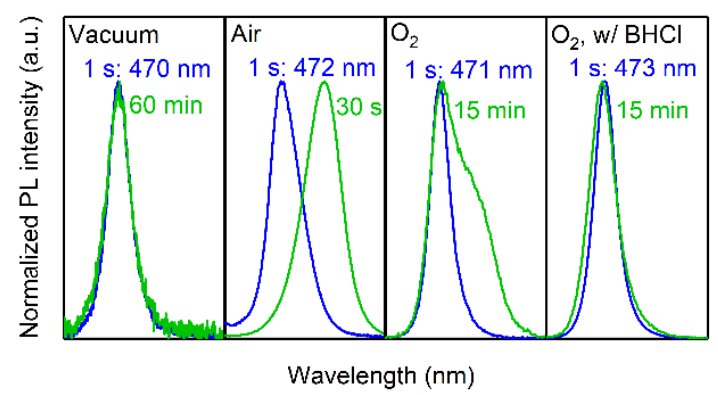

We demonstrated atmosphere- and light power-dependent PL spectral instability of $\mathrm{CsPb}\left(\mathrm{Br}_{0.54} \mathrm{Cl}_{0.46}\right)_{3}$ perovskite. This issue is found to associate with oxygen in the atmosphere and surface defects at perovskite grain boundaries. Via passivation agent incorporation to reduce the defects, the PL is more tolerant to light and oxygen. 


\section{Chapter 7}

Paper IV Single-emissive-layer white light-emitting diodes employing segregated mixed halide perovskite crystals

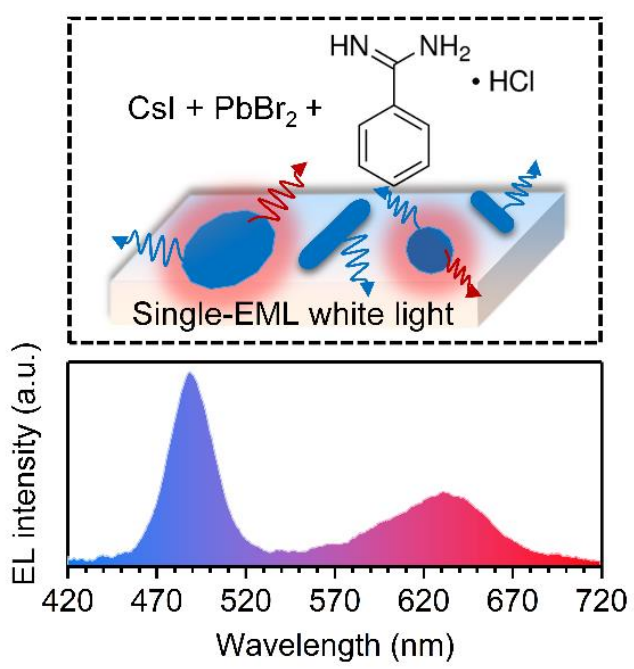

We demonstrated a single-emissive-layer all-perovskite white LED using a mixed halide perovskite film, which features mixed $\mathrm{Br} / \mathrm{Cl}$ and $\mathrm{Br} / \mathrm{I}$ perovskite phases with blue and red emissions, respectively. The formation of such dualcolor white-emitting film is attributed to effective modulation of the halide salt precursors. 


\section{References}

[1] K. Hirose, R. Sinmyo, J. Hernlund, Science 2017, 358, 734.

[2] M. Saliba, J.-P. Correa-Baena, M. Grätzel, A. Hagfeldt, A. Abate, Angew Chem. Int. Ed. 2018, 57, 2554.

[3] H. L. Wells, Zeitschrift für anorganische Chemie 1893, 3, 195.

[4] A. Kojima, K. Teshima, Y. Shirai, T. Miyasaka, J. Am. Chem. Soc. 2009, 131,6050 .

[5] J. Shamsi, A. S. Urban, M. Imran, L. De Trizio, L. Manna, Chem. Rev. 2019, 119, 3296.

[6] M. M. Lee, J. Teuscher, T. Miyasaka, T. N. Murakami, H. J. Snaith, Science 2012, 338, 643.

[7] J. M. Ball, M. M. Lee, A. Hey, H. J. Snaith, Energy Environ. Sci. 2013, 6, 1739 .

[8] "Best Research-Cell Efficiency Chart," https://www.nrel.gov/pv/cell-efficiency.html, 2020.

[9] W. Zhang, G. E. Eperon, H. J. Snaith, Nat. Energy 2016, 1, 16048.

[10] Z.-K. Tan, R. S. Moghaddam, M. L. Lai, P. Docampo, R. Higler, F. Deschler, M. Price, A. Sadhanala, L. M. Pazos, D. Credgington, F. Hanusch, T. Bein, H. J. Snaith, R. H. Friend, Nat. Nanotechnol. 2014, 9 , 687.

[11] G. Xing, N. Mathews, S. S. Lim, N. Yantara, X. Liu, D. Sabba, M. Grätzel, S. Mhaisalkar, T. C. Sum, Nat. Mater. 2014, 13, 476.

[12] W. Yu, F. Li, L. Yu, M. R. Niazi, Y. Zou, D. Corzo, A. Basu, C. Ma, S. Dey, M. L. Tietze, U. Buttner, X. Wang, Z. Wang, M. N. Hedhili, C. Guo, T. Wu, A. Amassian, Nat. Commun. 2018, 9, 5354.

[13] C. Bao, J. Yang, S. Bai, W. Xu, Z. Yan, Q. Xu, J. Liu, W. Zhang, F. Gao, Adv. Mater. 2018, 30, 1803422.

[14] H. Wei, Y. Fang, P. Mulligan, W. Chuirazzi, H.-H. Fang, C. Wang, B. R. Ecker, Y. Gao, M. A. Loi, L. Cao, J. Huang, Nat. Photonics 2016, 10, 333. 
[15] H. Chen, M. Zhang, X. Fu, Z. Fusco, R. Bo, B. Xing, H. T. Nguyen, C. Barugkin, J. Zheng, C. F. J. Lau, S. Huang, A. W. Y. Ho-Baillie, K. R. Catchpole, A. Tricoli, Phys. Chem. Chem. Phys. 2019, 21, 24187.

[16] Q. Chen, N. De Marco, Y. (Michael) Yang, T.-B. Song, C.-C. Chen, H. Zhao, Z. Hong, H. Zhou, Y. Yang, Nano Today 2015, 10, 355.

[17] M.-H. Chang, D. Das, P. V. Varde, M. Pecht, Microelectron. Reliab. 2012, 52, 762.

[18] N. Holonyak, S. F. Bevacqua, Appl. Phys. Lett. 1962, 1, 3.

[19] S. Adjokatse, H.-H. Fang, M. A. Loi, Mater. Today 2017, 20, 413.

[20] X. Hong, T. Ishihara, A. V. Nurmikko, Solid State Commun. 1992, 84, 657.

[21] M. Era, S. Morimoto, T. Tsutsui, S. Saito, Appl. Phys. Lett. 1994, 65, 676.

[22] N. Wang, L. Cheng, R. Ge, S. Zhang, Y. Miao, W. Zou, C. Yi, Y. Sun, Y. Cao, R. Yang, Y. Wei, Q. Guo, Y. Ke, M. Yu, Y. Jin, Y. Liu, Q. Ding, D. Di, L. Yang, G. Xing, H. Tian, C. Jin, F. Gao, R. H. Friend, J. Wang, W. Huang, Nat. Photonics 2016, 10, 699.

[23] Y.-H. Kim, H. Cho, T.-W. Lee, Proc Natl Acad Sci USA 2016, 113, 11694.

[24] M. Lu, Y. Zhang, S. Wang, J. Guo, W. W. Yu, A. L. Rogach, Adv. Funct. Mater. 2019, 29, 1902008.

[25] W. Xu, Q. Hu, S. Bai, C. Bao, Y. Miao, Z. Yuan, T. Borzda, A. J. Barker, E. Tyukalova, Z. Hu, M. Kawecki, H. Wang, Z. Yan, X. Liu, X. Shi, K. Uvdal, M. Fahlman, W. Zhang, M. Duchamp, J.-M. Liu, A. Petrozza, J. Wang, L.-M. Liu, W. Huang, F. Gao, Nat. Photonics 2019, 13, 418.

[26] T. Chiba, Y. Hayashi, H. Ebe, K. Hoshi, J. Sato, S. Sato, Y.-J. Pu, S. Ohisa, J. Kido, Nat. Photonics 2018, 12, 681.

[27] K. Lin, J. Xing, L. N. Quan, F. P. G. de Arquer, X. Gong, J. Lu, L. Xie, W. Zhao, D. Zhang, C. Yan, W. Li, X. Liu, Y. Lu, J. Kirman, E. H. Sargent, Q. Xiong, Z. Wei, Nature 2018, 562, 245.

[28] X.-B. Shi, Y. Liu, Z. Yuan, X.-K. Liu, Y. Miao, J. Wang, S. Lenk, S. Reineke, F. Gao, Adv. Opt. Mater. 2018, 6, 1800667.

[29] N. K. Kumawat, X.-K. Liu, D. Kabra, F. Gao, Nanoscale 2019, 11, 2109. 
[30] H. Cho, Y.-H. Kim, C. Wolf, H.-D. Lee, T.-W. Lee, Adv. Mater. 2018, 30, 1704587.

[31] Y. Wu, X. Li, H. Zeng, ACS Energy Lett. 2019, 4, 673.

[32] Y. Dong, Y.-K. Wang, F. Yuan, A. Johnston, Y. Liu, D. Ma, M.-J. Choi, B. Chen, M. Chekini, S.-W. Baek, L. K. Sagar, J. Fan, Y. Hou, M. Wu, S. Lee, B. Sun, S. Hoogland, R. Quintero-Bermudez, H. Ebe, P. Todorovic, F. Dinic, P. Li, H. T. Kung, M. I. Saidaminov, E. Kumacheva, E. Spiecker, L.-S. Liao, O. Voznyy, Z.-H. Lu, E. H. Sargent, Nat. Nanotechnol. 2020, 15, 668.

[33] M. Kuno, M. C. Brennan, Matter 2020, 2, 21.

[34] Q. Dong, L. Lei, J. Mendes, F. So, J. Phys. Mater. 2020, 3, 012002.

[35] M. A. Green, A. Ho-Baillie, H. J. Snaith, Nature Photon 2014, 8, 506.

[36] Y. Fu, H. Zhu, J. Chen, M. P. Hautzinger, X.-Y. Zhu, S. Jin, Nat. Rev. Mater. 2019, 4, 169.

[37] X. Y. Chin, A. Perumal, A. Bruno, N. Yantara, S. A. Veldhuis, L. Martínez-Sarti, B. Chandran, V. Chirvony, A. S.-Z. Lo, J. So, C. Soci, M. Grätzel, H. J. Bolink, N. Mathews, S. G. Mhaisalkar, Energy Environ. Sci. 2018, 11, 1770.

[38] C. Ran, J. Xu, W. Gao, C. Huang, S. Dou, Chem. Soc. Rev. 2018, 47, 4581.

[39] Q. A. Akkerman, G. Rainò, M. V. Kovalenko, L. Manna, Nat. Mater. 2018, 17, 394.

[40] M. V. Kovalenko, L. Protesescu, M. I. Bodnarchuk, Science 2017, 358, 745 .

[41] D. Shi, V. Adinolfi, R. Comin, M. Yuan, E. Alarousu, A. Buin, Y. Chen, S. Hoogland, A. Rothenberger, K. Katsiev, Y. Losovyj, X. Zhang, P. A. Dowben, O. F. Mohammed, E. H. Sargent, O. M. Bakr, Science 2015, 347, 519.

[42] N. K. Noel, A. Abate, S. D. Stranks, E. S. Parrott, V. M. Burlakov, A. Goriely, H. J. Snaith, ACS Nano 2014, 8, 9815.

[43] W.-J. Yin, T. Shi, Y. Yan, Advanced Materials 2014, 26, 4653.

[44] L. Chouhan, S. Ghimire, C. Subrahmanyam, T. Miyasaka, V. Biju, Chem. Soc. Rev. 2020, 49, 2869. 
[45] Y. Wang, Y. Zhang, P. Zhang, W. Zhang, Phys. Chem. Chem. Phys. 2015, 17, 11516.

[46] S. Tao, I. Schmidt, G. Brocks, J. Jiang, I. Tranca, K. Meerholz, S. Olthof, Nat. Commun. 2019, 10, 2560.

[47] Y.-H. Kim, J. S. Kim, T.-W. Lee, Adv. Mater. 2019, 31, 1804595.

[48] A. D. Wright, C. Verdi, R. L. Milot, G. E. Eperon, M. A. Pérez-Osorio, H. J. Snaith, F. Giustino, M. B. Johnston, L. M. Herz, Nat. Commun. 2016, 7, 11755.

[49] M. B. Johnston, L. M. Herz, Acc. Chem. Res. 2016, 49, 146.

[50] M. Yuan, L. N. Quan, R. Comin, G. Walters, R. Sabatini, O. Voznyy, S. Hoogland, Y. Zhao, E. M. Beauregard, P. Kanjanaboos, Z. Lu, D. H. Kim, E. H. Sargent, Nat. Nanotechnol.2016, 11, 872.

[51] L. M. Herz, Annu. Rev. Phys. Chem. 2016, 67, 65.

[52] X. Gong, O. Voznyy, A. Jain, W. Liu, R. Sabatini, Z. Piontkowski, G. Walters, G. Bappi, S. Nokhrin, O. Bushuyev, M. Yuan, R. Comin, D. McCamant, S. O. Kelley, E. H. Sargent, Nat. Mater. 2018, 17, 550.

[53] G. Grancini, M. K. Nazeeruddin, Nat. Rev. Mater. 2019, 4, 4.

[54] X.-K. Liu, F. Gao, J. Phys. Chem. Lett. 2018, 9, 2251.

[55] L. N. Quan, B. P. Rand, R. H. Friend, S. G. Mhaisalkar, T.-W. Lee, E. H. Sargent, Chem. Rev. 2019, 119, 7444.

[56] J. Xing, Y. Zhao, M. Askerka, L. N. Quan, X. Gong, W. Zhao, J. Zhao, H. Tan, G. Long, L. Gao, Z. Yang, O. Voznyy, J. Tang, Z.-H. Lu, Q. Xiong, E. H. Sargent, Nat. Commun. 2018, 9, 3541.

[57] L. Cheng, T. Jiang, Y. Cao, C. Yi, N. Wang, W. Huang, J. Wang, Adv. Mater. 2020, 32, 1904163.

[58] A. C. Berends, C. de Mello Donega, J. Phys. Chem. Lett. 2017, 8, 4077.

[59] L. Protesescu, S. Yakunin, M. I. Bodnarchuk, F. Krieg, R. Caputo, C. H. Hendon, R. X. Yang, A. Walsh, M. V. Kovalenko, Nano Lett. 2015, 15, 3692 .

[60] J. Li, L. Xu, T. Wang, J. Song, J. Chen, J. Xue, Y. Dong, B. Cai, Q. Shan, B. Han, H. Zeng, Adv. Mater. 2017, 29, 1603885.

[61] J. Song, J. Li, X. Li, L. Xu, Y. Dong, H. Zeng, Adv. Mater. 2015, 27, 7162 . 
[62] K. Hong, Q. V. Le, S. Y. Kim, H. W. Jang, J. Mater. Chem. C 2018, 6, 2189.

[63] J. Sun, J. Wu, X. Tong, F. Lin, Y. Wang, Z. M. Wang, Adv. Sci. 2018, 5, 1700780 .

[64] M. M. Tavakoli, L. Gu, Y. Gao, C. Reckmeier, J. He, A. L. Rogach, Y. Yao, Z. Fan, Sci. Rep. 2015, 5, 14083.

[65] H. Cho, S.-H. Jeong, M.-H. Park, Y.-H. Kim, C. Wolf, C.-L. Lee, J. H. Heo, A. Sadhanala, N. Myoung, S. Yoo, S. H. Im, R. H. Friend, T.-W. Lee, Science 2015, 350, 1222.

[66] N. J. Jeon, J. H. Noh, Y. C. Kim, W. S. Yang, S. Ryu, S. I. Seok, Nat. Mater. 2014, 13, 897.

[67] Z. Wang, B. Huai, G. Yang, M. Wu, J. Yu, J. Lumin. 2018, 204, 110.

[68] T. Bu, L. Wu, X. Liu, X. Yang, P. Zhou, X. Yu, T. Qin, J. Shi, S. Wang, S. Li, Z. Ku, Y. Peng, F. Huang, Q. Meng, Y.-B. Cheng, J. Zhong, Adv. Energy Mater. 2017, 7, 1700576.

[69] M. Konstantakou, D. Perganti, P. Falaras, T. Stergiopoulos, Crystals 2017, 7, 291.

[70] L. Meng, E.-P. Yao, Z. Hong, H. Chen, P. Sun, Z. Yang, G. Li, Y. Yang, Advanced Materials 2017, 29, 1603826.

[71] P. Docampo, T. Bein, Acc. Chem. Res. 2016, 49, 339.

[72] H. H. Ma, M. Imran, Z. Dang, Z. Hu, Crystals 2018, 8, 182.

[73] X. Zhang, H. Lin, H. Huang, C. Reckmeier, Y. Zhang, W. C. H. Choy, A. L. Rogach, Nano Lett. 2016, 16, 1415.

[74] L. Protesescu, S. Yakunin, S. Kumar, J. Bär, F. Bertolotti, N. Masciocchi, A. Guagliardi, M. Grotevent, I. Shorubalko, M. I. Bodnarchuk, C.-J. Shih, M. V. Kovalenko, ACS Nano 2017, 11, 3119.

[75] S. Sun, D. Yuan, Y. Xu, A. Wang, Z. Deng, ACS Nano 2016, 10, 3648.

[76] S. Chang, Z. Bai, H. Zhong, Adv. Opt. Mater. 2018, 6, 1800380.

[77] Z. Xiao, R. A. Kerner, L. Zhao, N. L. Tran, K. M. Lee, T.-W. Koh, G. D. Scholes, B. P. Rand, Nat. Photonics 2017, 11, 108.

[78] H. Yu, H. Wang, J. Zhang, J. Lu, Z. Yuan, W. Xu, L. Hultman, A. A. Bakulin, R. H. Friend, J. Wang, X.-K. Liu, F. Gao, Small 2019, 15, 1804947. 
[79] B. R. Sutherland, E. H. Sargent, Nat. Photonics 2016, 10, 295.

[80] H. D. Pham, L. Xianqiang, W. Li, S. Manzhos, A. K. K. Kyaw, P. Sonar, Energy Environ. Sci. 2019, 12, 1177.

[81] H. Kim, K.-G. Lim, T.-W. Lee, Energy Environ. Sci. 2016, 9, 12.

[82] X. Dai, Z. Zhang, Y. Jin, Y. Niu, H. Cao, X. Liang, L. Chen, J. Wang, X. Peng, Nature 2014, 515, 96.

[83] L. Zhang, X. Yang, Q. Jiang, P. Wang, Z. Yin, X. Zhang, H. Tan, Y. (Michael) Yang, M. Wei, B. R. Sutherland, E. H. Sargent, J. You, Nat. Commun. 2017, 8, 15640.

[84] J. Fan, J. Fan, J. Fan, J. Fan, W. Chen, W. Chen, W. Yuan, X. Fan, G. Zhang, Opt. Express, 2020, 28, 13921.

[85] Q. Shan, J. Li, J. Song, Y. Zou, L. Xu, J. Xue, Y. Dong, C. Huo, J. Chen, B. Han, H. Zeng, J. Mater. Chem. C 2017, 5, 4565.

[86] A. Fakharuddin, W. Qiu, G. Croes, A. Devižis, R. Gegevičius, A. Vakhnin, C. Rolin, J. Genoe, R. Gehlhaar, A. Kadashchuk, V. Gulbinas, P. Heremans, Adv. Funct. Mater. 2019, 29, 1904101.

[87] S. Cool, J. G. Pieters, K. C. Mertens, S. Mora, F. Cointault, J. Dubois, T. Van de Gucht, J. Vangeyte, Sensors 2015, 15, 28627.

[88] M. Anaya, B. P. Rand, R. J. Holmes, D. Credgington, H. J. Bolink, R. H. Friend, J. Wang, N. C. Greenham, S. D. Stranks, Nat. Photonics 2019, 13,818 .

[89] X. Zhang, J.-X. Shen, C. G. V. de Walle, Adv. Energy Mater. 2020, 10, 1902830 .

[90] F. Zhao, D. Ma, Mater. Chem. Front. 2017, 1, 1933.

[91] S.-Y. Kim, J.-J. Kim, Org. Electron. 2010, 11, 1010.

[92] S. Ashok Kumar, J. S. Shankar, B. K Periyasamy, S. K. Nayak, Polym. Plast. Technol. Mater. 2019, 58, 1597.

[93] J. J. Shiang, T. J. Faircloth, A. R. Duggal, J. Appl. Phys. 2004, 95, 2889.

[94] B. Zhao, S. Bai, V. Kim, R. Lamboll, R. Shivanna, F. Auras, J. M. Richter, L. Yang, L. Dai, M. Alsari, X.-J. She, L. Liang, J. Zhang, S. Lilliu, P. Gao, H. J. Snaith, J. Wang, N. C. Greenham, R. H. Friend, D. Di, Nat. Photonics 2018, 12, 783.

[95] Y. Qu, M. Slootsky, S. R. Forrest, Nat. Photonics 2015, 9, 758. 
[96] Q. Shan, J. Song, Y. Zou, J. Li, L. Xu, J. Xue, Y. Dong, B. Han, J. Chen, H. Zeng, Small 2017, 13, 1701770.

[97] A. Buin, R. Comin, J. Xu, A. H. Ip, E. H. Sargent, Chem. Mater. 2015, 27, 4405.

[98] Z. Yuan, Y. Miao, Z. Hu, W. Xu, C. Kuang, K. Pan, P. Liu, J. Lai, B. Sun, J. Wang, S. Bai, F. Gao, Nat. Commun. 2019, 10, 2818.

[99] Y. Cao, N. Wang, H. Tian, J. Guo, Y. Wei, H. Chen, Y. Miao, W. Zou, K. Pan, Y. He, H. Cao, Y. Ke, M. Xu, Y. Wang, M. Yang, K. Du, Z. Fu, D. Kong, D. Dai, Y. Jin, G. Li, H. Li, Q. Peng, J. Wang, W. Huang, Nature 2018, 562, 249.

[100] Y. Ling, Y. Tian, X. Wang, J. C. Wang, J. M. Knox, F. Perez-Orive, Y. Du, L. Tan, K. Hanson, B. Ma, H. Gao, Adv. Mater. 2016, 28, 8983.

[101] G. Li, Z.-K. Tan, D. Di, M. L. Lai, L. Jiang, J. H.-W. Lim, R. H. Friend, N. C. Greenham, Nano Lett. 2015, 15, 2640.

[102] P. Zhu, J. Zhu, InfoMat 2020, 2, 341.

[103] J. M. Ball, A. Petrozza, Nat. Energy 2016, $1,1$.

[104] S. Lee, C. H. Jang, T. L. Nguyen, S. H. Kim, K. M. Lee, K. Chang, S. S. Choi, S. K. Kwak, H. Y. Woo, M. H. Song, Adv. Mater. 2019, 31, 1900067.

[105] X. Yang, X. Zhang, J. Deng, Z. Chu, Q. Jiang, J. Meng, P. Wang, L. Zhang, Z. Yin, J. You, Nat. Commun. 2018, 9, 570.

[106] B. S. Mashford, M. Stevenson, Z. Popovic, C. Hamilton, Z. Zhou, C. Breen, J. Steckel, V. Bulovic, M. Bawendi, S. Coe-Sullivan, P. T. Kazlas, Nat. Photonics 2013, 7, 407.

[107] J. Yang, B. D. Siempelkamp, E. Mosconi, F. De Angelis, T. L. Kelly, Chem. Mater. 2015, 27, 4229.

[108] J. Wang, N. Wang, Y. Jin, J. Si, Z.-K. Tan, H. Du, L. Cheng, X. Dai, S. Bai, H. He, Z. Ye, M. L. Lai, R. H. Friend, W. Huang, Adv. Mater. 2015, 27, 2311.

[109] Y. Zhou, C. Fuentes-Hernandez, J. Shim, J. Meyer, A. J. Giordano, H. Li, P. Winget, T. Papadopoulos, H. Cheun, J. Kim, M. Fenoll, A. Dindar, W. Haske, E. Najafabadi, T. M. Khan, H. Sojoudi, S. Barlow, S. Graham, 
J.-L. Bredas, S. R. Marder, A. Kahn, B. Kippelen, Science 2012, 336, 327.

[110] Y. Nanishi, Nat. Photonics 2014, 8, 884.

[111] S. Nakamura, Rev. Mod. Phys. 2015, 87, 1139.

[112] N. K. Kumawat, A. Dey, A. Kumar, S. P. Gopinathan, K. L. Narasimhan, D. Kabra, ACS Appl. Mater. Interfaces 2015, 7, 13119.

[113] S. Peng, S. Wang, D. Zhao, X. Li, C. Liang, J. Xia, T. Zhang, G. Xing, Z. Tang, Small Methods 2019, 3, 1900196.

[114] S. Hou, M. K. Gangishetty, Q. Quan, D. N. Congreve, Joule 2018, 2, 2421.

[115] G. Nedelcu, L. Protesescu, S. Yakunin, M. I. Bodnarchuk, M. J. Grotevent, M. V. Kovalenko, Nano Lett. 2015, 15, 5635.

[116] S. D. Stranks, ACS Energy Lett. 2017, 2, 1515.

[117] Q. Wang, X. Wang, Z. Yang, N. Zhou, Y. Deng, J. Zhao, X. Xiao, P. Rudd, A. Moran, Y. Yan, J. Huang, Nat. Commun. 2019, 10, 1.

[118] X. Zheng, S. Yuan, J. Liu, J. Yin, F. Yuan, W.-S. Shen, K. Yao, M. Wei, C. Zhou, K. Song, B.-B. Zhang, Y. Lin, M. N. Hedhili, N. Wehbe, Y. Han, H.-T. Sun, Z.-H. Lu, T. D. Anthopoulos, O. F. Mohammed, E. H. Sargent, L.-S. Liao, O. M. Bakr, ACS Energy Lett. 2020, 5, 793.

[119] P. Vashishtha, M. Ng, S. B. Shivarudraiah, J. E. Halpert, Chem. Mater. 2019, 31, 83.

[120] Z. Li, Z. Chen, Y. Yang, Q. Xue, H.-L. Yip, Y. Cao, Nat. Commun. 2019, $10,1027$.

[121] G. Li, F. W. R. Rivarola, N. J. L. K. Davis, S. Bai, T. C. Jellicoe, F. de la Peña, S. Hou, C. Ducati, F. Gao, R. H. Friend, N. C. Greenham, Z.-K. Tan, Adv. Mater. 2016, 28, 3528.

[122] Y. Dong, Y.-K. Wang, F. Yuan, A. Johnston, Y. Liu, D. Ma, M.-J. Choi, B. Chen, M. Chekini, S.-W. Baek, L. K. Sagar, J. Fan, Y. Hou, M. Wu, S. Lee, B. Sun, S. Hoogland, R. Quintero-Bermudez, H. Ebe, P. Todorovic, F. Dinic, P. Li, H. T. Kung, M. I. Saidaminov, E. Kumacheva, E. Spiecker, L.-S. Liao, O. Voznyy, Z.-H. Lu, E. H. Sargent, Nat. Nanotechnol. 2020, 15, 668 . 
[123] Y. Liu, J. Cui, K. Du, H. Tian, Z. He, Q. Zhou, Z. Yang, Y. Deng, D. Chen, X. Zuo, Y. Ren, L. Wang, H. Zhu, B. Zhao, D. Di, J. Wang, R. H. Friend, Y. Jin, Nat. Photonics 2019, 13, 760.

[124] Y. Jiang, C. Qin, M. Cui, T. He, K. Liu, Y. Huang, M. Luo, L. Zhang, H. Xu, S. Li, J. Wei, Z. Liu, H. Wang, G.-H. Kim, M. Yuan, J. Chen, Nat. Commun. 2019, 10, 1868.

[125] Z. Chen, C. Zhang, X.-F. Jiang, M. Liu, R. Xia, T. Shi, D. Chen, Q. Xue, Y.-J. Zhao, S. Su, H.-L. Yip, Y. Cao, Adv. Mater. 2017, 29, 1603157.

[126] E. T. Hoke, D. J. Slotcavage, E. R. Dohner, A. R. Bowring, H. I. Karunadasa, M. D. McGehee, Chem. Sci. 2015, 6, 613.

[127] A. J. Knight, L. M. Herz, Energy Environ. Sci. 2020, 13, 2024.

[128] D. P. McMeekin, G. Sadoughi, W. Rehman, G. E. Eperon, M. Saliba, M. T. Hörantner, A. Haghighirad, N. Sakai, L. Korte, B. Rech, M. B. Johnston, L. M. Herz, H. J. Snaith, Science 2016, 351, 151.

[129] M. Hu, C. Bi, Y. Yuan, Y. Bai, J. Huang, Adv. Sci. 2016, 3, 1500301.

[130] S. Draguta, O. Sharia, S. J. Yoon, M. C. Brennan, Y. V. Morozov, J. S. Manser, P. V. Kamat, W. F. Schneider, M. Kuno, Nat. Commun. 2017, 8,800 .

[131] S. T. Ochsenbein, F. Krieg, Y. Shynkarenko, G. Rainò, M. V. Kovalenko, ACS Appl. Mater. Interfaces 2019, 11, 21655.

[132] W. Fan, Y. Shi, T. Shi, S. Chu, W. Chen, K. O. Ighodalo, J. Zhao, X. Li, Z. Xiao, ACS Energy Lett. 2019, 4, 2052.

[133] S. Draguta, O. Sharia, S. J. Yoon, M. C. Brennan, Y. V. Morozov, J. S. Manser, P. V. Kamat, W. F. Schneider, M. Kuno, Nat. Commun. 2017, 8, 200.

[134] M. C. Brennan, A. Ruth, P. V. Kamat, M. Kuno, Trends Chem. 2020, 2, 282.

[135] F. Brivio, C. Caetano, A. Walsh, J. Phys. Chem. Lett. 2016, 7, 1083.

[136] W. Rehman, D. P. McMeekin, J. B. Patel, R. L. Milot, M. B. Johnston, H. J. Snaith, L. M. Herz, Energy Environ. Sci. 2017, 10, 361.

[137] C. G. Bischak, C. L. Hetherington, H. Wu, S. Aloni, D. F. Ogletree, D. T. Limmer, N. S. Ginsberg, Nano Lett. 2017, 17, 1028. 
[138] C. G. Bischak, A. B. Wong, E. Lin, D. T. Limmer, P. Yang, N. S. Ginsberg, J. Phys. Chem. Lett. 2018, 9, 3998.

[139] A. J. Knight, L. M. Herz, Energy Environ. Sci. 2020, 13, 2024.

[140] R. A. Belisle, K. A. Bush, L. Bertoluzzi, A. Gold-Parker, M. F. Toney, M. D. McGehee, ACS Energy Lett. 2018, 3, 2694.

[141] A. J. Knight, A. D. Wright, J. B. Patel, D. P. McMeekin, H. J. Snaith, M. B. Johnston, L. M. Herz, ACS Energy Lett. 2019, 4, 75.

[142] P. Vashishtha, J. E. Halpert, Chem. Mater. 2017, 29, 5965.

[143] I. L. Braly, R. J. Stoddard, A. Rajagopal, A. R. Uhl, J. K. Katahara, A. K.-Y. Jen, H. W. Hillhouse, ACS Energy Lett. 2017, 2, 1841.

[144] M. Abdi-Jalebi, Z. Andaji-Garmaroudi, S. Cacovich, C. Stavrakas, B. Philippe, J. M. Richter, M. Alsari, E. P. Booker, E. M. Hutter, A. J. Pearson, S. Lilliu, T. J. Savenije, H. Rensmo, G. Divitini, C. Ducati, R. H. Friend, S. D. Stranks, Nature 2018, 555, 497.

[145] Y. Zhou, Y.-H. Jia, H.-H. Fang, M. A. Loi, F.-Y. Xie, L. Gong, M.-C. Qin, X.-H. Lu, C.-P. Wong, N. Zhao, Adv. Funct. Mater. 2018, 28, 1803130 .

[146] J.-N. Yang, Y. Song, J.-S. Yao, K.-H. Wang, J.-J. Wang, B.-S. Zhu, M.M. Yao, S. U. Rahman, Y.-F. Lan, F.-J. Fan, H.-B. Yao, J. Am. Chem. Soc. 2020, 142, 2956.

[147] Z. Wang, Y. Wang, Z. Nie, Y. Ren, H. Zeng, Nanoscale Adv. 2019, 1, 4459 .

[148] X. Tang, M. van den Berg, E. Gu, A. Horneber, G. J. Matt, A. Osvet, A. J. Meixner, D. Zhang, C. J. Brabec, Nano Lett. 2018, 18, 2172.

[149] Y. Yuan, J. Huang, Acc. Chem. Res. 2016, 49, 286.

[150] F. Yang, H. Chen, R. Zhang, X. Liu, W. Zhang, J. Zhang, F. Gao, L. Wang, Adv. Funct. Mater. 2020, 30, 1908760.

[151] B. Chen, P. N. Rudd, S. Yang, Y. Yuan, J. Huang, Chem. Soc. Rev. 2019, 48, 3842 .

[152] R. Brenes, C. Eames, V. Bulović, M. S. Islam, S. D. Stranks, Adv. Mater. 2018, 30, 1706208.

[153] J. Cho, J. H. Park, J. K. Kim, E. F. Schubert, Laser Photonics Rev. 2017, $11,1600147$. 
[154] T. Pulli, T. Dönsberg, T. Poikonen, F. Manoocheri, P. Kärhä, E. Ikonen, Light Sci. Appl. 2015, 4, e332.

[155] M. L. S. Sudhir, 2016, 4, 7.

[156] J. Luo, X. Wang, S. Li, J. Liu, Y. Guo, G. Niu, L. Yao, Y. Fu, L. Gao, Q. Dong, C. Zhao, M. Leng, F. Ma, W. Liang, L. Wang, S. Jin, J. Han, L. Zhang, J. Etheridge, J. Wang, Y. Yan, E. H. Sargent, J. Tang, Nature 2018, 563, 541.

[157] Y. Narukawa, M. Sano, M. Ichikawa, S. Minato, T. Sakamoto, T. Yamada, T. Mukai, Jpn. J. Appl. Phys. 2007, 46, L963.

[158] Y. Narukawa, J. Narita, T. Sakamoto, T. Yamada, H. Narimatsu, M. Sano, T. Mukai, Phys. Status Solidi A 2007, 204, 2087.

[159] B. W. D’Andrade, S. R. Forrest, Adv. Mater. 2004, 16, 1585.

[160] S. Reineke, F. Lindner, G. Schwartz, N. Seidler, K. Walzer, B. Lüssem, K. Leo, Nature 2009, 459, 234.

[161] Y. Narukawa, M. Ichikawa, D. Sanga, M. Sano, T. Mukai, J. Phys. D: Appl. Phys. 2010, 43, 354002.

[162] L. Zhang, X.-L. Li, D. Luo, P. Xiao, W. Xiao, Y. Song, Q. Ang, B. Liu, Materials 2017, 10, 1378.

[163] Y. Sun, N. C. Giebink, H. Kanno, B. Ma, M. E. Thompson, S. R. Forrest, Nature 2006, 440, 908.

[164] G.-E. Wang, G. Xu, M.-S. Wang, L.-Z. Cai, W.-H. Li, G.-C. Guo, Chem. Sci. 2015, 6, 7222.

[165] M. C. Gather, A. Köhnen, K. Meerholz, Adv. Mater. 2011, 23, 233.

[166] J. Meyer, F. Tappe, Adv. Opt. Mater. 2015, 3, 424.

[167] Y.-S. Park, J.-W. Kang, D. M. Kang, J.-W. Park, Y.-H. Kim, S.-K. Kwon, J.-J. Kim, Adv. Mater. 2008, 20, 1957.

[168] C.-C. Chang, J.-F. Chen, S.-W. Hwang, C. H. Chen, Appl. Phys. Lett. 2005, 87, 253501.

[169] K.-J. Chen, H.-C. Chen, K.-A. Tsai, C.-C. Lin, H.-H. Tsai, S.-H. Chien, B.-S. Cheng, Y.-J. Hsu, M.-H. Shih, C.-H. Tsai, H.-H. Shih, H.-C. Kuo, Adv. Funct. Mater. 2012, 22, 5138.

[170] M. D. Smith, H. I. Karunadasa, Acc. Chem. Res. 2018, 51, 619. 
[171] W. Ning, F. Wang, B. Wu, J. Lu, Z. Yan, X. Liu, Y. Tao, J.-M. Liu, W. Huang, M. Fahlman, L. Hultman, T. C. Sum, F. Gao, Adv. Mater. 2018, 30, 1706246.

[172] Y. Wei, Z. Cheng, J. Lin, Chem. Soc. Rev. 2019, 48, 310.

[173] Y. Wei, X. Deng, Z. Xie, X. Cai, S. Liang, P. Ma, Z. Hou, Z. Cheng, J. Lin, Adv. Funct. Mater. 2017, 27, 1703535.

[174] Y. Wei, H. Xiao, Z. Xie, S. Liang, S. Liang, X. Cai, S. Huang, A. A. A. Kheraif, H. S. Jang, Z. Cheng, J. Lin, Adv. Opt. Mater. 2018, 6, 1701343.

[175] H. Liao, S. Guo, S. Cao, L. Wang, F. Gao, Z. Yang, J. Zheng, W. Yang, Adv. Opt. Mater. 2018, 6, 1800346.

[176] C. Sun, Y. Zhang, C. Ruan, C. Yin, X. Wang, Y. Wang, W. W. Yu, Adv. Mater. 2016, 28, 10088.

[177] C. de Weerd, L. Gomez, H. Zhang, W. J. Buma, G. Nedelcu, M. V. Kovalenko, T. Gregorkiewicz, J. Phys. Chem. C 2016, 120, 13310.

[178] C.-Y. Chang, A. N. Solodukhin, S.-Y. Liao, K. P. O. Mahesh, C.-L. Hsu, S. A. Ponomarenko, Y. N. Luponosov, Y.-C. Chao, J. Mater. Chem. C 2019, 7, 8634.

[179] E.-P. Yao, Z. Yang, L. Meng, P. Sun, S. Dong, Y. Yang, Y. Yang, Adv. Mater. 2017, 29, 1606859.

[180] R. Sun, P. Lu, D. Zhou, W. Xu, N. Ding, H. Shao, Y. Zhang, D. Li, N. Wang, X. Zhuang, B. Dong, X. Bai, H. Song, ACS Energy Lett. 2020, 5 , 2131.

[181] G. C. Adhikari, S. Thapa, H. Zhu, P. Zhu, Adv. Opt. Mater. 2019, 7, 1900916.

[182] M. Jung, S.-G. Ji, G. Kim, S. I. Seok, Chem. Soc. Rev. 2019, 48, 2011.

[183] J. Mao, H. Lin, F. Ye, M. Qin, J. M. Burkhartsmeyer, H. Zhang, X. Lu, K. S. Wong, W. C. H. Choy, ACS Nano 2018, 12, 10486.

[184] Q. A. Akkerman, V. D'Innocenzo, S. Accornero, A. Scarpellini, A. Petrozza, M. Prato, L. Manna, J. Am. Chem. Soc. 2015, 137, 10276.

[185] H. Yu, H. Wang, G. Pozina, C. Yin, X.-K. Liu, F. Gao, Chem. Sci. 2020, 137, DOI 10.1039/D0SC04508J. 


\section{Papers}

The papers associated with this thesis have been removed for copyright reasons. For more details about these see:

http://urn.kb.se/resolve?urn=urn:nbn:se:liu:diva-171237 


\section{FACULTY OF SCIENCE AND ENGINEERING}

Linköping Studies in Science and Technology, Dissertation No. 2089, 2020

Department of Physics, Chemistry and Biology (IFM)

Linköping University

SE-581 83 Linköping, Sweden

www.liu.se 